Florida International University FIU Digital Commons

FIU Electronic Theses and Dissertations

University Graduate School

6-5-2015

\title{
Black Carbon: Sources, Mobility and Fate in Freshwater Systems
}

Sasha Wagner

Florida International University, swagn004@fiu.edu

DOI: 10.25148 /etd.FIDC000086

Follow this and additional works at: https:// digitalcommons.fiu.edu/etd

Part of the Biogeochemistry Commons, and the Environmental Chemistry Commons

\section{Recommended Citation}

Wagner, Sasha, "Black Carbon: Sources, Mobility and Fate in Freshwater Systems" (2015). FIU Electronic Theses and Dissertations. 2213.

https://digitalcommons.fiu.edu/etd/2213

This work is brought to you for free and open access by the University Graduate School at FIU Digital Commons. It has been accepted for inclusion in FIU Electronic Theses and Dissertations by an authorized administrator of FIU Digital Commons. For more information, please contact dcc@fiu.edu. 


\section{FLORIDA INTERNATIONAL UNIVERSITY}

Miami, Florida

\section{BLACK CARBON: SOURCES, MOBILITY AND FATE IN FRESHWATER SYSTEMS}

A dissertation submitted in partial fulfillment of

the requirements for the degree of

DOCTOR OF PHILOSOPHY

in

CHEMISTRY

by

Sasha Wagner

2015 
To: Dean Michael R. Heithaus

College of Arts and Sciences

This dissertation, written by Sasha Wagner, and entitled Black Carbon: Sources, Mobility and Fate in Freshwater Systems, having been approved in respect to style and intellectual content, is referred to you for judgment.

We have read this dissertation and recommend that it be approved.

$\begin{array}{r}\hline \text { John Berry } \\ \hline \text { Piero Gardinali } \\ \hline \text { Jaroslava Miksovska Anderson } \\ \hline \text { Rudolf Jaffé, Major Professor }\end{array}$

Date of Defense: June 5, 2015

The dissertation of Sasha Wagner is approved.

Dean Michael R. Heithaus College of Arts and Sciences

Dean Lakshmi N. Reddi University Graduate School

Florida International University, 2015 
(C) Copyright 2015 by Sasha Wagner

All rights reserved. 


\section{DEDICATION}

To Jim -

For your constant love and never-ending support of my pursuits. The last ten years have been quite a journey and I cannot wait to see what the future has in store for us ... 


\section{ACKNOWLEDGMENTS}

I would first like to thank my advisor, and friend, Rudolf Jaffé for his unwavering encouragement and enthusiasm for both my professional and personal endeavors. I am incredibly lucky to have worked with someone who is so considerate of my career goals and goes out of his way to provide new opportunities for academic development. I am a better scientist today because of your attention, care and guidance. I am also grateful to committee members Piero Gardinali, John Berry, Bill Anderson and Jaroslava Miksovska for providing input and advice that has improved this thesis.

I would like to thank Thorsten Dittmar for being such a welcoming host during my time spent working abroad in his lab and for the use of his mass spectrometer. I am grateful to Kaelin Cawley for her helpful guidance on many research-related issues. Anssi Vähätalo is thanked for providing global river samples. I am thankful for other collaborators including Fernando Rosario-Ortiz, Thomas Riedel and Jutta Niggemann for their valuable inputs to this research. I am thankful for Jenny Ding, who patiently taught me the black carbon method and am grateful to Daniel Wiedemeier and Michael Schmidt for their assistance with particulate black carbon measurements. I would like to acknowledge all others who helped with sample collection, preparation and/or analysis: K. Klaproth, I. Ulber, M. Friebe (mass spectrometry technical assistance); M. Quirke (molecular structure elucidation); R. Travieso, J. Lehmann, J. Oropeza, A. Hohner, E. Townsend (sample collection and processing).

I would like to thank the Department of Chemistry and Biochemistry for providing financial support via teaching assistantships. I am grateful to the National Science Foundation and the Florida Coastal Everglades Long Term Ecological Research 
program for research assistantship funding. The Southeast Environmental Research Center's George Barley Endowment (awarded to R. Jaffé) is acknowledged for their financial support through research assistantships and providing travel funds to collect samples, attend conferences and carry out collaborative efforts abroad. Thank you to journals Organic Geochemistry and Biogeochemistry for allowing me to include my published work in this thesis.

I have been fortunate to work in such a positive research environment where days in lab were happily spent with fun and supportive labmates including Jenny Ding, Kaelin Cawley, Laura Belicka, Alice Ya, Oliver He, Cristina Romera-Castillo, Helen Du, Peter Regier, Wenxi Huang, Oliva Pisani and Alan Roebuck. Thank you to Jim O’Leary for ensuring that the HPLC pump heads were thoroughly rinsed at all times. Special thanks to my parents - By dropping a handful of raisins into a glass of seltzer, my Mom unknowingly put me on the path to becoming a scientist years ago. My Dad has been nothing but supportive of my academic endeavors, but he probably would prefer it if the title of my thesis read "Black Carbon: The Search for Machinosaurus." I would also like to acknowledge all other family, friends and colleagues who have shown their encouragement over the years. 


\section{ABSTRACT OF THE DISSERTATION \\ BLACK CARBON: SOURCES, MOBILITY AND FATE IN \\ FRESHWATER SYSTEMS}

by

Sasha Wagner

Florida International University, 2015

Miami, Florida

Professor Rudolf Jaffé, Major Professor

Black carbon (BC) is a complex mixture of polycondensed aromatic compounds produced by the incomplete combustion of biomass during events such as wildfires and the burning of fossil fuels. Black carbon was initially considered to be a refractory form of organic matter. However, recent studies have shown that $\mathrm{BC}$ can be quite mobile and reactive in the terrestrial environment. Black carbon can be translocated from soils and sediments in the form of dissolved BC (DBC). A global correlation between DBC and bulk dissolved organic carbon (DOC) has been established for fluvial systems where DBC comprises approximately $10 \%$ of the total DOC pool, which suggests that DBC may be a significant contributor to the global carbon cycle.

The primary objective of this thesis was to further characterize DBC and elucidate some of the specific physical and chemical processes that promote its transfer to the aqueous phase and drive the DBC-DOC relationship. The molecular composition and qualitative distribution of DBC was assessed using Fourier transform ion cyclotron resonance mass spectrometry. Black carbon in both dissolved and particulate (PBC) phases was quantified by the benzenepolycarboxylic acid method. Dissolved BC was 
found to contain considerable amounts of nitrogen and the export of this dissolved black nitrogen was linked to watershed land use in global rivers. The riverine flux of $\mathrm{PBC}$, a previously unstudied BC removal mechanism, was significantly increased by local wildfire activity. However in-stream DBC did not appear to be affected by short-term fire events. Once translocated to surface waters, DBC is susceptible to photodegradative processes. Dissolved BC in high molecular weight DOC fractions was more photoreactive than DBC associated with lower molecular weight fractions.

In the coming decades, wildfire frequency is expected to increase with climate change and natural lands will continue to be altered for anthropogenic use. These processes have already been shown to significantly impact the composition of DOC and associated DBC exported to inland waters. The quality of DBC influences its stability in soil and resistance to degradation. Therefore, it is essential that we aim to fully understand DBC dynamics in natural systems in order to assess its contribution to global carbon cycling. 


\section{TABLE OF CONTENTS}

CHAPTER

PAGE

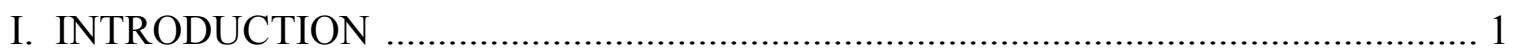

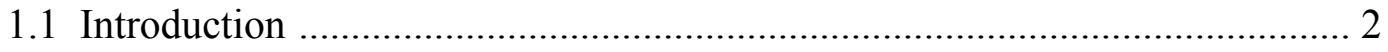

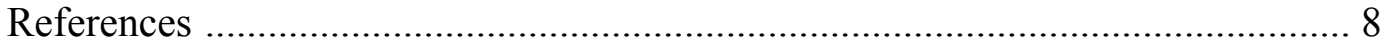

II. MOLECULAR CHARACTERIZATION OF DISSOLVED BLACK NITROGEN VIA ELECTROSPRAY IONIZATION FOURIER TRANSFORM ION CYCLOTRON RESONANCE MASS SPECTROMETRY …………………….... 12

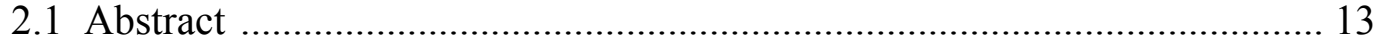

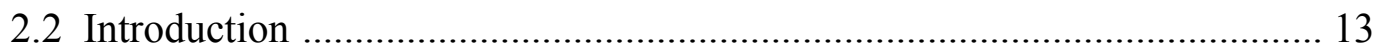

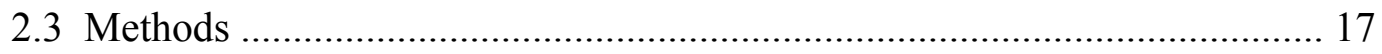

2.3.1 Sample collection .................................................................... 17

2.3.2 Soil and char leachates and DOM extraction .............................. 18

2.3.3 FT-ICRMS analysis: Broadband spectra ..................................... 19

2.3.4 FT-ICRMS analysis: Collision-induced

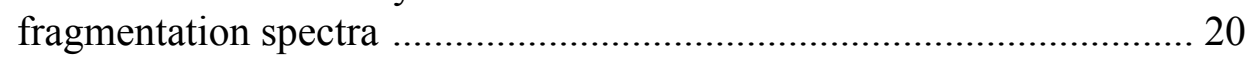

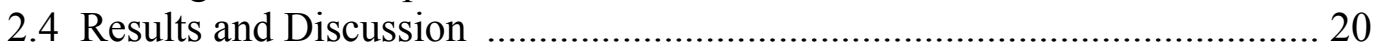

2.4.1 Overview of broadband mass spectra …………......................... 20

2.4.2 Distribution and environmental significance

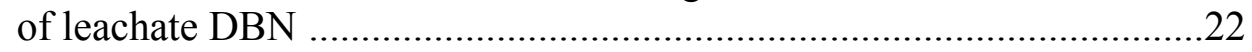

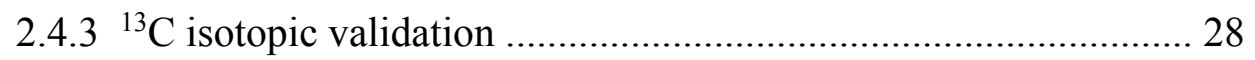

2.4.4 Fragmentation patterns ............................................................ 28

2.4.5 Kendrick mass analysis .......................................................... 33

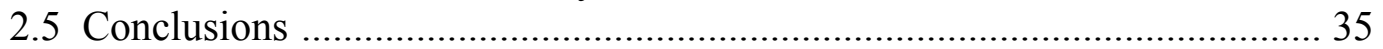

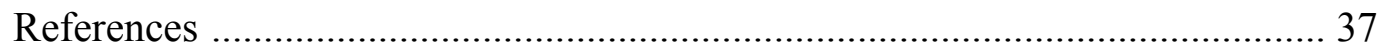

III. LINKING THE MOLECULAR SIGNATURE OF HETEROATOMIC

DISSOLVED ORGANIC MATTER TO WATERSHED CHARACTERISTICS

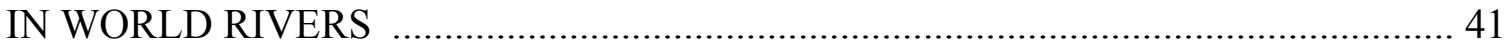

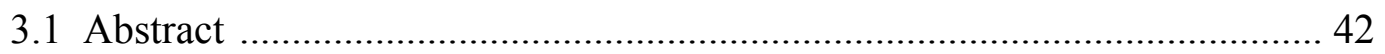

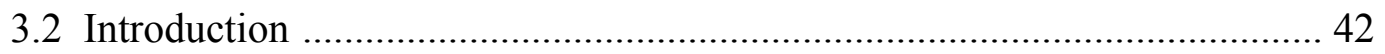

3.3 Materials and Methods .......................................................................... 45

3.3.1 Sample collection and preparation ............................................... 45

3.3.2 Ultrahigh-resolution mass spectrometry ...................................... 46

3.3.3 Land cover and statistical methods ............................................ 48

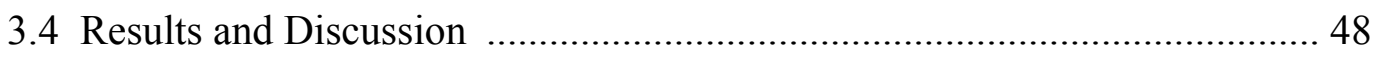

3.4.1 Comparison of exemplary DOM broadband mass spectra .......... 48

3.4.2 General trends in riverine DOM composition .............................. 50

3.4.3 Linking DOM molecular signatures to watershed land cover and source material ............................................................... 55

3.4.4 Visualizing characteristic compound classes among world river DOM 
3.4.5 Correlation between land use and dissolved black nitrogen ........ 63

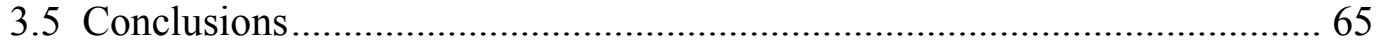

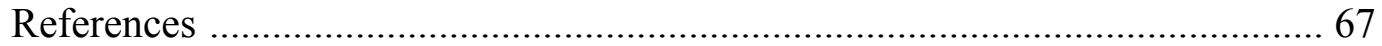

IV. IN-STREAM SOURCES AND LINKS BETWEEN PARTICULATE AND

DISSOLVED BLACK CARBON FOLLOWING A WILDFIRE ………………........ 74

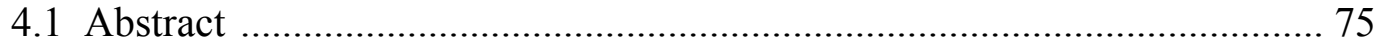

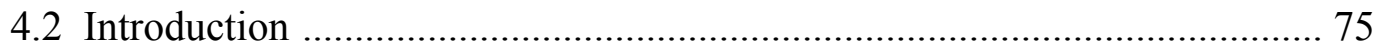

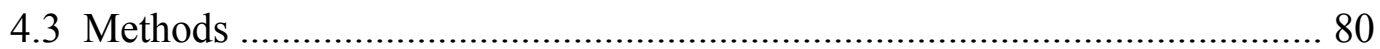

4.3.1 Site description ...................................................................... 80

4.3.2 Measurement of TSS and DOC …………………………....... 81

4.3.3 Determination of DBC and PBC via the BPCA method .............. 82

4.3.4 Statistical methods .................................................................... 83

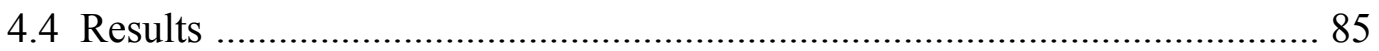

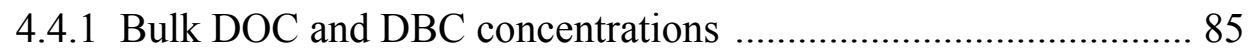

4.4.2 Bulk TSS and PBC concentrations ……………....................... 86

4.4.3 Quality of PBC and DBC based on BPCA composition ............. 88

4.4.4 BC fluxes in particulate and dissolved phase ............................. 92

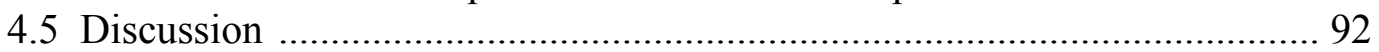

4.5.1 Controls on bulk DOC and DBC export …………................... 92

4.5.2 DBC and PBC source material ………………….................... 95

4.5.3 Controls on bulk TSS and PBC export ....................................... 99

4.5.4 Decoupling of PBC and DBC export in

fire-affected rivers ........................................................................... 102

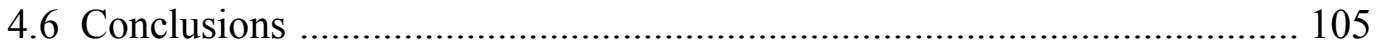

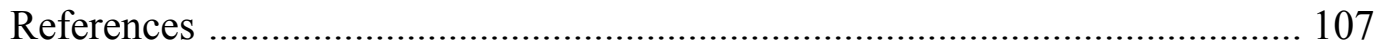

V. EFFECT OF PHOTODEGRADATION ON MOLECULAR SIZE

DISTRIBUTION AND QUALITY OF DISSOLVED BLACK CARBON .................. 113

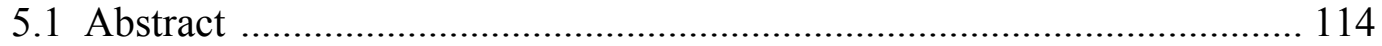

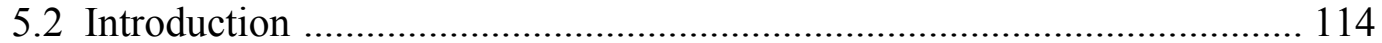

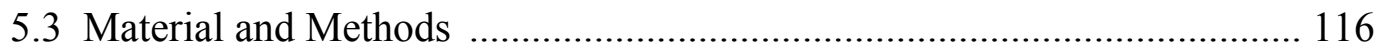

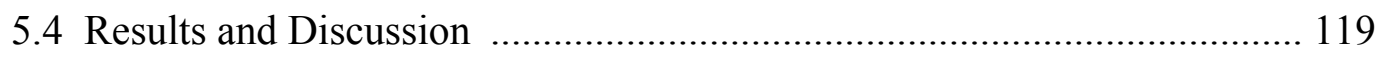

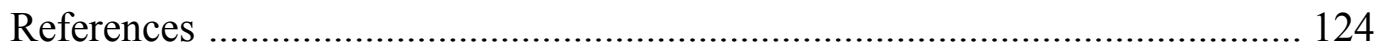

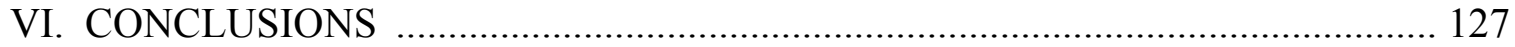

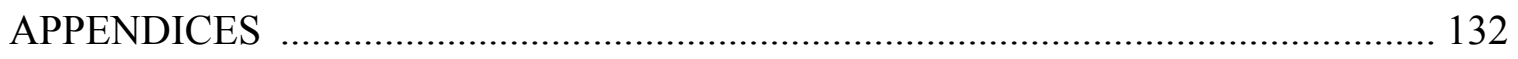

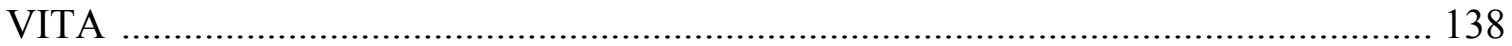




\section{LIST OF TABLES}

TABLE

PAGE

2.1 Molecular formula classification for DOM reference samples, soil leachates and char leachates

2.2 Validation of selected DBN peaks from ${ }^{13} \mathrm{C}$ isotopic comparison

3.1 Total number and proportions of each formula type assigned to mass spectral peaks for river DOM

3.2 Molecular parameters of global river DOM derived from assigned molecular formulae

4.1 Black carbon, DOC and TSS data for all three Poudre River sites throughout the sampling period

4.2 Water discharge rates and calculated black carbon fluxes for the PNF sampling site

5.1 Summary of data for whole and size-fractionated DOM before and after photo-exposure 


\section{LIST OF FIGURES}

FIGURE

PAGE

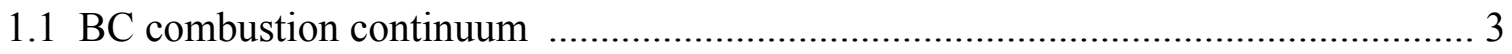

1.2 Correlation between DBC and DOC concentrations in global rivers systems .......... 3

1.3 Mobilization and reactivity of DBC during transport from terrestrial to marine

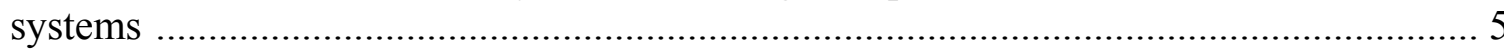

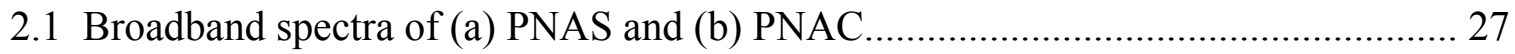

2.2 Van Krevelen diagrams depict the distribution of assigned formulae in (a) PNAS

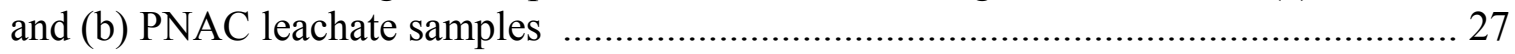

2.3 Isotopic validation of DBN formulae in PNAS leachate ..................................... 29

2.4 CID fragmentation patterns for 6 selected DBN formulae at nominal masses (parent peak denoted with $\bullet 228 \mathrm{Da}$, (b) $360 \mathrm{Da}$, (c) $376 \mathrm{Da}$, (d) $404 \mathrm{Da}$, (e) $410 \mathrm{Da}$

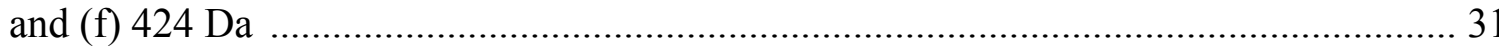

2.5 Observed neutral losses during fragmentation of DBN structure at nominal mass

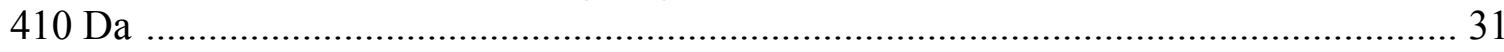

2.6 Possible fragmentation pathway of parent ion with $\mathrm{m} / \mathrm{z} 410.051754$ and assigned

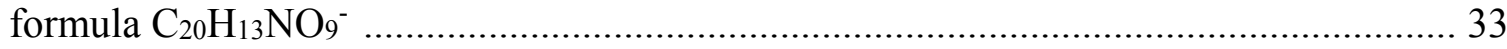

2.7 Possible DBN structures based on fragmentation spectra ................................... 34

3.1 Broadband mass spectral distribution for the (a) Amazon, (b) GangesBrahmaputra and (c) St. Lawrence Rivers ............................................................. 50

3.2 Principle component analysis of intensity weighted average values (molecular DOM characteristics) listed in Table 3.2 for global river DOM ................................ 55

3.3 Van Krevelen diagrams of molecular formulae (a) common among all global river DOM, (b) identified in one or more of the natural rivers, which includes the Amazon, Congo and Lena, (c) identified in one or more of the anthropogenically-impacted rivers, which includes the Danube, Ganges-Brahmaputra, Yangtze, Mekong, Mississippi, Panama and St. Lawrence and (d) unique to the Paraná and/or St. Lawrence Rivers 60

3.4 Principle component analysis of log-normalized dissolved black carbon (AI-mod > 0.66) peak intensities common to all global river DOM which includes the (a) loading 
plot and (b) score plot and correlations between PC2 and proportion of watershed (c)

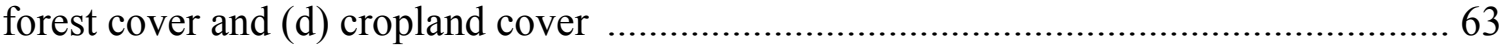

4.1 Map of the High Park Fire burn site ................................................................. 81

4.2 Seasonal distribution of water discharge rates and bulk DOC (a) and DBC (b) concentrations for burned (PSF grey squares; PNF black triangles) and unburned (PBR open circles) sites along the Poudre River transect

4.3 Seasonal distribution of water discharge rates and bulk TSS (a) and PBC (b) concentrations for fire-affected site PNF (black triangles) and unburned reference site PBR (open circles)

4.4 Seasonally-averaged PBC BPCA distributions for PBR and PNF (a) and the seasonal distribution of PBC quality (B5:B4) at PBR (open circles) and PNF (black triangles $(b)$

4.5 Seasonally-averaged DBC BPCA distributions for PMR, PSF and PNF (a) and the seasonal distribution of DBC quality (B5:B4) averaged across each of the three sampling sites (grey diamonds) (b)

4.6 PCA where loadings included the relative proportion of DBC BPCAs at all sampling sites throughout the season (a)

4.7 Seasonal fluxes for DBC (black circles) and PBC (black squares) at the fire-affected PNF sampling site

5.1 SEC fractionation (F1 - F8) of Everglades area DOM before (solid line) and after (dashed line) photo-exposure 118

5.2 Relative proportion of DBC in each DOM size fraction before (black bars) and after (gray bars) photodegradation 


\section{CHAPTER I}

INTRODUCTION 


\subsection{Introduction}

Black carbon $(\mathrm{BC})$ is generated from the incomplete combustion of biomass during events such as wildfires and the burning of fossil fuels (Goldberg, 1985). Black carbon is a complex mixture of pyrogenic biomacromolecules whose heterogeneity is best described using the combustion continuum model (Figure 1.1; Masiello, 2004). The $\mathrm{BC}$ pool ranges from slightly charred biomass to soot particles with highly polycondensed molecular structures. Black carbon is generally characterized as has having high $\mathrm{C}$ content with increased degrees of aromaticity. The composition of $\mathrm{BC}$ is indicative of its original source biomass and the combustion conditions under which it was formed (Masiello, 2004). Black carbon formed under mild thermal conditions can still retain some of the original macromolecular functionalities of the plant source material (Baldock and Smernik, 2002). However, increased charring temperature generates more refractory forms of BC with large fused ring structures (Schneider et al., 2010).

Black carbon can be stabilized in the soil matrix (Glaser et al., 1998; Schmidt et al., 1999; Skjemstad et al., 1999), where it was thought to persist for thousands of years. Therefore, $\mathrm{BC}$ was largely considered to be a global carbon sink as a result of its seemingly long residence time in soils. However, an apparent imbalance exists between production and loss processes of for $\mathrm{BC}$ in terrestrial systems. If it is assumed that the rate of $\mathrm{BC}$ production via biomass burning has remained constant for the last tens of thousands of years, then BC should comprise $25-125 \%$ of the total soil organic carbon (OC) pool (Masiello and Druffel, 2003; Masiello, 2004). Such high percentages of BC seem to be unreasonably high and it is obvious that soil OC cannot consist entirely of BC. 


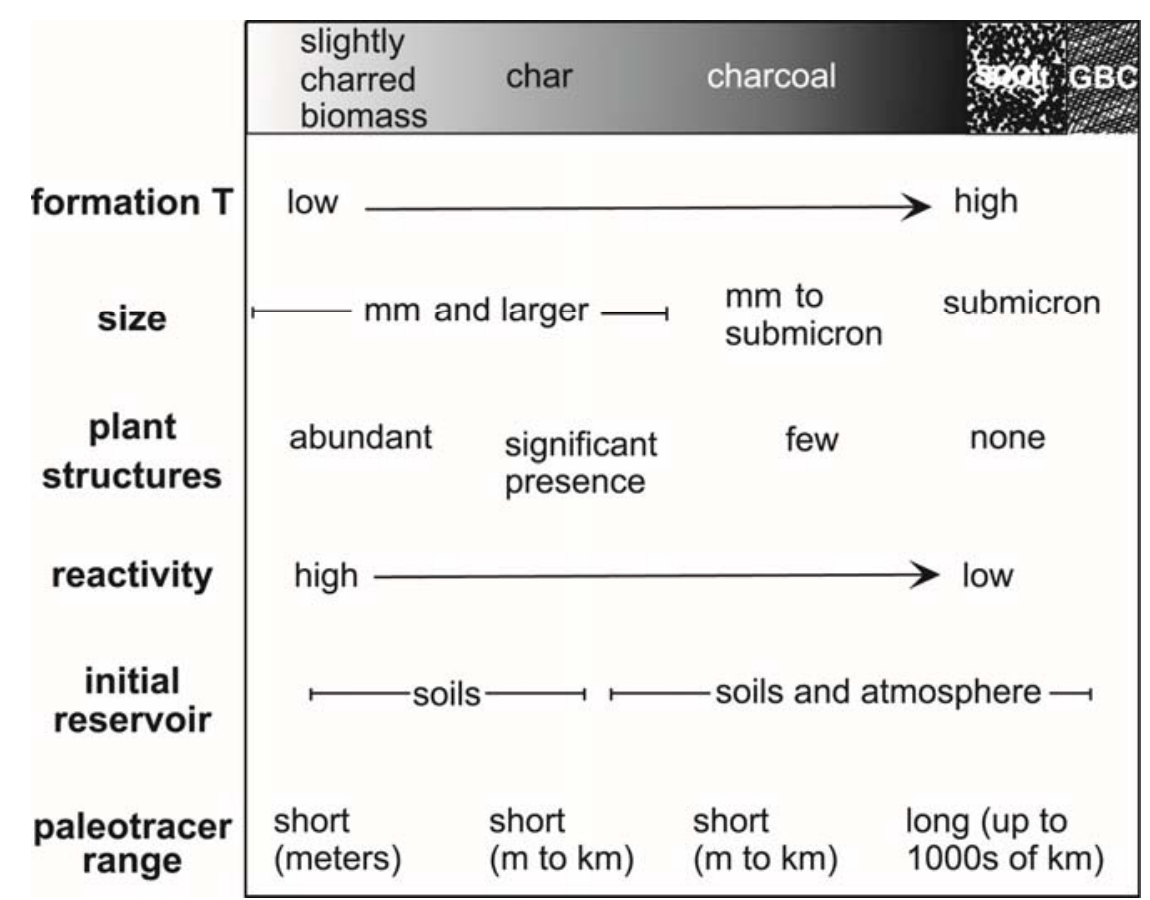

Figure 1.1 The BC combustion continuum (from Masiello, 2004)

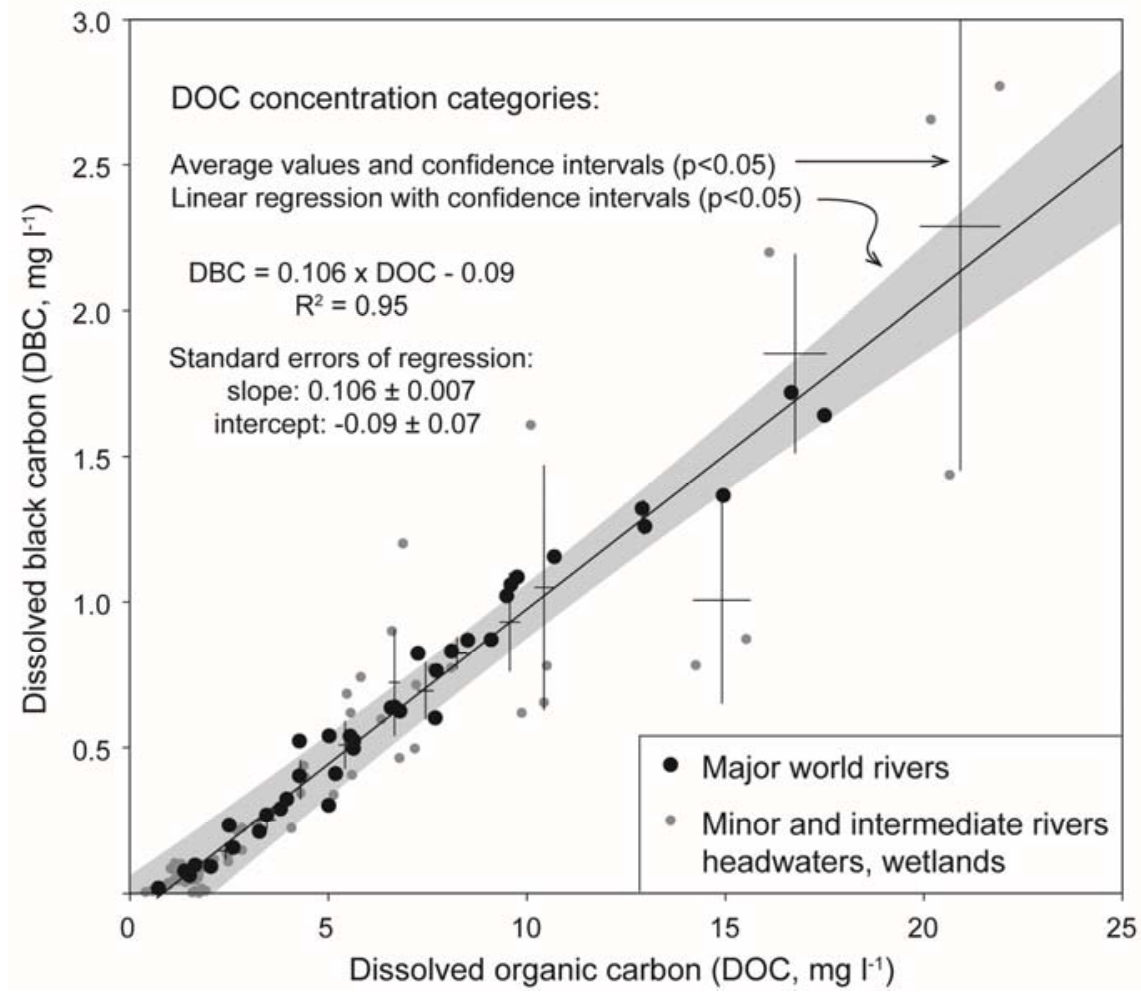

Figure 1.2 Correlation between DBC and DOC concentrations in global river systems (from Jaffé et al., 2013) 
Major et al. (2009) found that $20-53 \%$ of applied BC was somehow removed from surface soils but could not be explained by mineralization processes or transfer to deeper soil horizons. These findings indicated that other significant BC removal mechanisms indeed exist, but were unable to be identified at the time.

Recent studies have shown that BC turnover rates in soils can occur on much shorter timescales than previously thought (Singh et al., 2012). Black carbon can undergo both biotic and abiotic oxidation processes (Cheng et al., 2006) where the addition of polar functional groups to its fused ring structure seems to enhance its solubility (Abiven et al., 2011). As such, a significant portion of soil BC can be mobilized and transported as dissolved BC (DBC). Approximately 26.5 million tons of DBC are exported annually via rivers (Jaffé et al., 2013). It is believed that the transport of soluble charcoal may be a significant loss process for $\mathrm{BC}$ in terrestrial systems, thereby adding a missing piece to the global pyrogenic carbon cycle. In fluvial systems, DBC has been shown to strongly correlate with bulk dissolved OC (DOC) on a global scale (Figure 2; Jaffé et al., 2013), which suggests that the degradation and release processes for DBC and DOC are somehow inter-related. However, little is known about the exact physico-chemical mechanisms that control DBC export from soils and facilitate its interaction with bulk dissolved organic matter (DOM).

Inland waters cover a relatively small proportion of the Earth's surface, however they are key contributors to the transformation and cycling of DOM, and associated DBC, on a global scale (Cole et al., 2007; Battin et al., 2008; Jaffé et al., 2013). Extensive connectivity exists between rivers and the landscapes they drain. Therefore, DBC and other DOM components can be used to assess how basin characteristics, such 
as land use and wildfire activity, can impact fluvial health (Degens et al., 1991; Richey et al., 2004). While it has been well-established that anthropogenic activities increase nutrient export to inland surface waters (Scott et al., 2007; Wilson and Xenopoulos, 2009; Mattson et al., 2009), it is not yet known how humans may impact the composition of the DBC pool via processes such as urbanization and agricultural development. Wildfires are ubiquitous across landscapes (Korontzi et al., 2006) and can significantly alter the geomorphology and hydrology of watersheds in which they occur (Shakesby and Doerr, 2006 and references therein). Surprisingly, recent fire activity does not seem to impact the export of DBC (Ding et al., 2013; Myers-Pigg et al., 2015), however DBC can continue to be measured in rivers decades after large burn events (Dittmar et al., 2012). The continued export of $\mathrm{DBC}$ over time suggests that in-soil aging and oxidation of $\mathrm{BC}$ may be a prerequisite to its export in the dissolved phase (Abiven et al., 2011).

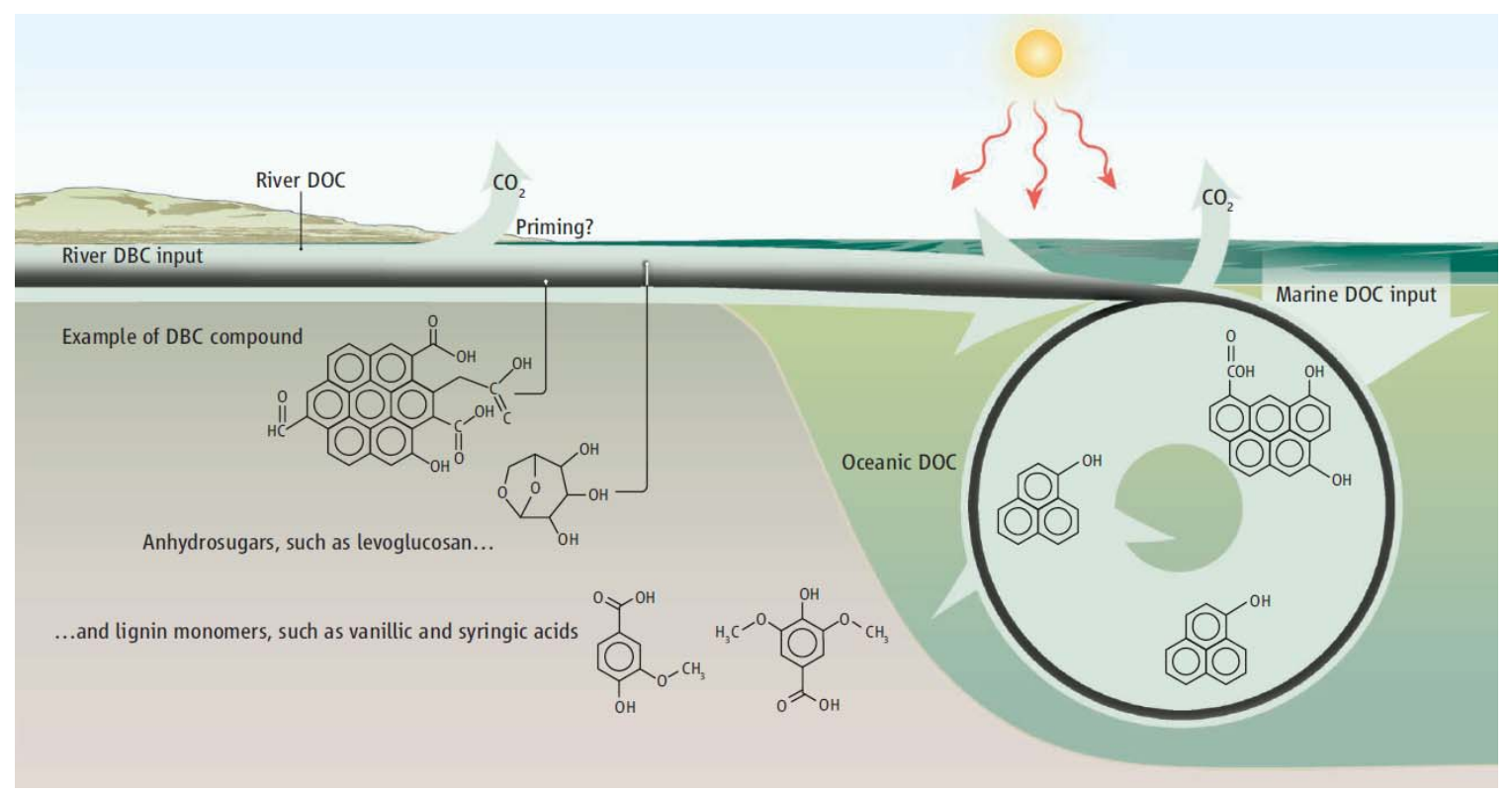

Figure 1.3 Mobilization and reactivity of DBC during transport from terrestrial to marine systems (from Masiello and Louchouarn, 2013) 
Once DBC enters aquatic systems, it is subject to a variety of degradative and removal processes that can alter the residence time of this refractory DOM component in terrestrial systems (Figure 3; Masiello and Louchouarn, 2013). Dissolved BC likely interacts with other DOM structures via participation in supramolecular assemblies (Simpson et al., 2002; Piccolo, 2001) and can be preferentially removed or chemically altered through photodegradative processes (Stubbins et al., 2010; 2012). Condensed aromatic DOM components have also been shown to co-vary with humic-type substances (Stubbins et al., 2014). Therefore, DBC may be susceptible to environmental processes, such as flocculation or adsorption, which influence the mobility of other portions of the hydrophobic, aromatic DOM pool (Uher et al., 2001; Kothawala et al., 2012).

The primary objective of the present work was to elucidate some of the specific physical and chemical processes that promote the translocation of DBC to the aqueous phase and drive the DBC-DOC relationship. Ultrahigh-resolution mass spectrometry was carried out to obtain molecular-level information for DBC (Dittmar and Koch, 2006) and the broader DOM pool (Kujawinski, 2002; Sleighter and Hatcher, 2007). The assignment of specific molecular formulae to mass spectral peaks allowed for the assessment of heteroatomic contributions, such as nitrogen, to the DBC pool. "Black nitrogen” (BN) is formed during the burning of nitrogen-rich biomass (Knicker, 2007; 2010) and may influence the lability of BC (de la Rosa and Knicker, 2011). Tandem mass spectrometry was carried out to obtain structural details for dissolved BN (DBN) leached from soils and char (Chapter II). Little is known about the origins and biogeochemical processing of DBN in terrestrial aquatic systems. Therefore, the contribution of DBN and other heteroatomic components to the DOM signature was 
assessed to link the impacts of land use to DBC quality in global rivers (Chapter III). Dissolved BC was quantified by measuring benzenepolycarboxylic acids (BPCAs), molecular markers generated during the chemo-thermal oxidation of polycondensed ring structures (Dittmar, 2008; Ding et al., 2013). The BPCAs are benzene rings polysubstituted with three (B3CA), four (B4CA), five (B5CA) or six (B6CA) carboxylic acid groups. Large $\mathrm{BC}$ molecules typically generate greater proportions of $\mathrm{B} 5 \mathrm{CA}$ and B6CA (Dittmar, 2008). The export of DBC via inland waters is a significant removal process of BC from fire-affected systems (Jaffé et al., 2013). However, it is not known how burn events impact the transfer of $\mathrm{BC}$ in the particulate phase (PBC) to fluvial systems. The flux of both PBC and DBC was compared for a wildfire-impacted watershed to assess the nature of the relationship of $\mathrm{BC}$ mobilization in the particulate and dissolve phases (Chapter IV). Once DBC enters the dissolved phase, it is strongly related to DOC (Jaffé et al., 2013). The observed DBC-DOC correlation may be controlled by DOM supramolecular assemblies (Simpson et al., 2002; Piccolo, 2001) which possibly influence the lability and mobilization of DOM-associated DBC throughout the water column. Dissolved BC is preferentially removed from the bulk DOC pool when exposed to sunlight (Stubbins et al., 2012), however it is unknown how such photodegradative processes impact supramolecular interactions between DBC and DOM. Therefore, the photoreactivity of DBC along the DOM molecular weight continuum was assessed (Chapter V). It is essential that we aim to constrain DBC dynamics in order to accurately assess its reactivity in natural systems and overall contribution to global carbon cycling. 


\section{References}

Abiven, S., Hengartner, P., Schneider, M.P.W., Singh, N., Schmidt, M.W.I., 2011. Pyrogenic carbon soluble fraction is larger and more aromatic in aged charcoal than fresh charcoal. Soil Biology and Biochemistry 43, 1615-1617.

Baldock, J.A., Smernik, R.J., 2002. Chemical composition and bioavailability of thermally altered Pinus resinosa (Red pine) wood. Organic Geochemistry 33, 10931109.

Battin, T.J., Kaplan, L.A., Findlay, S., Hopkinson, C.S., Marti, E., Packman, A. I., Newbold, J.D., Sabater, F., 2008. Biophysical controls on organic carbon fluxes in fluvial networks. Nature Geoscience 1, 95-100.

Cheng, C.H., Lehmann, J., Thies, J.E., Burton, S.D., Engelhard, M.H., 2006. Oxidation of black carbon by biotic and abiotic processes. Organic Geochemistry 37, 1477-1488.

Cole, J.J., Prairie, Y.T., Caraco, N.F., McDowell, W.H., Tranvik, L.J., Striegl, R.G., Duarte, C.M., Kortelainen, P., Downing J.A., Middelburg, J.J., Melack J., 2007.

Plumbing the global carbon cycle: Integrating inland waters into the terrestrial carbon budget. Ecosystems 10, 171-184.

de la Rosa, J.M., Knicker, H., 2011. Bioavailability of N released from N-rich pyrogenic organic matter: an incubation study. Soil Biology and Biochemistry 43, 2368-2373.

Degens, E. T., Kempe, S., Richey, J. E., Eds. Biogeochemistry of Major World Rivers SCOPE 42; John Wiley and Sons, Inc.: New York, 1991.

Ding, Y., Yamashita, Y., Dodds, W.K., Jaffé, R., 2013. Dissolved black carbon in grassland streams: is there an effect of recent fire history? Chemosphere 90, 2557-2562.

Dittmar, T., 2008. The molecular level determination of black carbon in marine dissolved organic matter. Organic Geochemistry 39, 396-407.

Dittmar, T., Koch, B.P., 2006. Thermogenic organic matter dissolved in the abyssal ocean. Marine Chemistry 102, 208-217.

Dittmar, T., de Rezende, C.E., Manecki, M., Niggeman, J., Ovalle, A.R.C., Stubbins, A., Bernardes, M.C., 2012. Continuous flux of dissolved black carbon from a vanished tropical forest biome. Nature Geoscience 5, 618-622.

Glaser, B., Haumaier, L., Guggenberger, G., Zech, W., 1998. Black carbon in soils: the use of benzene polycarboxylic acids as specific markers. Organic Geochemistry 29, 811819. 
Goldberg, E., 1985. Black Carbon in the Environment. John Wiley and Sons, New York.

Jaffé, R., Ding, Y., Niggeman, J., Vähätalo, A.V., Stubbins, A., Spencer, R.M., Campbell, J., Dittmar, T., 2013. Global charcoal mobilization from soils via dissolution and riverine transport to oceans. Science 340, 345-347.

Knicker, H., 2007. How does fire affect the nature and stability of soil organic nitrogen and carbon? A review. Biogeochemistry 85, 91-118.

Knicker, H., 2010. "Black nitrogen" - an important fraction in determining the recalcitrance of charcoal. Organic Geochemistry 41, 947-950.

Kothawala, D.N., Roehm, C., Blodau, C., Moore, T.R., 2012. Selective adsorption of dissolved organic matter to mineral soils. Geoderma 189-190, 334-342.

Korontzi, S., McCarty, J., Loboda, T., Kumar, S., Justice, C., 2006. Global distribution of agricultural fires in croplands from 3 years of Moderate Resolution Imaging Spectroradiometer (MODIS) data. Global Biogeochemical Cycles 20, GB2021, doi:10.1029/2005GB002529.

Kujawinski, E.B., 2002. Electrospray ionization Fourier transform ion cyclotron resonance mass spectrometry (ESI FT-ICR MS): characterization of complex environmental mixtures. Environmental Forensics 3, 207-216.

Major, J., Lehmann, J., Rondon, M., Goodale, C., 2009. Fate of soil-applied black carbon: Downward migration, leaching and soil respiration. Global Change Biology 16, 1366-1379.

Masiello, C.A., 2004. New directions in black carbon organic geochemistry. Marine Chemistry 92, 201-213.

Masiello, C.A., Druffel, E.R.M., 2003. Organic and black carbon ${ }^{13} \mathrm{C}$ and ${ }^{14} \mathrm{C}$ through the Santa Monica Basin oxic-anoxic transition. Geophysical Research Letters 30, 1185.

Masiello, C.A., Louchouarn, P., 2013. Fire in the ocean. Science 340, 287-288.

Mattson, T., Kortelainen, P., Laubel, A., Evans, D., Pujo-Pay, M., Räike, A., Conan, P., 2009. Export of dissolved organic matter in relation to land use along a European climatic gradient. Science of the Total Environment 407, 1967-1976.

Myers-Pigg, A.N., Louchouarn, P., Amon, R.M.W., Prokushkin, A., Pierce, K., Rubtsov, A., 2015. Labile pyrogenic dissolved organic carbon in major Siberian Arctic rivers: implications for wildfire-stream metabolic linkages. Geophysical Research Letters doi:10.1002/2014GL062762 
Piccolo, A., 2001.The supramolecular structure of humic substances. Soil Science 166, $810-832$.

Richey, J. E.; et al. Case Study 1: Integrated Analysis of a Humid Tropical Region - The Amazon Basin. In Vegetation, Water, Humans and the Climate; Kabat, P., Claussen, M., Dirmeyer, P. A., Gash, J. H. C., de Guenni, L. B., Meybeck, M., Pielke, R. A., Vörösmarty, C. I., Hutjes, R. W. A., Lütkemeier, S., Eds.; Springer-Verlag: Berlin Heidelberg 2004; pp 415-528

Schmidt, M.W.I., Skjemstad, J.O., Gehrt, E., Kögel-Knabner, I., 1999. Charred organic carbon in German chernozemic soils. European Journal of Soil Science 50, 351-365.

Schneider, M.P.W., Hilf, M., Vogt, U.F., Schmidt, M.W.I., 2010. The benzene polycarboxylic acid (BPCA) pattern of wood pyrolyzed between $200^{\circ} \mathrm{C}$ and $1000^{\circ} \mathrm{C}$. Organic Geochemistry 41, 1082-1088.

Scott, D., Harvey, J., Alexander, R., Schwarz, G., 2007. Dominance of organic nitrogen from headwater streams to large rivers across the conterminous United States. Global Biogeochemical Cycles 21, GB1003, doi:10.1029/2006GB002730.

Shakesby, R.A., Doerr, S.H., 2006. Wildfire as a hydrological and geomorphological agent. Earth-Science Reviews 74, 269-307.

Simpson, A.J., Kingery, W.L., Hayes, M.H.B, Spraul, M., Humpfer, E., Dvortsak, P., Kerssebaum, R., Godejohann, M., Hofmann, M., 2002. Molecular structures and associations of humic substances. Naturwissenschaften 89, 84-88.

Singh, N., Abiven, S., Torn, M.S., Schmidt, M.W.I., 2012. Fire-derived organic carbon in soil turns over on a centennial scale. Biogeosciences 9, 2847-2857.

Skjemstad, J.O., Taylor, J.A., Janik, L.J., Marvanek, S.P., 1999. Soil organic carbon dynamics under long-term sugar cane monoculture. Australian Journal of Soil Research $37,151-164$.

Sleighter, R.L., Hatcher, P.G., 2007. The application of electrospray ionization coupled to ultrahigh resolution mass spectrometry for the molecular characterization of natural organic matter. Journal of Mass Spectrometry 42, 559-574.

Stubbins, A., Spencer, R.G.M., Chen, H., Hatcher, P.G., Mopper, K., Hernes, P.J., Mwamba, V.L., Mangangu, A.M., Wabakanghanzi, J.N., Six, J., 2010. Illuminated darkness: Molecular signatures of Congo River dissolved organic matter and its photochemical alteration as revealed by ultrahigh resolution mass spectrometry. Limnology and Oceanography 55, 1467-1477. 
Stubbins, A., Niggemann, J., Dittmar, T., 2012. Photo-lability of deep ocean dissolved black carbon. Biogeosciences 9, 1661-1670.

Stubbins, A., Lapierre, J.F., Berggren, M., Prairie, Y.T., Dittmar, T., del Giorgio, P.A., 2014. What's in an EEM? Molecular signatures associated with dissolved organic fluorescence in boreal Canada. Environmental Science and Technology 48, 10598-10606.

Uher, G., Hughes, C., Henry, G., Upstill-Goddard, R.C., 2001. Non-conservative mixing behavior of colored dissolved organic matter in a humic-rich, turbid estuary. Geophysical Research Letters 28, 3309-3312.

Wilson, H.F., Xenopoulos, M.A., Effects of agricultural land use on the composition of fluvial dissolved organic matter. Nature Geoscience 2, 37-41. 
CHAPTER II

\section{MOLECULAR CHARACTERIZATION OF DISSOLVED BLACK NITROGEN VIA ELECTROSPRAY IONIZATION FOURIER TRANSFORM ION CYCLOTRON RESONANCE MASS SPECTROMETRY \\ (Modified from Wagner et al., 2015, Organic Geochemistry)}




\subsection{Abstract}

Combustion produces a complex mixture of polycondensed aromatic compounds known as black carbon (BC). Such products can become remobilized from char and soil in the form of dissolved BC (DBC). Ultrahigh-resolution Fourier transform ion cyclotron resonance mass spectrometry (ESI-FT-ICRMS) analysis of a variety of soil and char leachates showed that a significant proportion of DBC compounds contained one or more nitrogen atoms. While the presence of black nitrogen $(\mathrm{DBN})$ in dissolved organic matter (DOM) has been reported, its molecular features were uncharacterized. Results of the FTICRMS characterization of DBN is presented, where assigned formulae were validated on the basis on their ${ }^{13} \mathrm{C}$ isotope signatures and fragmentation patterns obtained via collision induced dissociation. Possible chemical structures were assigned for several DBN formulae and suggest that nitrogen was incorporated into the core ring system as a pyrrole-type moiety. Most DBN compounds existed as part of homologous series where homologs differed by a mass corresponding to $\mathrm{CO}_{2}$, suggesting that they were polysubstituted with carboxylic acid groups. The environmental contribution of such novel, aromatic, combustion-derived nitrogen compounds with respect to global nitrogen cycling remains elusive. The biogeochemical implications of the input of such firederived products to aquatic ecosystems as part of climate change therefore need to be assessed.

\subsection{Introduction}

Black carbon $(\mathrm{BC})$ results from partial combustion of organic matter (OM) during events such as wildfires and fossil fuel burning (Goldberg, 1985). A significant portion is 
incorporated into soil, potentially affecting long term carbon cycling in the environment. It has been estimated that $\mathrm{BC}$ comprises between $2 \%$ and $45 \%$ of soil organic carbon (OC; Glaser et al., 1998, Schmidt et al., 1999 and Skjemstad et al., 1999) and it was initially thought to be refractory, persisting in soils for thousands of years. Recent studies have shown, however, that turnover rates can occur on much shorter timescales (Singh et al., 2012 and references therein) and a significant portion of BC (char) is solubilized and exported as dissolved BC (DBC; Jaffé et al., 2013). To obtain a better understanding of the driving force behind $\mathrm{BC}$ stability and mobility, a deeper knowledge of its chemical characteristics is necessary.

Many studies have focused on characterizing and quantifying the polycyclic aromatic portion of DBC (Kim et al., 2004, Dittmar and Paeng, 2009, Dittmar et al., 2012 and Ding et al., 2013). Pyrogenic OM is considered a heterogeneous mixture of thermally-altered biomacromolecules with considerable N, O and S content (Knicker, 2007). During biomass burning, most organic $\mathrm{N}$ is believed to become incorporated into the BC pool in the form of heterocyclic aromatic N (Knicker et al., 1996). Black nitrogen $(\mathrm{BN})$ is generated through the charring of $\mathrm{N}$-rich biomass sources such as plants and leaf litter and is likely to be more refractory than its proteinaceous precursor material (Knicker, 2007 and Knicker, 2010). However, BN may be more susceptible to chemical and biological transformation in the environment than bulk $\mathrm{BC}$ due to its heteroatomic nature. Then again, $\mathrm{N}$-rich char is less resistant to oxidation than cellulose char and can easily become bioavailable for plant uptake in soil (Knicker, 2010 and de la Rosa and Knicker, 2011). There is also evidence that BN is mobilized from soil and solubilized as dissolved BN (DBN; Maie et al., 2006 and Ding et al., 2014). This suggests that charcoal 
containing a large portion of $\mathrm{BN}$ may be more dynamic than previously thought and could contribute significantly to the global cycling of $\mathrm{N}$.

Little is known about the structure of DBN compounds. Aromatic N in soil humic acids has been detected with X-ray photoelectron spectroscopy (XPS; Abe and Watanabe, 2004) and attributed to the presence of DBN (Maie et al., 2006, Jaffé et al., 2012 and Ding et al., 2014). In another study, however, similar signals were interpreted solely as ammonium and amide functionalities (Monteil-Rivera et al., 2000). While the application of XPS for determining DBN provides the relative contribution of heterocyclic $\mathrm{N}$ to the dissolved organic N (DON) pool, it is limited with regard to structural assignment. Evidence of increased heterocyclic $\mathrm{N}$ with progressive burning of plant biomass was observed by Knicker et al. (1996), using solid state ${ }^{15} \mathrm{~N}$ nuclear magnetic resonance (NMR) spectroscopy. More recent studies have also suggested that pyrogenic $\mathrm{N}$ is incorporated into charcoal-derived compounds in the form of pyrrole-type functionalities and, to a lesser extent, pyridine-type moieties (Knicker et al., 2008 and Knicker, 2007). Although NMR consistently allows detection of heterocyclic N, its sensitivity is relatively low (Smernik and Baldock, 2005) and it is unable to provide detailed information about the structural characteristics of individual compounds in a mixture.

Fourier transform ion cyclotron resonance mass spectrometry (FT-ICRMS) offers detailed compositional and structural information about complex dissolved OM (DOM) mixtures (Kujawinski, 2002, Dittmar and Koch, 2006, Sleighter and Hatcher, 2007 and Dittmar and Paeng, 2009). Ultra-high resolution and mass accuracy with an error $<1 \mathrm{ppm}$ allow calculation and assignment of molecular formulae to resolved peaks in DOM (Stenson et al., 2003 and Koch et al., 2005). Using ultra-high resolution mass spectra and 
assigned formulae, FT-ICRMS data can be interpreted to allow classification of groups of compounds based on their elemental composition and to obtain molecular "fingerprints" of each sample. Van Krevelen diagrams organize elemental formulae from $\mathrm{H} / \mathrm{C}$ and $\mathrm{O} / \mathrm{C}$ ratios, allowing their categorization into various molecular classes (Kim et al., 2003). Data can also be sorted into homologous series via Kendrick nominal mass, where formulae differing by the gain or loss of a specific functional group are assigned (Hughey et al., 2001). The aromaticity index, developed by Koch and Dittmar (2006), can be applied for the unambiguous assignment of aromatic and polycondensed aromatic structures in DOM. More recently, FT-ICRMS fragmentation studies have been carried out for elucidation of specific structural characteristics of selected fulvic acid compounds (Witt et al., 2009).

Thus, FT-ICRMS provides a wealth of detailed molecular-level information. However, it has not been specifically applied for the analysis of heteroatoms in DBC. Fire-affected soil and char generated from $\mathrm{N}$-rich biomass sources are known to contain significant amounts of BN (Knicker, 2007 and Knicker, 2010) and DBN has been suggested to be ubiquitous in DOM (Ding et al., 2014). In the present study, the presence of DBN was verified in water leachates from a variety of soil and char samples using FTICRMS. Selected compounds were assigned molecular formulae and possible DBN molecular structures proposed from the fragmentation patterns. A deeper understanding of DBN structure and its chemistry is necessary in order to quantify pyrogenic $\mathrm{N}$ and to model its mobility and fate in environmental systems. 


\subsection{Methods}

\subsubsection{Sample collection}

Four soil samples were obtained from locations with a known history of wildfires or biomass burning. Surface peat soil (SRS2S) was collected from the Shark River Slough area of the Florida Coastal Everglades Long Term Ecological Research site (Florida, USA). The Shark River Slough receives pyrogenic input from burned sugar cane fields upstream and from transient prescribed fires that occur within the Everglades ecosystem. Surface soil was also collected at the location of a historic charcoal blast furnace site in Pennsylvania, USA (PA2S). Such furnace soil was collected from charcoal storage areas and is known to contain a high level of BC (Cheng et al., 2008). Surface soil directly impacted by the High Park wildfire (Colorado, USA) in June 2012 was collected $1 \mathrm{yr}$ after the burn (PNAS). It represented a soil sample impacted by more recent biomass burning events. Topsoil from the Hubbard Brook Experimental Forest (New Hampshire, USA), which experienced a large wildfire during the 1920s, was also collected (HBRS).

Four char samples were selected on the basis of their diverse biomass sources and charring conditions. Charcoal standards generated from rice straw (RICEC) and chestnut wood (WOODC) were obtained from the University of Zurich (Switzerland). Both chars were produced at $<500{ }^{\circ} \mathrm{C}$ in an $\mathrm{O} 2$-free atmosphere (Hammes et al., 2006). Char was also collected directly from a severely burned pine tree $1 \mathrm{yr}$ after the High Park wildfire (PNAC). Though some PNAC was exposed to weathering and sunlight before collection, it had experienced no direct soil interaction. Char pieces were collected from the ground at the site of the 1920s wildfire in the Hubbard Brook Experimental Forest (HBRC). The 
Hubbard Brook forest has experienced no additional wildfire activity since the 1920s, so HBRC represented an aged char sample.

For comparison, three DOM reference samples were also analyzed for DBN. Marine DOM was sampled from the deep ocean in the central North Pacific (Hawaii; Green et al., 2014). Pony Lake fulvic acid (PLFA) and Suwannee River humic acid (SRHA) DOM standards were obtained from the International Humic Substances Society and represented microbial and terrestrial types of DOM, respectively.

Field-collected soil and char samples were stored at $-20^{\circ} \mathrm{C}$ until further processing. Dissolved OM and char standards were stored in the dark at room temperature upon receipt. Frozen samples were thawed and air dried. Visible litter and other coarse OM was removed and samples were ground and passed through a 30 mesh sieve. Homogenized samples were dried overnight at $60{ }^{\circ} \mathrm{C}$ and stored in a desiccator.

\subsubsection{Soil and char leachates and DOM extraction}

Each dry sample $(0.4 \mathrm{~g} \mathrm{OC})$ was weighed directly into pre-combusted glass Erlenmeyer flasks and deionized water added $(150 \mathrm{ml})$. The mixture was agitated on a shaker table $(160 \mathrm{rpm})$ in the dark at $25^{\circ} \mathrm{C}$ for $72 \mathrm{~h}$. Each DOM sample was dissolved in deionized water to a concentration of ca. $5 \mathrm{ppm}$ dissolved OC (DOC) and agitated as described above. All mixtures were filtered through pre-combusted $0.7 \mu \mathrm{m}$ GF/F filters, rinsed with $110 \mathrm{ml}$ deionized water each and refrigerated until DOM extraction.

The filtrate was acidified to $\mathrm{pH} 2$ using $\mathrm{HCl}(32 \%)$ and DOM extracted using the method outlined by Dittmar et al. (2008). Solid phase extraction (SPE) is the most efficient method for complete desalting and isolation of DOM from aquatic samples. 
Extraction efficiency is typically $60 \%$ or better on a per carbon basis (Green et al., 2014).

Briefly, DOM was isolated from solution using SPE with a Varian Bond Elut PPL

cartridge $(5 \mathrm{~g})$. The cartridge was first conditioned with high performance liquid

chromatography (HPLC)-grade MeOH and equilibrated with MilliQ water acidified to

$\mathrm{pH} 2$ with $\mathrm{HCl}$. The filtrate was allowed to pass through the cartridge via gravity and the sorbent was subsequently rinsed with $\mathrm{pH} 2 \mathrm{MilliQ}$ water for excess salt removal before being dried under $\mathrm{N}_{2}$. Dissolved $\mathrm{OM}$ was then eluted with $\mathrm{MeOH}$ and stored in the dark at $-20^{\circ} \mathrm{C}$ until FT-ICRMS analysis.

\subsubsection{FT-ICRMS analysis: Broadband spectra}

The DOM MeOH extract was diluted to a DOC concentration of ca. $20 \mathrm{ppm}$ in $\mathrm{MeOH}$ and MilliQ water $(1: 1 \mathrm{v} / \mathrm{v})$ and passed through a Teflon filter $(0.2 \mu \mathrm{m})$ for electrospray ionization (ESI). Analysis was carried out at the University of Oldenburg (Germany) with a Bruker Solarix 15 Tesla FT-ICRMS instrument in negative ion mode, with 500 scans collected per sample and a reference mass list used to calibrate each spectrum. Data were filtered to remove peaks that only appeared in one sample and those with low signal/noise ratio $(<3)$. Formulae were assigned using a software program that considered combinations of $\mathrm{C}, \mathrm{H}, \mathrm{O}, \mathrm{N}, \mathrm{S}$ and $\mathrm{P}$ and filtered to remove unlikely DOM molecular combinations as described by Koch et al. (2007). The modified aromaticity index $(A I \geqslant 0.67)$ outlined by Koch and Dittmar (2006) was used to unambiguously categorize formulae with condensed aromatic structures, here referred to as DBC. Dissolved BN peaks were assigned as having formulae that contained one or more $\mathrm{N}$ 
atoms and $\mathrm{AI} \geqslant 0.67$. Isotopic simulation for select $\mathrm{DBN}$ peaks was carried out using the Bruker Daltonics Data Analysis software (Bremen, Germany).

\subsubsection{FT-ICRMS analysis: Collision-induced fragmentation spectra}

Nominal masses of targeted DBN peaks were isolated with a focusing quadrupole and accumulated in a hexapole collision cell. Parent ions were fragmented via collision induced dissociation (CID) with Ar, where the resulting neutral mass losses gave insight into the initial molecular structure. Fragmentation energy was optimized to yield the best ratio between parent and fragment ions. Spectra were calibrated using a reference mass list containing calculated exact masses of the parent ion and measured fragments after neutral losses. Molecular formulae were assigned and filtered as described previously. Structural information was obtained by identifying fragment peaks and calculating exact masses of neutral losses.

\subsection{Results and Discussion}

\subsubsection{Overview of broadband mass spectra}

The samples covered a wide range of DOM types derived from the deep ocean, microbial sources, terrestrial sources, soils and char. Electrospray ionization is the method of choice for analysis of polar compounds (Gross, 2011), including those within the DOM pool. As with any method employed for DOM characterization, ESI-FTICRMS has an analytical window, and not all compounds in the DOM pool may be represented in the MS trace. Ionization efficiency varies between different dissolved compounds, so peak detection and height may not directly reflect the relative 
concentration of DOM components. However, this study focused on the qualitative characterization of DBN, so differences in molecular ionization efficiency did not affect the interpretation of mass spectral data. The spectrum of each sample in negative ion mode resolved thousands of singly charged peaks between m/z 150 and m/z 800. All samples contained a highly complex mixture of dissolved components with multiple peaks at each nominal mass. The peak distribution maximum of the eight soil and char leachates was shifted to smaller $\mathrm{m} / \mathrm{z}$ values than deep ocean DOM, which may possibly be explained by the prominence of relatively large refractory thermogenic DOM found in marine water ( Dittmar and Paeng, 2009).

The AI was utilized to identify potential DBC molecular formulae. Introduced by Koch and Dittmar (2006), it is calculated solely using assigned formulae and provides evidence for the existence of condensed aromatic structures (AI $\geqslant 0.67)$. It is understood that it gives an insight into OM structural characteristics, but does not provide information about the source of these condensed aromatics. All formulae with AI $\geqslant 0.67$ containing one or more $\mathrm{N}$ atoms were tentatively referred to as $\mathrm{DBN}$, although it is possible that lower molecular weight compounds falling within these parameters could have come from biogenic sources. However, DBN formulae containing five or more condensed aromatic rings ( 20 or more carbons) were strongly indicative of pyrogenic sources.

Molecular assignments and formula classifications for each sample are outlined in Table 2.1. Deep ocean DOM (NELHA) contained very little DBC or DBN. It initially appeared that PLFA contained a considerable amount of DBC and DBN but, after categorizing the formulae on the basis of carbon number, it was evident that the majority 
of the polyaromatic formulae in PLFA were quite small $(<20$ carbons) and therefore possibly of biogenic origin. The molecular signature of terrestrially-derived SRHA most closely resembled that of leachate DOM generated from fresh wood char. The Suwannee River is a black water river fed by peat swamps where refractory OM, such as BC, may be retained and slowly released into the main stream over time. As such, the presence of DBC in SRHA has been reported and quantified using the benzene polycarboxylic acid method (Dittmar, 2008 and Ding et al., 2013). The mass spectral variation among all leachates was expected since the original soil and char samples were obtained from differing ecosystems and OM sources. On average, soil leachates yielded spectra with more resolved peaks and a larger proportion of formulae with heteroatomic substitutions than char leachates. Soil OM (SOM) is typically more complex and yields a larger portion of water-soluble components than charcoal due to multiple OM inputs from both vegetation and soil microbial communities (Kögel-Knabner, 2002).

\subsubsection{Distribution and environmental significance of leachate DBN}

On average, char leachates contained fewer DBN formulae than soil leachates (Table 2.1). However, there was considerable variation in the spectral characteristics within both the soil and char leachate sampling pools. It has been reported that aged char in the soil environment undergoes oxidation over time, thereby increasing the polarity of pyrogenic OM and mobilizing it as DBC (Abiven et al., 2011). The abundance of both

DBC and DBN formulae in the HBRC leachate (Table 2.1) likely reflected the increased solubility of pyrogenic $\mathrm{OM}$ as a result of these aging processes. The enhanced leaching of 
Table 2.1 Molecular formula classification for DOM reference samples, soil leachates and char leachates. Relative abundance of peaks assigned with DBN formulae was derived from the proportion of the sum height of DBN peak intensities to the sum height of all peaks within each sample.

\begin{tabular}{|c|c|c|c|c|c|c|c|c|c|c|c|}
\hline Sample & NELHA & PLFA & SRHA & SRS2S & PA2S & PNAS & HBRS & RICEC & WOODC & PNAC & HBRC \\
\hline \# m/z Values & 5181 & 5582 & 4402 & 7907 & 8517 & 8292 & 6180 & 6069 & 5883 & 5272 & 7872 \\
\hline \# Assigned Formulae & 4031 & 4474 & 3017 & 6021 & 5938 & 6034 & 4166 & 4123 & 3755 & 3673 & 5258 \\
\hline $\mathrm{CHO}(\%)$ & 45.9 & 40.3 & 84.6 & 48.6 & 61 & 54.7 & 79.4 & 62.6 & 83.2 & 80.9 & 71.4 \\
\hline CHON (\%) & 42.3 & 47.5 & 12.6 & 43.7 & 36.6 & 43 & 19 & 36.2 & 14.1 & 15.2 & 26.2 \\
\hline CHOS (\%) & 8.2 & 9.5 & 1.9 & 6.8 & 1.8 & 2.1 & 0.9 & 1 & 2.1 & 3.2 & 1.4 \\
\hline CHONS (\%) & 1.7 & 1.7 & 0.6 & 0.5 & 0.3 & 0.1 & 0.4 & 0 & 0.3 & 0 & 0.4 \\
\hline \# DBC Formulae & 164 & 517 & 624 & 1318 & 1708 & 1566 & 842 & 1206 & 620 & 478 & 1246 \\
\hline$[\mathrm{DB}] \mathrm{CHO}(\%)$ & 37.2 & 22.1 & 70.4 & 35.4 & 46.1 & 38.8 & 66.9 & 47.7 & 81.3 & 70.9 & 58.4 \\
\hline$[\mathrm{DB}] \mathrm{CHON}(\%)$ & 62.8 & 76.8 & 25.8 & 63.5 & 52.3 & 60.3 & 30.2 & 51.7 & 16.1 & 29.1 & 39.5 \\
\hline $\mathrm{DBC} \geq 20 \mathrm{Cs}(\%)$ & 28.7 & 8.1 & 42.6 & 29.8 & 46 & 38.1 & 44.7 & 16.8 & 46.1 & 25.7 & 21.9 \\
\hline $\mathrm{DBC}<20 \mathrm{Cs}(\%)$ & 71.3 & 91.9 & 57.4 & 70.2 & 54 & 61.9 & 55.3 & 83.2 & 53.9 & 74.3 & 78.1 \\
\hline \# DBN Formulae & 103 & 401 & 182 & 843 & 915 & 950 & 276 & 626 & 111 & 139 & 516 \\
\hline DBN[1] (\%) & 33 & 28.7 & 87.9 & 48.2 & 54.3 & 51.1 & 74.6 & 63.4 & 82.9 & 87.8 & 67.2 \\
\hline $\mathrm{DBN}[2](\%)$ & 47.6 & 40.6 & 11.5 & 35.3 & 33.4 & 33.5 & 25 & 33.5 & 11.7 & 10.1 & 27.7 \\
\hline $\mathrm{DBN}[3](\%)$ & 17.5 & 28.4 & 0.5 & 15.7 & 11.9 & 14.3 & 0.4 & 2.9 & 0.9 & 0 & 4.5 \\
\hline $\mathrm{DBN}[4](\%)$ & 1.9 & 2.2 & 0 & 0.8 & 0.3 & 1.2 & 0 & 0.2 & 4.5 & 2.2 & 0.6 \\
\hline $\mathrm{DBN} \geq 20 \mathrm{Cs}(\%)$ & 1.9 & 1.7 & 24.2 & 20.9 & 29 & 26.3 & 19.2 & 27.5 & 15.3 & 1.4 & 31.6 \\
\hline $\mathrm{DBN}<20 \mathrm{Cs}(\%)$ & 98.1 & 98.3 & 75.8 & 79.1 & 71 & 73.7 & 80.8 & 72.5 & 84.7 & 98.6 & 68.4 \\
\hline DBN Abundance (\%) & 0.03 & 2.06 & 0.05 & 6.74 & 6.55 & 24.22 & 0.17 & 4.5 & 0.03 & 0.25 & 0.95 \\
\hline
\end{tabular}


older char could also be explained by the release of SOM previously sorbed to its surface during long term soil interaction (Liang et al., 2008 and Cheng et al., 2014). Contrary to HBRC, RICEC was recently generated in a lab setting and was not subjected to soil interaction. Thus, natural aging and SOM sorption are not likely explanations for the equally large abundance of fire-derived formulae in the RICEC leachate sample. As suggested by Knicker (2007), the characteristics of BC generated by wildfires depend largely on the source OM. As shown in Table 2.1, ca. $40 \%$ of the DBC formulae in the RICEC leachate contained $\mathrm{N}$. This further indicates that proteinaceous precursor OM, such as grass or rice straw, may generate N-rich charcoal (Knicker, 2010). Knicker et al. (1996) also noted that grass-derived char retained a substantial portion of carboxyl functionality after heating, which could explain the enhanced solubility of pyrogenic OM from RICEC specifically. In contrast, DOM leached from freshly-produced wood chars (WOODC, PNAC) contained ca. 78\% fewer DBN peaks than DOM generated from grass char and aged wood char (Table 2.1). These results could be due to the lignin-enriched, $\mathrm{N}$-depleted woody biomass sources and lack of exposure to soil microbial and abiotic oxidation after charring.

Soil samples not only leached a greater abundance of DBN formulae, but the composition of these formulae also differed from those leached by char. HBRS had a different molecular signature compared with SRS2S, PA2S and PNAS, all of which had very similar spectral characteristics (Table 2.1). It was noted that HBRS contained a considerable amount of fine roots and organic material consistent with sampling of the upper organic soil horizon. The increased contribution of fresh organic material, such as unburned roots and leaf litter, and lack of recent fire activity in the sampling area could 
have explained the reduced presence of pyrogenic formulae in the HBRS leachate. Not only did the SRS2S, PA2S and PNAS leachate DOM contain a greater abundance of DBN spectral peaks than the char-derived DOM, but roughly half of their DBN formulae contained more than one $\mathrm{N}$ atom (Table 2.1). Dissolved BN formulae with two or more $\mathrm{N}$ atoms may be explained by the presence of heterocyclic functionalities such as pyrazoles or imidazoles, which can be generated by the thermal degradation of grass or soil microorganisms (Schulten and Schnitzer, 1998). The diversity of BN found in fireaffected soil originates either from the incorporation of pyrogenic $\mathrm{OM}$ or the charring of the soil itself (Knicker, 2007). Thus, the overall abundance and diversity of DBN in soilderived DOM was likely a result of the combination of heterogenous pyrogenic source material and the variety of biogeochemical processes that transformed it.

Although the suite of soil and char leachates was relatively small, mechanisms controlling the transport of $\mathrm{BN}$ from terrigenous to aquatic systems could be tentatively explored on the basis of broadband mass spectral patterns. Pyrogenic source OM appeared to considerably contribute to the molecular composition of soluble portions of charcoal. Char generated from N-rich precursor material, such as grass or straw, leached more molecular formulae that could be classified as DBN. Freshly-produced wood chars rich in lignin-derived BC generated less DBN. However, the increase in leached DBN from aged wood chars suggested that biotic and/or abiotic oxidation may have enhanced the release of such materials over time. Desorption of previously sorbed DBN-containing DOM may have also contributed to this observation. Black $\mathrm{N}$ in wildfire-affected soils may thus originate from charred material that is subsequently incorporated into SOM or from the direct thermal alteration of SOM itself. The heterogeneity of the DBN pool 
leached from these soils was a result of both the extreme diversity of source OM and the large variety of microbial and abiotic oxidative processes pyrogenic material undergoes.

Broadband spectra (Fig. 2.1) and Van Krevelen diagrams (Fig. 2.2) for PNAS and PNAC leachates depicted the distinct differences in molecular signature between thermally altered soil and charcoal generated naturally from the same fire event. These two samples were collected on the same day from the site of a Colorado wildfire that had occurred 1 yr earlier. The peak distribution maximum for PNAS was shifted to smaller $\mathrm{m} / \mathrm{z}$ values than that for PNAC (Fig. 2.1). This shift in overall apparent molecular weight for soil-derived DOM likely reflected the enhanced breakdown of pyrogenic and other soil OM through biotic and abiotic degradation. Another notable difference between these two leachates was that peaks at even nominal masses for PNAC had lower overall intensity than those for PNAS (Fig. 2.1). Formulae with odd numbers of $\mathrm{N}$ atoms have even nominal mass in negative ion mode due to the elemental exchange of $\mathrm{CH}(13 \mathrm{Da})$ for $\mathrm{N}(14 \mathrm{Da})$. This discrepancy at even nominal mass was in part due to the high relative abundance of DBN peaks in PNAS (Table 2.1). Similar trends were observed between the DOM spectra generated from other wood-derived chars and fire-affected soils within the group of samples. However, PNAS was certainly a unique leachate in the data set because it was the only sample to have such diverse and abundant N-containing peaks at even nominal mass values. Both PNAS and PA2S were selected for isotopic validation and fragmentation analysis due to their high relative abundance of DBN peaks (Table 2.1). Results were reproducible for both samples, but only PNAS data are shown. 

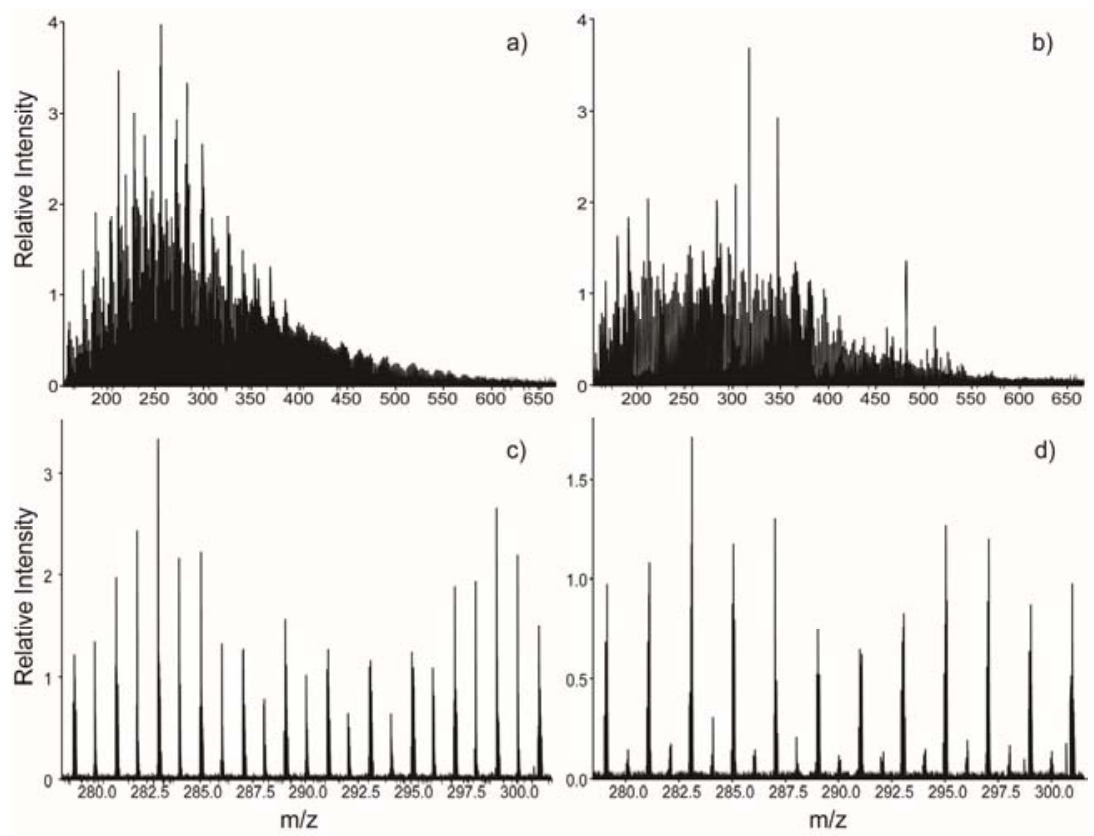

Figure 2.1 Broadband spectra of (a) PNAS and (b) PNAC. Detailed views of a $20 \mathrm{Da}$ section of (c) PNAS and (d) PNAC reveal differences in spectral peak intensities at even nominal masses.

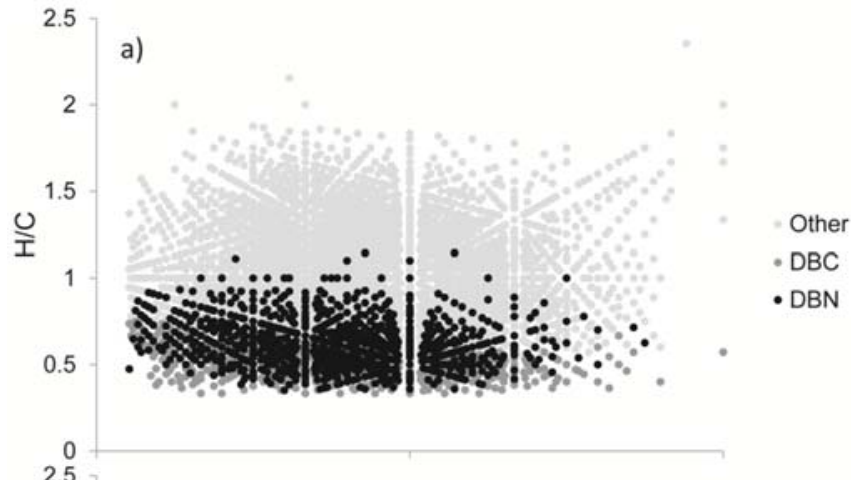

b)

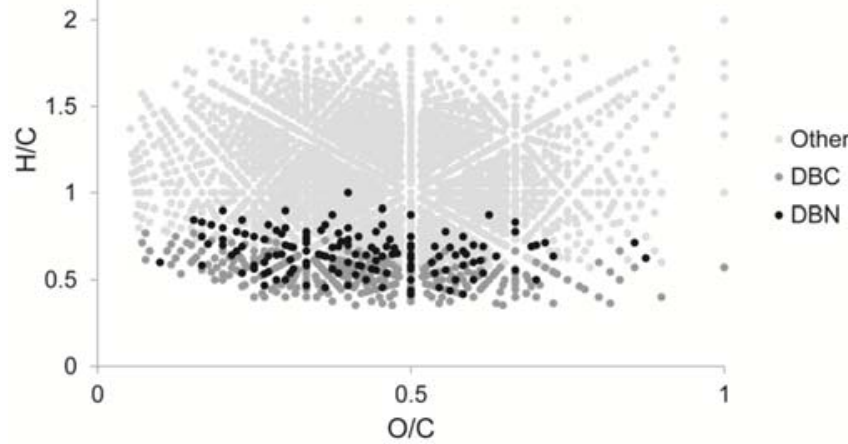

Figure 2.2 Van Krevelen diagrams depict the distribution of assigned formulae in (a) PNAS and (b) PNAC leachate samples. 


\subsection{3 ${ }^{13} \mathrm{C}$ isotopic validation}

Isotopic validation of selected peaks can provide strong support that the DBN formulae are indeed correctly assigned. Therefore, isotopic peaks, where the assigned formula substitutes one ${ }^{12} \mathrm{C}$ for one ${ }^{13} \mathrm{C}$, were measured to validate several different $\mathrm{DBN}$ formulae. Six abundant DBN peaks were selected, having $\mathrm{m} / \mathrm{z}$ values of 228.030229 , $360.051377,376.046280,404.041235,410.051754$ and 424.031026 and assigned formulae of $\mathrm{C}_{12} \mathrm{H}_{6} \mathrm{NO}_{4}{ }^{-}, \mathrm{C}_{20} \mathrm{H}_{10} \mathrm{NO}_{6}{ }^{-}, \mathrm{C}_{20} \mathrm{H}_{11} \mathrm{NO}_{7}^{-}, \mathrm{C}_{21} \mathrm{H}_{11} \mathrm{NO}_{8}{ }^{-}, \mathrm{C}_{20} \mathrm{H}_{13} \mathrm{NO}_{9}{ }^{-}$and $\mathrm{C}_{20} \mathrm{H}_{11} \mathrm{NO}_{10}{ }^{-}$, respectively. Isotopic peaks were computer-simulated on the basis of the relative natural abundance of ${ }^{12} \mathrm{C}$ and ${ }^{13} \mathrm{C}$ isotopes. The measured ${ }^{13} \mathrm{C} /{ }^{12} \mathrm{C}$ isotopic peak ratio for each formula was determined and compared with the ${ }^{13} \mathrm{C} /{ }^{12} \mathrm{C}$ of simulated peaks. Fig. 2.3 shows the side-by-side comparison of simulated and measured isotopic DBN peaks for $\mathrm{C}_{12} \mathrm{H}_{6} \mathrm{NO}_{4}^{-}$. Simulated intensity and measured peak intensity for each selected $\mathrm{m} / \mathrm{z}$ value and the corresponding ${ }^{13} \mathrm{C} /{ }^{12} \mathrm{C}$ ratio values are listed in Table 2.2. Average isotopic ratio values between simulated and measured peaks were statistically similar according to the Student's t-Test ( $\mathrm{p}>0.05$ ). Results here could be extrapolated to other DOM spectra where ${ }^{13} \mathrm{C}$ isotopic peaks were not as well resolved and to other homologues within the same DBN series for the sample.

\subsubsection{Fragmentation patterns}

Masses selected for CID fragmentation were the same as those used for isotopic validation and were chosen from their high relative intensity in the PNAS leachate. Fragmentation patterns for each parent mass are shown in Fig. 2.4. Within each nominal 
Table 2.2 Validation of selected DBN peaks from ${ }^{13} \mathrm{C}$ isotopic comparison.

\begin{tabular}{|c|c|c|c|c|c|c|c|c|c|}
\hline \multirow[b]{2}{*}{$\begin{array}{l}\text { Nominal } \\
\text { mass (Da) }\end{array}$} & \multirow[b]{2}{*}{$\begin{array}{l}\text { Neutral } \\
\text { formula }\end{array}$} & \multicolumn{3}{|c|}{ Calculated } & \multicolumn{2}{|c|}{ Simulated } & \multicolumn{3}{|c|}{ Measured } \\
\hline & & $m / z\left({ }^{12} \mathrm{C}\right)$ & $m / z\left({ }^{13} \mathrm{C}\right)$ & ${ }^{12} \mathrm{C}$ Peak I & ${ }^{13} \mathrm{C}$ Peak I & ${ }^{13} \mathrm{C} /{ }^{12} \mathrm{C}(\%)$ & ${ }^{12} \mathrm{C}$ Peak I & ${ }^{13} \mathrm{C}$ Peak I & ${ }^{13} \mathrm{C} /{ }^{12} \mathrm{C}(\%)$ \\
\hline 228 & $\mathrm{C}_{12} \mathrm{H}_{7} \mathrm{NO}_{4}$ & 228.030229 & 229.033584 & 100.0 & 13.0 & 13.0 & 71.9 & 8.6 & 12.0 \\
\hline 360 & $\mathrm{C}_{20} \mathrm{H}_{11} \mathrm{NO}_{6}$ & 360.051377 & 361.054732 & 100.0 & 21.6 & 21.6 & 8.6 & 1.7 & 19.9 \\
\hline 376 & $\mathrm{C}_{20} \mathrm{H}_{12} \mathrm{NO}_{7}$ & 376.046280 & 377.049635 & 100.0 & 21.6 & 21.6 & 13.4 & 2.1 & 15.9 \\
\hline 404 & $\mathrm{C}_{21} \mathrm{H}_{12} \mathrm{NO}_{8}$ & 404.041235 & 405.044590 & 100.0 & 22.8 & 22.8 & 10.1 & 2.0 & 19.6 \\
\hline 410 & $\mathrm{C}_{20} \mathrm{H}_{14} \mathrm{NO}_{9}$ & 410.051754 & 411.055109 & 100.0 & 21.6 & 21.6 & 8.4 & 1.4 & 16.7 \\
\hline 424 & $\mathrm{C}_{20} \mathrm{H}_{12} \mathrm{NO}_{10}$ & 424.031026 & 425.034381 & 100.0 & 21.8 & 21.8 & 9.4 & 1.6 & 17.0 \\
\hline
\end{tabular}

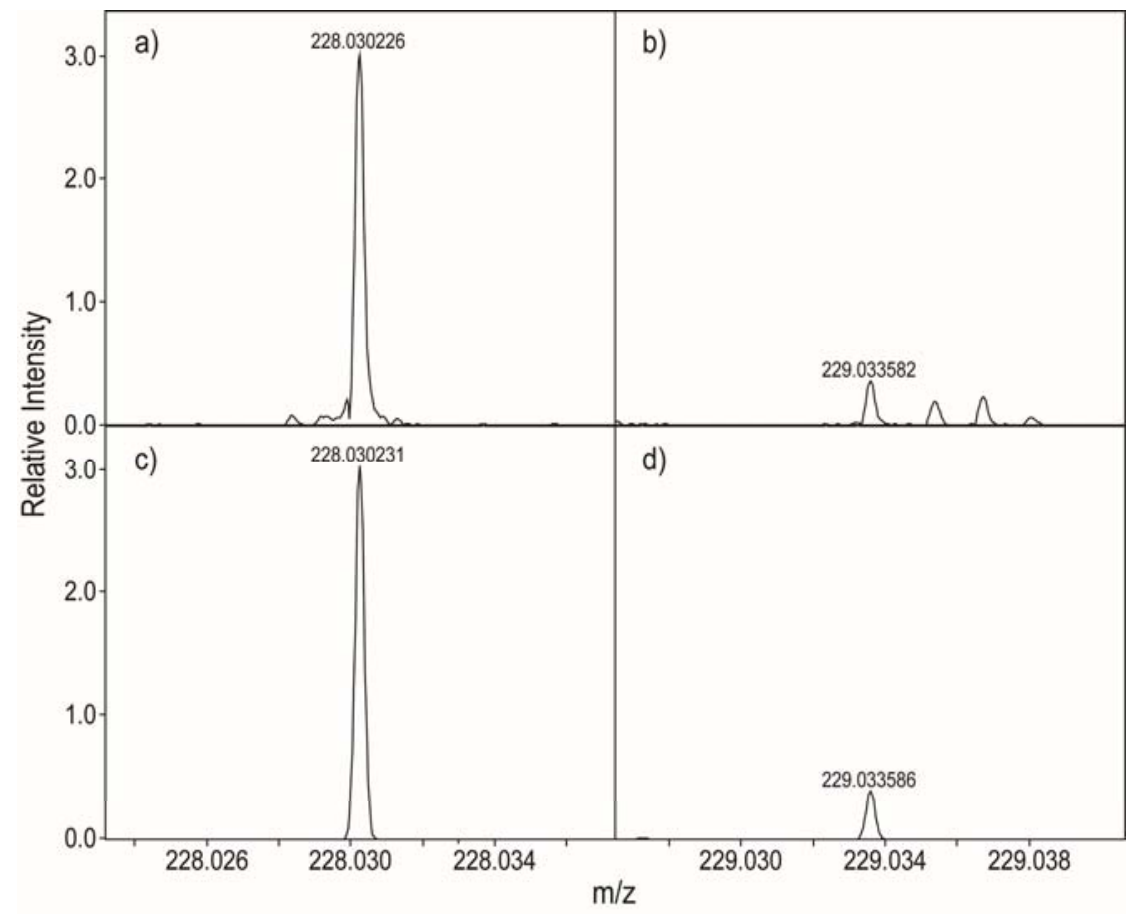

Figure 2.3 Isotopic validation of DBN formulae in PNAS leachate. Measured intensities of (a) ${ }^{12} \mathrm{C}$ and (b) ${ }^{13} \mathrm{C}$ monoisotopic peaks are compared to simulated (c) ${ }^{12} \mathrm{C}$ and (d) ${ }^{13} \mathrm{C}$ monoisotopic peaks. 
mass, the selected DBN peak was the most abundant for all masses with one exception. The DBN peak at $\mathrm{m} / \mathrm{z} 360.051377$ had the second highest intensity at nominal mass 360 Da. All six parent ions had similar neutral losses and general fragmentation patterns. Losses of $\mathrm{CO}_{2}$ and $\mathrm{CO}$ were the most common among all isolated peaks. Neutral losses of $\mathrm{H}_{2} \mathrm{O}$ and $\mathrm{CH}_{3} \mathrm{OH}$ were also observed. Similar neutral loss patterns for O-containing functionalities have been observed in other DOM components such as fulvic acids (Witt et al., 2009). No losses of N-containing functionalities were observed, strengthening support for the stable incorporation of $\mathrm{N}$ into the polyaromatic core structure of DBN compounds.

An example of neutral mass losses for parent ion at $\mathrm{m} / \mathrm{z} 410.051754$, with formula $\mathrm{C}_{20} \mathrm{H}_{13} \mathrm{NO}_{9}{ }^{-}$, is shown in Fig. 2.5. Oxygen was determined to be present predominantly in the form of carboxylic acid groups, as evidenced by the stepwise reduction in fragment intensity through neutral $\mathrm{CO}_{2}$ losses. In this particular spectrum (Fig. 2.5), methoxy and phenolic substitutions to the core structure are also suggested due to detectable losses of $\mathrm{H}_{2} \mathrm{O}$ and $\mathrm{CH}_{3} \mathrm{OH}$. The number of double bond equivalents (DBEs) was also calculated for each assigned formula using the number of atoms and valence of each element. DBE represents the degree of unsaturation and indicates the total number of rings and double bonds within a structure (Koch and Dittmar, 2006). Based on its fragmentation pattern, formula and DBE, possible parent ion structure and fragmentation pathways for $\mathrm{C}_{20} \mathrm{H}_{13} \mathrm{NO}_{9}{ }^{-}$were outlined (Fig. 2.6). 


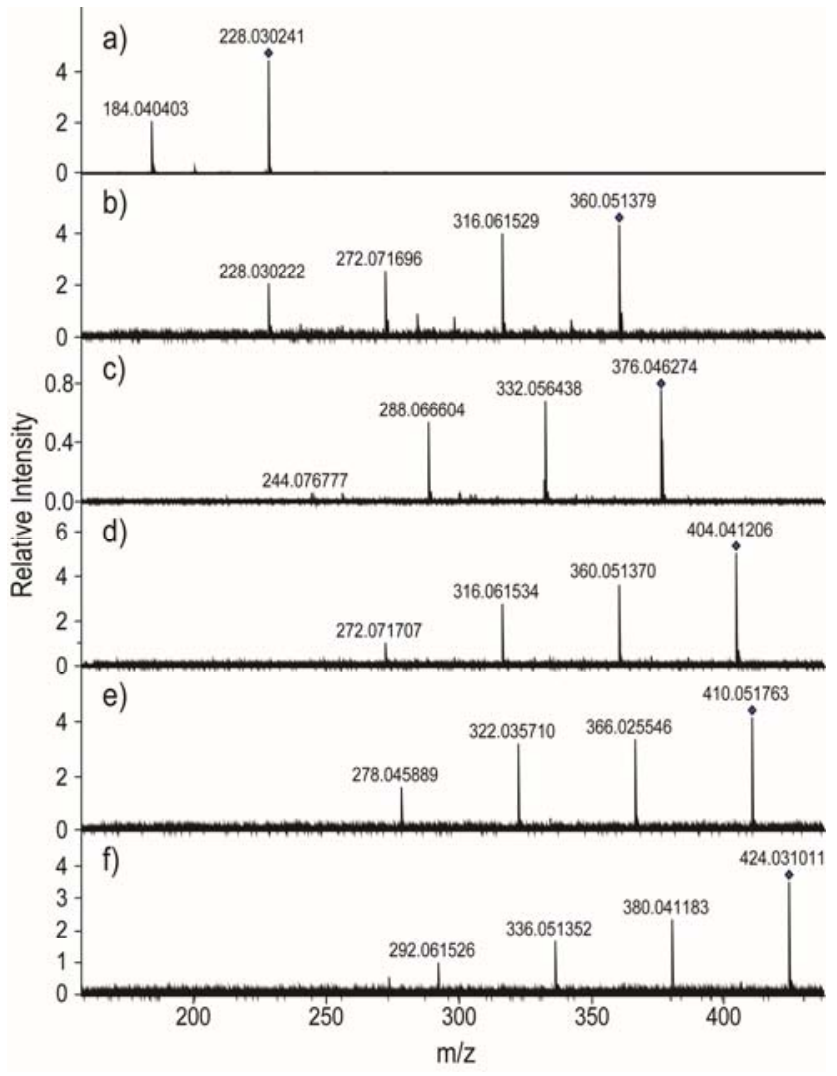

Figure 2.4 CID fragmentation patterns for 6 selected DBN formulae (parent peak denoted with ) at nominal masses (a) $228 \mathrm{Da}$, (b) $360 \mathrm{Da}$, (c) $376 \mathrm{Da}$, (d) $404 \mathrm{Da}$, (e) $410 \mathrm{Da}$ and (f) $424 \mathrm{Da}$. Most abundant peaks represent losses of carboxylic acid groups $\left(\mathrm{CO}_{2}\right)$.

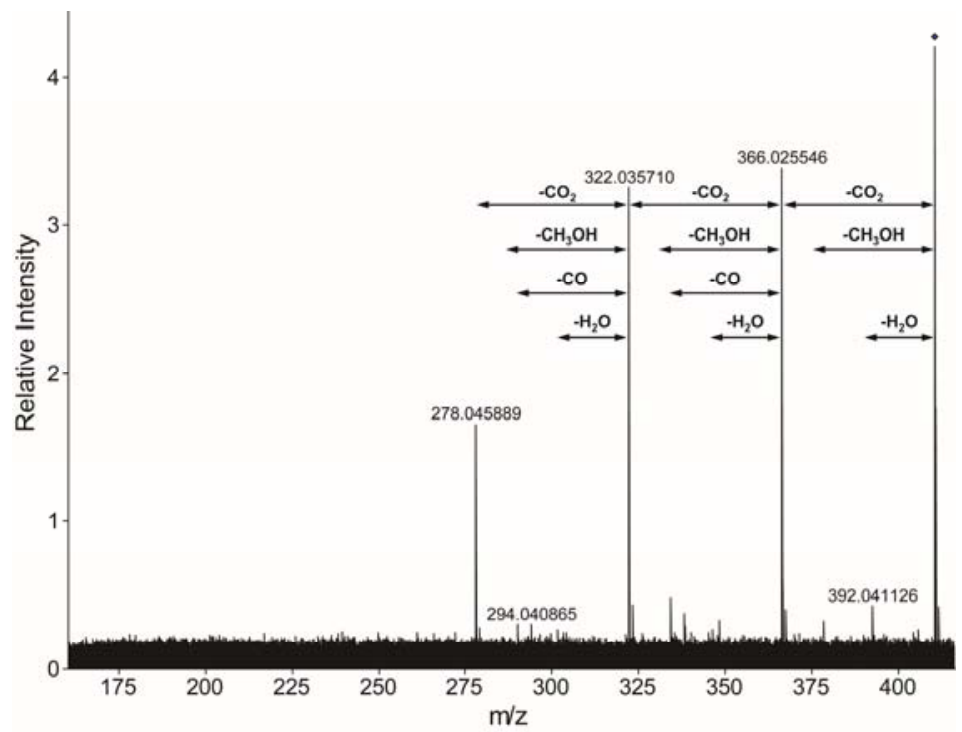

Figure 2.5 Observed neutral losses during fragmentation of DBN structure at nominal mass 410 Da. 
Potential neutral structures for all six fragmented DBN masses are proposed in Fig. 2.7. Though it should be mentioned that structural isomers can exist for the same formula and mass, it is emphasized that each example showed $\mathrm{N}$ as being incorporated into the condensed aromatic structure of pyrogenic OM. Nitrogen-containing neutral losses were not observed in any of the fragmentation patterns for the six selected DBN masses, which suggested that $\mathrm{N}$ was not present in substituted aromatic functionalities (such as nitrate) that are easily lost during CID (LeClair et al., 2012). The suggestion that $\mathrm{N}$ is present in pyrrolic moieties was most suitable when determining the proposed structures of DBN (Fig. 2.7) as compounds containing $\mathrm{N}$ in this form fit within the restrictions set by formula assignment and fragmentation spectra. It has been shown that polyaromatic compounds containing pyrroles can ionize more efficiently during ESI in negative ion mode (Purcell et al., 2007). Therefore, this study does not exclude the possibility that DBN compounds may also contain $\mathrm{N}$ in pyridinic aromatic functionalities. However, NMR analysis has indicated that pyrogenic structures incorporate N primarily in pyrrolic forms (Knicker et al., 2008). As the proposed structure for formula $\mathrm{C}_{20} \mathrm{H}_{12} \mathrm{NO}_{6}$ suggested (Fig. 2.7), the inclusion of phenyl ether linkages is possible. Cleavage of the ether group occurs readily during CID fragmentation, resulting in large neutral mass losses (Gallart-Ayala et al., 2010). Losses suggesting phenyl ether bridges were not observed for any of the other selected DBN formulae. However, it was possible that some of these losses indeed occurred but the resulting fragments fell outside the mass spectral window $(\mathrm{m} / \mathrm{z}<180)$ and therefore were not taken into account during structure elucidation. The potential presence of a fused ring lactone was also suggested for this particular formula on the basis of its fragmentation spectrum and DBE, as neutral losses 
of $\mathrm{CO}_{2}$ and $\mathrm{CO}$ can also be indicative of lactone functionalities and occur after cleavage of the heterocyclic ring structure (Li et al., 2008).

\subsubsection{Kendrick mass analysis}

The most abundant neutral mass loss among all six selected parent masses was $\mathrm{CO}_{2}$. The extent of DBN carboxylic acid substitution was further investigated using

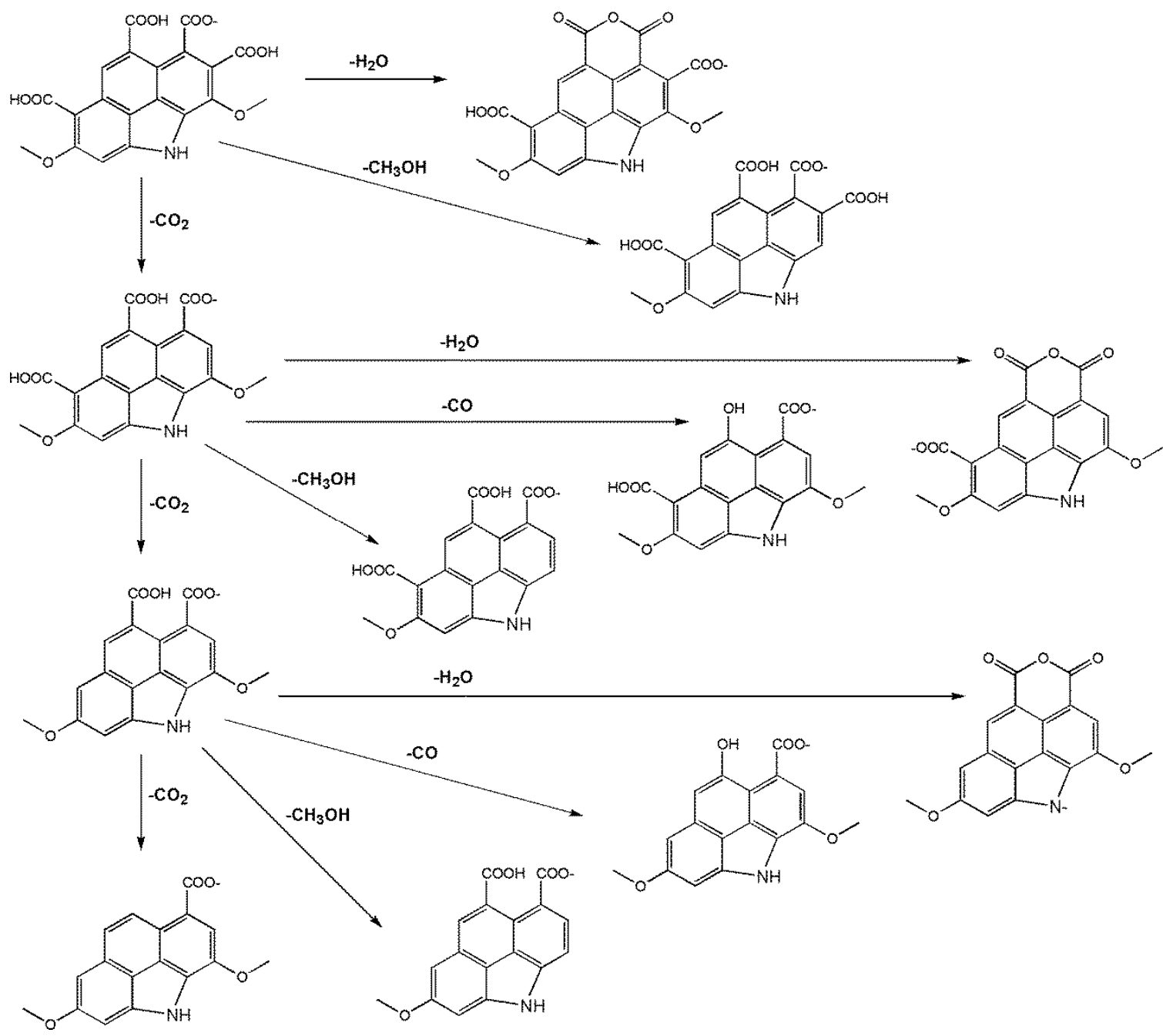

Figure 2.6 Possible fragmentation pathway of parent ion with $\mathrm{m} / \mathrm{z} 410.051754$ and assigned formula $\mathrm{C}_{20} \mathrm{H}_{13} \mathrm{NO}_{9}$. 

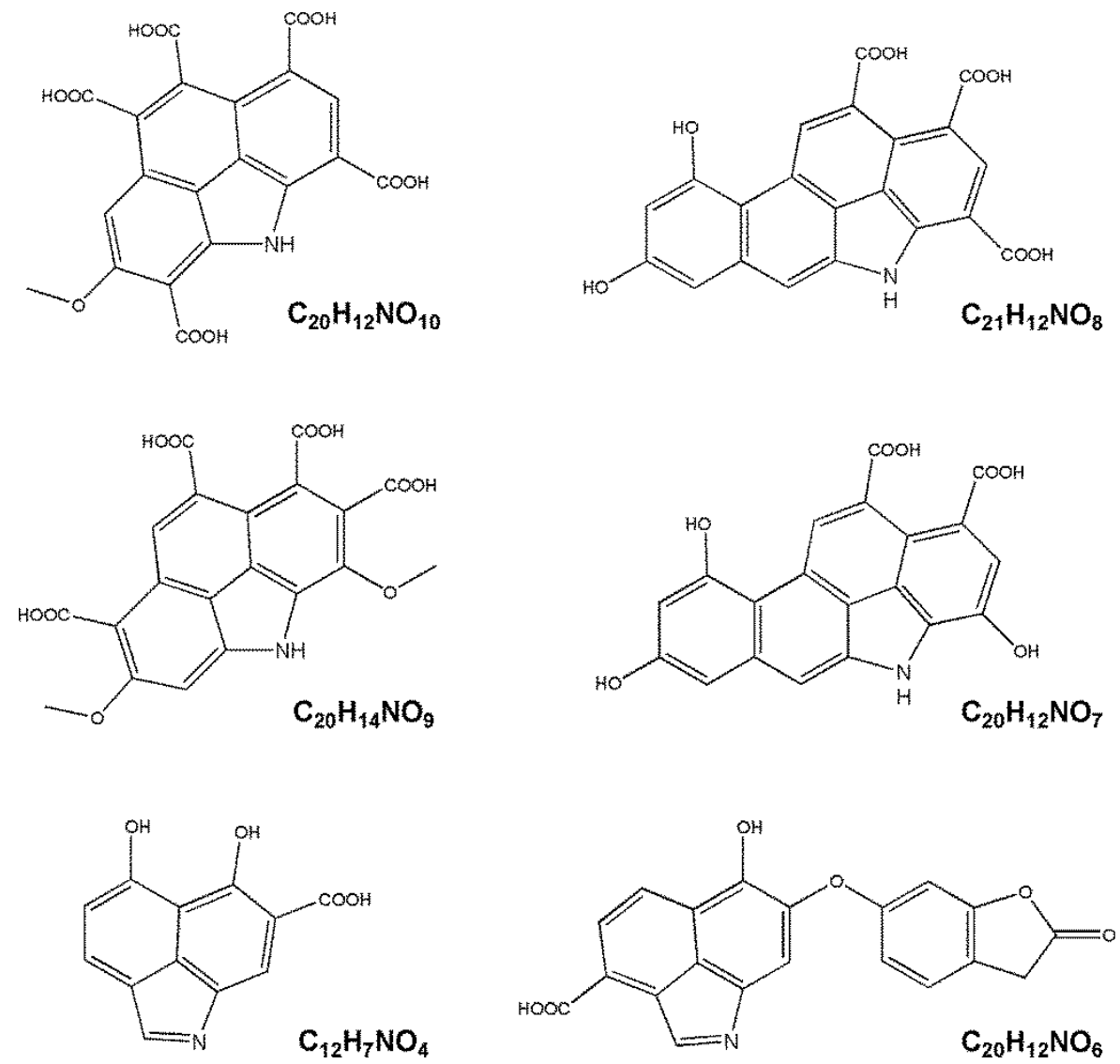

Figure 2.7 Possible DBN structures based on fragmentation spectra.

Kendrick mass analysis, where DBN homologous series were assigned on the basis of the Kendrick mass defect for $\mathrm{CO}_{2}$. The heavy carboxylation of DBN compounds seemed in agreement with observations of Kramer et al. (2004) for the analysis of BC in volcanic ash soil. Kendrick plots for DBN in PNAS and PNAC leachates can be found in the Supplementary data (Appendix 2.1). Dissolved BN formulae that differed by the exact mass of $\mathrm{CO}_{2}$ fell on a horizontal line separated by a nominal mass of $44 \mathrm{Da}$. Related formulae containing $>1 \mathrm{~N}$ atom (where $\mathrm{OH}$ is replaced by $\mathrm{N}$ ) also fell on the same horizontal line, but were separated by a nominal mass of only $3 \mathrm{Da}$. In PNAS, up to six 
formulae were assigned in one homologous series, suggesting that some DBN structures can be substituted with up to six or more carboxylic acid functionalities. The PNAC leachate contained much fewer DBN peaks than PNAS and only up to two homologs were observed in each series. The observation of smaller homologous series could possibly be attributed to increased microbial and abiotic degradation in soils (Liang et al., 2008 and Abiven et al., 2011), resulting in the observation of partially oxidized DBN compounds. The degree of carboxylic substitution was also a function of molecular size. Dissolved BN formulae with smaller nominal mass, such as those in PNAC, likely had a core structure that contained up to three condensed aromatic rings. Larger nominal masses allowed for DBN structures with $>5$ rings, offering space for multiple carboxyl group functionality without steric hindrance. Dissolved BN homologous series were observed in all eight soil and char leachates. The identification of homologous series provides further evidence of DBN structures where heteroatoms are incorporated into the aromatic core structure and are primarily substituted with O-containing functionalities.

\subsection{Conclusions}

The present study is the first to report the molecular composition of DBN as characterized with FT-ICRMS in the complex mixture of organic compounds that characterize natural DOM. DBN formulae were validated by comparison of the relative intensities of ${ }^{12} \mathrm{C}$ and ${ }^{13} \mathrm{C}$ DBN peaks. Possible DBN chemical structures were deduced from mass fragmentation patterns where pyrogenic $\mathrm{N}$ appeared to be incorporated into the condensed aromatic core structures of $\mathrm{BC}$ compounds in the form of pyrrole-type moieties. Stepwise neutral losses of $\mathrm{CO}_{2}$ and Kendrick mass analysis suggested DBN 
molecules to also be polysubstituted with carboxylic acid moieties, and to a lesser extent phenolic and methoxy groups. These functionalities potentially provide the needed polarity to allow such structures to be present in the dissolved phase. The preliminary elucidation of DBN molecular structures gives important insight into its potential mobility and reactivity in the environment.

As evidenced here, DBN is mobilized from soils and char and could play a dynamic role in aquatic systems. It was shown that $>50 \%$ of DBC formulae leached from some soils and char contain $\mathrm{N}$, suggesting that a significant portion of DBC contains heteroatoms. Considering that an estimated $26.5 \times 10^{6}$ tons of DBC is exported globally by rivers per year (Jaffé et al., 2013), the flux of DBN could also be substantial. The proportion of soluble $\mathrm{BN}$ in charcoal and in fire-affected soil appears to be controlled by both the molecular composition of the precursor organic material and the extent of SOM sorption and oxidation that occur after thermal alteration. The quality of DBC, as evidenced by its varying $\mathrm{N}$ content, could greatly affect its stability in soil and resistance to degradation. While FT-ICRMS affords detailed information regarding DBN structure, a method for its quantification has yet to be developed. Further research addressing the reactivity and biolability of DBN is needed in order to fully realize the potentially critical role of its cycling on the global nitrogen budget. 


\section{References}

Abe, T., Watanabe, A., 2004. X-ray photoelectron spectroscopy of nitrogen functional groups in soil humic acids. Soil Science 169, 35-43.

Abiven, S., Hengartner, P., Schneider, M.P.W., Singh, N., Schmidt, M.W.I., 2011. Pyrogenic carbon soluble fraction is larger and more aromatic in aged charcoal than fresh charcoal. Soil Biology and Biochemistry 43, 1615-1617.

Cheng, C.H., Lehmann, J., Thies, J.E., Burton, S.D., 2008. Stability of black carbon in soils across a climatic gradient. Journal of Geophysical Research 113, G02027.

Cheng, C.H., Lin, T.P., Lehmann, J., Fang, L.J., Yang, Y.W., Menyailo, O.V., Chang, K.H., Lai, J.S., 2014. Sorption properties for black carbon (wood char) after long term exposure in soils. Organic Geochemistry 70, 53-61.

de la Rosa, J.M., Knicker, H., 2011. Bioavailability of N released from N-rich pyrogenic organic matter: an incubation study. Soil Biology and Biochemistry 43, 2368-2373.

Ding, Y., Yamashita, Y., Dodds, W.K., Jaffé, R., 2013. Dissolved black carbon in grassland streams: is there an effect of recent fire history? Chemosphere 90, 2557-2562.

Ding, Y., Watanabe, A., Jaffé, R., 2014. Dissolved black nitrogen (DBN) in freshwater environments. Organic Geochemistry 68, 1-4.

Dittmar, T., Koch, B.P., 2006. Thermogenic organic matter dissolved in the abyssal ocean. Marine Chemistry 102, 208-217.

Dittmar, T., 2008. The molecular level determination of black carbon in marine dissolved organic matter. Organic Geochemistry 39, 396-407.

Dittmar, T., Koch, B., Hertkorn, N., Kattner, G., 2008. A simple and efficient method for the solid-phase extraction of dissolved organic matter (SPE-DOM) from seawater. Limnology and Oceanography-Methods 6, 230-235.

Dittmar, T., Paeng, J., 2009. A heat-induced molecular signature in marine dissolved organic matter. Nature Geoscience 2, 175-179.

Dittmar, T., de Rezende, C.E., Manecki, M., Niggeman, J., Ovalle, A.R.C., Stubbins, A., Bernardes, M.C., 2012. Continuous flux of dissolved black carbon from a vanished tropical forest biome. Nature Geoscience 5, 618-622.

Gallart-Ayala, H., Moyano, E., Galceran, M.T., 2010. Multiple-stage mass spectrometry analysis of bisphenol A diglycidyl ether, bisphenol F diglycidyl ether and their derivatives. Rapid Communications in Mass Spectrometry 24, 3469-3477. 
Glaser, B., Haumaier, L., Guggenberger, G., Zech, W., 1998. Black carbon in soils: the use of benzene polycarboxylic acids as specific markers. Organic Geochemistry 29, 811819.

Goldberg, E., 1985. Black Carbon in the Environment. John Wiley and Sons, New York.

Green, N.W., Perdue, E.M., Aiken, G.R., Butler, K.D., Chen, H., Dittmar, T., Niggemann, J., Stubbins, A., 2014. An intercomparison of three methods for the largescale isolation of oceanic dissolved organic matter. Marine Chemistry 161, 14-19.

Gross, J., 2011. Mass Spectrometry: A Textbook, second ed. Springer.

Hammes, K., Smernik, R.J., Skjemstad, J.O., Herzog, A., Vogt, U.F., Schmidt, M.W.I., 2006. Synthesis and characterization of laboratory-charred grass straw (Oryza sativa) and chestnut wood (Castanea sativa) as reference materials for black carbon quantification. Organic Geochemistry 37, 1629-1633.

Hughey, C.A., Hendrickson, C.L., Rodgers, R.P., Marshall, A.G., 2001. Kendrick mass defect spectrum: a compact visual analysis for ultrahigh-resolution broadband mass spectra. Analytical Chemistry 73, 4676-4681.

Jaffé, R., Yamashita, Y., Maie, N., Cooper, W.T., Dittmar, T., Dodds, W.K., Jones, J.B., Myoshi, T., Ortiz-Zayas, J.R., Podgorski, D.C., Watanabe, A., 2012. Dissolved organic matter in headwater streams: compositional variability across climatic regions of North America. Geochimica et Cosmochimica Acta 94, 95-108.

Jaffé, R., Ding, Y., Niggeman, J., Vähätalo, A.V., Stubbins, A., Spencer, R.M., Campbell, J., Dittmar, T., 2013. Global charcoal mobilization from soils via dissolution and riverine transport to oceans. Science 340, 345-347.

Kim, S., Kramer, R.W., Hatcher, P.G., 2003. Graphical method for analysis of ultrahighresolution broadband mass spectra of natural organic matter, the Van Krevelen diagram. Analytical Chemistry 75, 5336-5344.

Kim, S., Kaplan, L.A., Benner, R., Hatcher, P.G., 2004. Hydrogen-deficient molecules in natural riverine water samples - evidence for the existence of black carbon in DOM. Marine Chemistry 92, 225-234.

Knicker, H., Almendros, G., González-Vila, F.J., Martin, F., Lüdemann, H.D., 1996. ${ }^{13} \mathrm{C}$ and ${ }^{15} \mathrm{~N}-\mathrm{NMR}$ spectroscopic examination of the transformation of organic nitrogen in plant biomass during thermal treatment. Soil Biology and Biochemistry 28, 1053-1060.

Knicker, H., 2007. How does fire affect the nature and stability of soil organic nitrogen and carbon? A review. Biogeochemistry 85, 91-118. 
Knicker, H., Hilscher, A., Gonzalez-Vila, F.J., Almendros, G., 2008. A new conceptual model for the structural properties of char produced during vegetation fires. Organic Geochemistry 39, 935-939.

Knicker, H., 2010. “'Black nitrogen" - an important fraction in determining the recalcitrance of charcoal. Organic Geochemistry 41, 947-950.

Koch, B.P., Witt, M., Engbrodt, R., Dittmar, T., Kattner, G., 2005. Molecular formulae of marine and terrigenous dissolved organic matter detected by electrospray ionization Fourier transform ion cyclotron resonance mass spectrometry. Geochimica et Cosmochimica Acta 13, 3299-3308.

Koch, B.P., Dittmar, T., 2006. From mass to structure: an aromaticity index for highresolution mass data of natural organic matter. Rapid Communications in Mass Spectrometry 20, 926-932.

Koch, B.P., Dittmar, T., Witt, M., Kattner, G., 2007. Fundamentals of molecular formula assignment to ultrahigh resolution mass data of natural organic matter. Analytical Chemistry 79, 1758-1763.

Kögel-Knabner, I., 2002. The macromolecular organic composition of plant and microbial residues as inputs to soil organic matter. Soil Biology and Biochemistry 34, $139-162$.

Kramer, R.W., Kujawinski, E.B., Hatcher, P.G., 2004. Identification of black carbon derived structures in a volcanic ash soil humic acid by Fourier transform ion cyclotron resonance mass spectrometry. Environmental Science and Technology 38, 3387-3395.

Kujawinski, E.B., 2002. Electrospray ionization Fourier transform ion cyclotron resonance mass spectrometry (ESI FT-ICR MS): characterization of complex environmental mixtures. Environmental Forensics 3, 207-216.

LeClair, J.P., Collett, J.L., Massoleni, L.R., 2012. Fragmentation analysis of watersoluble atmospheric organic matter using ultrahigh-resolution FT-ICR mass spectrometry. Environmental Science and Technology 46, 4312-4322.

Li, R., Peng, A., He, C., Wang, X., Shi, J., Chen, L., Wei, Y., 2008. Analysis of triptophenolide and its related compounds from Tripterygium wilfordii Hook.f by electrospray ionization tandem mass spectrometry. International Journal of Mass Spectrometry 278, 38-49.

Liang, B., Lehmann, J., Solomon, D., Sohi, S., Thies, J.E., Skjemstad, J.O., Luizao, F.J., Engelhard, M.H., Neves, E.G., Wirick, S., 2008. Stability of biomass-derived black carbon in soils. Geochimica et Cosmochimica Acta 72, 6069-6078. 
Maie, N., Parish, K.J., Watanabe, A., Knicker, H., Benner, R., Abe, T., Kaiser, K., Jaffé, R., 2006. Chemical characteristics of dissolved organic nitrogen in an oligotrophic subtropical coastal ecosystem. Geochimica et Cosmochimica Acta 70, 4491-4506.

Monteil-Rivera, F., Brouwer, E.B., Masset, S., Deslandes, Y., Dumonceau, J., 2000. Combination of X-ray photoelectron and solid-state ${ }^{13} \mathrm{C}$ nuclear magnetic resonance spectroscopy in the structural characterization of humic acids. Analytical Chimica Acta $424,243-255$.

Purcell, J.M., Rodgers, R.P., Hendrickson, C.L., Marshall, A.G., 2007. Speciation of nitrogen containing aromatics by atmospheric pressure photoionization or electrospray ionization Fourier transform ion cyclotron resonance mass spectrometry. Journal of the American Society for Mass Spectrometry 18, 1265-1273.

Schmidt, M.W.I., Skjemstad, J.O., Gehrt, E., Kögel-Knabner, I., 1999. Charred organic carbon in German chernozemic soils. European Journal of Soil Science 50, 351-365.

Schulten, H.R., Schnitzer, M., 1998. The chemistry of soil organic nitrogen: a review. Biology and Fertility of Soils 26, 1-15.

Singh, N., Abiven, S., Torn, M.S., Schmidt, M.W.I., 2012. Fire-derived organic carbon in soil turns over on a centennial timescale. Biogeosciences 9, 2847-2857.

Skjemstad, J.O., Taylor, J.A., Janik, L.J., Marvanek, S.P., 1999. Soil organic carbon dynamics under long-term sugar cane monoculture. Australian Journal of Soil Research $37,151-164$.

Sleighter, R.L., Hatcher, P.G., 2007. The application of electrospray ionization coupled to ultrahigh resolution mass spectrometry for the molecular characterization of natural organic matter. Journal of Mass Spectrometry 42, 559-574.

Smernik, R.J., Baldock, J.A., 2005. Does solid-state ${ }^{15} \mathrm{~N}$ NMR spectroscopy detect all soil organic nitrogen? Biogeochemistry 75, 507-528.

Stenson, A.C., Marshall, A.G., Cooper, W.T., 2003. Exact masses and chemical formulas of individual Suwanee River fulvic acids from ultrahigh resolution electrospray ionization Fourier transform ion cyclotron resonance mass spectra. Analytical Chemistry $75,1275-1284$.

Witt, M., Fuchser, J., Koch, B.P., 2009. Fragmentation studies of fulvic acids using collision induced dissociation Fourier transform ion cyclotron mass spectrometry. Analytical Chemistry 81, 2688-2694. 
CHAPTER III

LINKING THE MOLECULAR SIGNATURE OF HETEROATOMIC DISSOLVED ORGANIC MATTER TO WATERSHED CHARACTERISTICS IN WORLD RIVERS

(In review at Environmental Science and Technology) 


\subsection{Abstract}

Large world rivers are significant sources of dissolved organic matter (DOM) to the oceans. Watershed geomorphology and land use can drive the quality and reactivity of DOM. Determining the molecular composition of riverine DOM is essential for understanding its source, mobility and fate across landscapes. In this study, DOM from the main stem of ten global rivers covering a wide climatic range and land use features was molecularly characterized via ultrahigh-resolution Fourier-transform ion cyclotron resonance mass spectrometry (FT-ICR-MS). The FT-ICR mass spectral data revealed an overall similarity in molecular components among the rivers. However, when focusing specifically on the contribution of non-oxygen heteroatomic molecular formulae (CHON, $\mathrm{CHOS}, \mathrm{CHOP}$, etc.) to the bulk molecular signature, patterns relating DOM composition and watershed land use became apparent. Greater abundances of N- and S-containing molecular formulae were identified in rivers influenced by anthropogenic inputs, whereas rivers with primarily forested watersheds had DOM signatures relatively depleted in heteroatomic content. A strong correlation between cropland cover and dissolved black nitrogen was established when focusing specifically on the pyrogenic class of compounds. The present study demonstrated how changes in land use directly affect downstream DOM quality and could impact $\mathrm{C}$ and nutrient cycling on a global scale.

\subsection{Introduction}

Inland waters cover a relatively small percentage of Earth's surface area, however they play a very important role in the transformation and global cycling of dissolved organic matter (DOM) and associated carbon (DOC). ${ }^{1,2}$ Large fluvial systems, such as 
the Amazon, Congo and Yangtze Rivers, are dominant contributors to DOC fluxes to the ocean. ${ }^{3}$ Smaller order streams export DOM that primarily reflects local organic matter $(\mathrm{OM})$ inputs and dynamics, ${ }^{4,5}$ whereas the main stem of major rivers integrate basin-wide OM sources and transformations. ${ }^{3}$ Dissolved OM is continually reworked via processes such as photo- ${ }^{6}$ and bio-degradation ${ }^{7}$ as it moves from low to high order streams. ${ }^{8}$ However, DOM appears to retain some compositional components of its original source material despite undergoing these biogeochemical alterations. ${ }^{9}$

Because of the extensive connectivity between rivers and the landscapes they drain, patterns within the DOM signature can be used to assess how vegetation cover and land use impact fluvial health. Thus, the DOM that flows through downstream reaches of large river systems serves as a continuous indicator of the cumulative effects of watershed processes on in-stream water quality. ${ }^{10}$ It has been well established that human activities influence the composition of DOM and increase the proportion of nutrients exported to inland surface waters. ${ }^{11-13}$ The enrichment of organic nutrients, such as $\mathrm{N}, \mathrm{S}$, and $\mathrm{P}$, can alter DOM reactivity and sorption processes ${ }^{14}$ or trigger autochthonous production of relatively labile DOM. ${ }^{15,16}$ As such, the conversion of natural vegetation landscapes to agricultural fields has been strongly linked to increased contributions of dissolved organic N (DON) to in-stream DOM. ${ }^{12,13,17}$ Anthropogenic sources of dissolved organic P (DOP) and S (DOS) have been observed for freshwater systems receiving inputs from cropland runoff ${ }^{13}$ and waste water effluent. ${ }^{18,19}$ Although it is apparent that anthropogenic activities and associated land use change can have a significant impact on DOM quality and reactivity, ${ }^{20,21}$ little is currently known about the specific molecular characteristics of these heteroatomic DOM contributions. 
Ultrahigh-resolution Fourier transform ion cyclotron resonance mass spectrometry (FT-ICR-MS) is uniquely suited for molecular characterizing complex organic mixtures such as DOM. ${ }^{22-24}$ As a consequence of the ultrahigh mass accuracy, FT-ICR-MS resolves these mixtures on a molecular formula level, as thousands of individual mass spectral peaks can be detected in DOM, to which molecular formulae are subsequently assigned. ${ }^{25,26}$ A molecular formula cannot inherently be linked to a specific molecular structure, as it can represent multiple structural isomers. However, molecular parameters have been established to categorize the formulae into different structural classes. Van Krevelen distribution plots (elemental ratios of $\mathrm{H} / \mathrm{C}$ vs. O/C) can be used to aid in the visual assessment of overall DOM composition ${ }^{27}$ and the aromaticity index (AI) has been established for the unambiguous identification of aromatic DOM components. ${ }^{28}$ These elemental parameters have been used in combination to establish cutoffs for different compound classes depending on degrees of saturation, oxidation and aromaticity. 29,30

Changes in catchment land use have been shown to significantly impact in-stream DOM composition, whereby heteroatomic contributions are notably increased. ${ }^{12,13}$ Molecular formulae containing N, S and P, as identified by FT-ICR-MS, have been reported previously for fluvial ${ }^{31}$ and lacustrine systems. ${ }^{32,33}$ Other studies have employed FT-ICR-MS to elucidate the structural details of specific heteratomic DOM components such as those sourced from waste water effluent, ${ }^{19}$ charcoal leachates ${ }^{34}$ or oceanic waters. ${ }^{35}$ The main objective of the present study was to assess the potential relationship between heteroatomic DOM components and watershed land use on a global scale, focusing on DOM from major world rivers. Determining the relationship between 
environmental drivers and DOM composition is critical in the understanding of the potential effects of anthropogenic activities on large fluvial systems, and could have significant implications for the bioavailability, reactivity and oceanic fate of these organic nutrients.

\subsection{Materials and Methods}

\subsubsection{Sample collection and preparation}

Surface water samples were obtained from ten major world rivers (Amazon, Congo, Danube, Ganges-Brahmaputra, Yangtze, Mekong, Mississippi, Lena, Paraná and St. Lawrence Rivers). Samples were collected during the season of peak flow in the downstream reaches of the main stem of each river, with the exception of the Amazon River which was sampled in Manaus from the two main stems (Rio Negro and Rio Solimões) as explained in detail by Jaffé et al., ${ }^{36}$ Xiao et al., ${ }^{37}$ Lalonde et al. ${ }^{38}$ and the Supporting Information. The Amazon River sample was prepared by mixing $25 \%$ of the Rio Negro sample and $75 \%$ of the Rio Solimões sample representing the natural mixing of these stems of rivers in downstream Manaus on the basis of their discharge rates. Surface waters were collected in polyethylene containers (pre-cleaned with detergent, acid and rinsed with ultrapure water) and shipped, unfiltered, to the laboratory at environmental temperature and subsequently frozen. As a result of the sample delivery protocol, the DOM analyzed in this study is considered refractory. Samples were thawed and filtered through pre-combusted glass fiber filters (Whatman GF/F, $0.7 \mu \mathrm{m}$ pore size). Filtrates were then acidified to $\mathrm{pH} 2$ with $\mathrm{HCl}(32 \%$, ultrapure) and stored in the dark at $4^{\circ} \mathrm{C}$ until further preparation. Dissolved $\mathrm{OM}$ was isolated from each water sample by 
solid phase extraction (SPE) prior to FT-ICR-MS analysis with commercially available

modified styrene divinylbenzene polymer adsorbers ( $1 \mathrm{~g}$, Varian Bond Elut PPL). ${ }^{39}$

Extraction efficiencies were $54 \pm 13 \%$ on a carbon basis when determined for evaporated extracts re-dissolved in ultrapure water.

\subsubsection{Ultrahigh-resolution mass spectrometry}

For mass spectral analysis, the SPE samples were diluted with ultrapure water to 1:1 MeOH/water (v/v) and a DOC concentration of $20 \mathrm{mg} \mathrm{L}^{-1}$ for analysis on the Bruker Solarix 15 T FT-ICR-MS instrument at the University of Oldenburg (Germany).

Samples were continuously infused into the electrospray ionization (ESI) unit at a flow rate of $120 \mu \mathrm{L} \mathrm{h}^{-1}$ in ESI negative ion mode. The ESI needle voltage was set to $-4 \mathrm{kV}$. Ions were accumulated in a hexapole ion trap for $0.2 \mathrm{~s}$ before being introduced into the ICR cell. Four megawords of data were recorded per broadband mass scan. The lower and upper mass limit was set to m/z 150 and 2000, respectively. Five hundred transients were summed per sample. The spectra were mass calibrated (linear) with an internal calibration list consisting of 51 compounds covering the entire relevant mass range. Maximum mass error was $<0.1 \mathrm{ppm}$.

Employing ESI-FT-ICR-MS in negative ion mode predominantly ionizes polar compounds and allows for the enhanced detection of heteroatomic molecular structures, which makes it the technique of choice for determining the detailed composition of complex DOM mixtures. ${ }^{23,27}$ However, it is well understood that ionization efficiencies among different compound classes may not be equal, and the relative intensities of FTICR-MS components may not accurately reflect actual concentrations or be 
representative of the entire DOM pool. All samples were analyzed within two consecutive days. Instrument reproducibility was assessed twice daily (every morning and evening) by analyzing a DOM reference isolated from deep North Pacific waters collected off the coast of Hawaii, USA.

Molecular formulae containing the elements $\mathrm{C}, \mathrm{H}, \mathrm{O}, \mathrm{N}, \mathrm{S}$ and/or $\mathrm{P}$ were assigned using a self-written software routine ${ }^{40}$ using the criteria suggested by Stenson et al..$^{25}$ and Koch et al. ${ }^{41}$ Mass spectral peaks falling below the method detection limit (MDL) ${ }^{42}$ were excluded from further analysis. Briefly, blank spectra were collected and the MDL was calculated from the number of blank signals available using a Student's T-test. ${ }^{42}$ The use of the MDL is more statistically robust than the simple application of a $3 \mathrm{x}$ the standard deviation of noise rule, for example. Therefore, the MDL was the method of choice for differentiating between analyte and noise peaks within the global river DOM data set. An example of the assignment of molecular formulae at $417 \mathrm{Da}$ is shown in Figure S1 df. The modified aromaticity index (AI-mod) ${ }^{28}$ and double bond equivalent (DBE) were calculated for each assigned molecular formula. These molecular descriptors both reflect the degree of aromaticity within a molecule. Double bond equivalent is commonly used in mass spectrometry and describes the number of rings and unsaturations within a molecule. However, the calculation of DBE does not consider double bonds that may occur between $\mathrm{C}$ and heteroatomic elements (e.g., O, N, S, P). The AI-mod allows for the unambiguous identification of condensed aromatic structures by taking into account that $50 \%$ of oxygen atoms are typically bound in carbonyl-type functionalities. ${ }^{43,44}$ Therefore, the AI-mod is primarily used within the text to describe the degree of unsaturation of assigned molecular formulae. These and other molecular parameters 
$(\mathrm{m} / \mathrm{z}, \mathrm{H} / \mathrm{C}, \mathrm{O} / \mathrm{C}$, etc.), derived from peak formula assignments were expressed as intensity weighted average (wa) values. Therefore, these values directly reflect the relative contribution of each $\mathrm{m} / \mathrm{z}$ peak to the entire DOM mass spectrum.

\subsubsection{Land cover and statistical methods}

Land cover information for each river was obtained from the Watersheds of the World database compiled by IUCN-The World Conservation Union, the International Water Management Institute, the Ramsar Convention Bureau and the World Resources Institute (http://multimedia.wri.org/watersheds_2003/). Statistical analyses were carried out using IBM SPSS Statistics software (Version 20, IBM Corp.). The significance of linear correlations between two parameters was calculated using the Pearson's productmoment correlation coefficient. Cluster analysis was conducted using Ward's method by applying squared Euclidean distance to measure the degree of similarity between DOM spectral peaks common to all rivers included within the scope of this study. Principle component analyses (PCA) were carried out using either weight averaged means of mass spectral parameters or log-normalized relative peak intensities common to all river DOM spectra.

\subsection{Results and Discussion}

\subsubsection{Comparison of exemplary DOM broadband mass spectra}

All DOM mass spectra exhibited a generally typical Gaussian distribution with clusters of approximately 10 to 25 detected peaks at each nominal mass as exemplified for three rivers in Figure 3.1. Amazon, Ganges-Brahmaputra and St. Lawrence River 
DOM were sourced from different climatic regions and exhibit varying degrees of oxidation and heteroatomic content (Table 3.1; Table 3.2). Therefore, their spectra served as examples for which to compare how relative mass distributions differ across the entire mass range and within exemplary nominal mass $417 \mathrm{Da}$ (Figure S1). Although the DOM broadband spectral distributions were similar in overall shape (Figure 3.1a-c), the relative intensities of peaks detected at 417 Da differed considerably (Figure 3.1d-f). Amazon and St. Lawrence River DOM both exhibited symmetrical relative abundances of $\mathrm{CHO}$ compounds across each nominal mass (Figure 3.1d and Figure 3.1f, respectively). The $\mathrm{CHO}$ compounds detected for Ganges-Brahmaputra River DOM were generally shifted to higher mass defects compared to all other global river DOM samples (data not shown). The $\mathrm{CHO}$ compounds at higher mass defects reflect a lower number of oxygen atoms and/or more $\mathrm{H}$ atoms when $\mathrm{O}$ is replaced with $\mathrm{CH}_{4}$ for molecular formulae sharing the same nominal mass (e.g. $\mathrm{C}_{21} \mathrm{H}_{22} \mathrm{O}_{9}$ vs. $\mathrm{C}_{22} \mathrm{H}_{26} \mathrm{O}_{8}$ in Figure 3.1) ${ }^{45}$ which indicated that DOM exported by the Amazon and St. Lawrence Rivers was generally more oxidized than Ganges-Brahmaputra River DOM. Amazon and St. Lawrence River DOM exhibited the lowest and highest relative abundance of heteroatomic formulae, respectively, at the nominal mass of $417 \mathrm{Da}$ (Figure 3.1d-f). The CHON and CHOS peaks were also detected at $417 \mathrm{Da}$ for each of the three rivers. St. Lawrence River DOM was unique in that it also had detectable peaks assigned with CHOP formulae. The direct comparison of broadband mass spectra at a single nominal mass indicated that variability of both $\mathrm{CHO}$ and heteroatomic contributions to the molecular signature of these global rivers may provide important insight to the source and quality of global river DOM. 

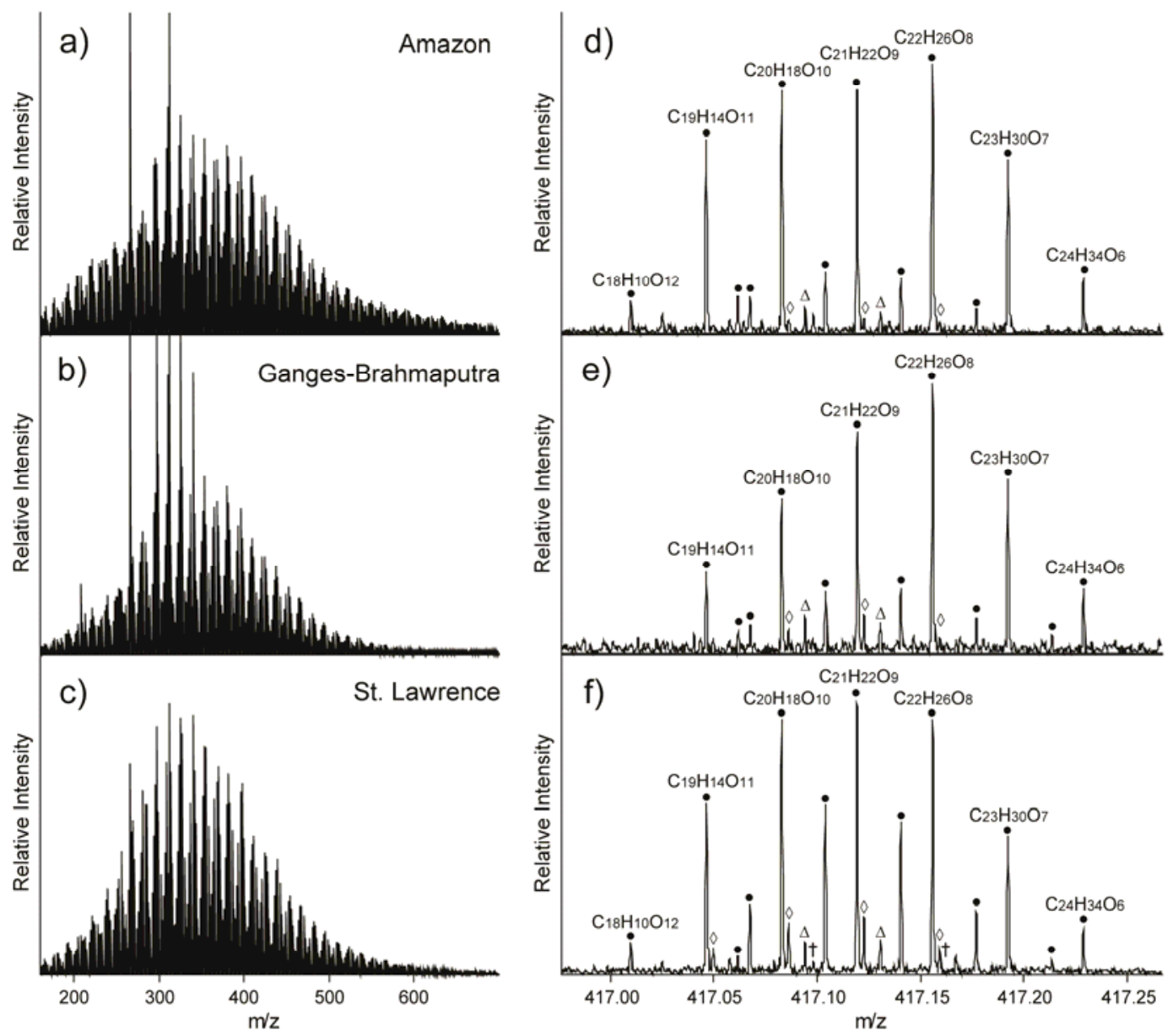

Figure 3.1 Broadband mass spectral distribution for the (a) Amazon, (b) GangesBrahmaputra and (c) St. Lawrence Rivers. Relative intensities of detected $\mathrm{m} / \mathrm{z}$ peaks at nominal mass $417 \mathrm{Da}$ for the (d) Amazon, (e) Ganges-Brahmaputra and (f) St. Lawrence Rivers. Symbols denote formula types $\mathrm{CHO}(\bullet), \mathrm{CHON}(\Delta), \mathrm{CHOS}(\diamond)$ and CHOP $(\dagger)$. For the sake of clarity, the assigned molecular formulae are shown only for the most abundant ions.

\subsubsection{General trends in riverine DOM composition}

The variability in DOM composition is generally expected to be highest among small headwater streams, where it reflects local DOM sources. ${ }^{4,5}$ As smaller streams coalesce into larger ones, the variability of DOM derived from local sources is dampened and downstream DOM signals become more representative of total watershed 
processes. ${ }^{3,10}$ Since the samples for the current study were collected from some of the largest rivers on earth during the season of highest discharge, these analyses were carried out following the assumption that small-scale, localized sources of DOM did not have a disproportionate contribution to the molecular signature of main stem DOM. Despite variations in land use, the global rivers shared some similar trends in DOM composition. Across all rivers examined, the assigned molecular formulae consisted primarily of $\mathrm{C}, \mathrm{H}$ and $\mathrm{O}(\mathrm{CHO})$ followed by formulae with additional $\mathrm{N}(\mathrm{CHON}), \mathrm{S}(\mathrm{CHOS})$ and $\mathrm{P}$ (CHOP; Table 3.1). The number of formulae with two different heteroatoms was highest with CHONS followed by CHOSP and CHONP (Table 3.1). When the assigned formulae were divided into seven groups of compounds, ${ }^{29,30}$ highly unsaturated aliphatic molecules were most abundant followed by polyphenols, condensed aromatics and unsaturated aliphatic molecules (Appendix 3.2). Saturated fatty acids, sugars and peptides made up $<2 \%$ of formulae (Appendix 3.2). It should also be noted that the number of assigned formulae was highly variable, ranging from $~ 3000$ (GangesBrahmaputra) to $\sim 6800$ (Paraná), which indicated a high degree of molecular diversity among the fluvial systems (Table 3.1).

Among the rivers, the mean weighted average composition of DOM varied most in terms of heteroatom content (Table 3.2). The variation in the molecular mass, $\mathrm{C}, \mathrm{H}$ and $\mathrm{O}$ contents as well as indices derived from these was moderate but nevertheless showed distinct differences among rivers (see e.g., Ganges-Brahmaputra in Table 3.2). When the variation in the mean molecular composition of DOM (Table 3.2) was examined with a principal component analysis (PCA), the first principal component 
Table 3.1 Total number and proportions of each formula type assigned to mass spectral peaks for river DOM.

\begin{tabular}{|c|c|c|c|c|c|c|c|c|}
\hline River & $\begin{array}{c}\text { No. of } \\
\text { Assigned } \\
\text { Formulae }\end{array}$ & $\mathrm{CHO}$ & $\mathrm{CHON}$ & CHOS & $\mathrm{CHOP}$ & CHONS & CHONP & CHOSP \\
\hline Amazon & 4839 & $2888(59.7 \%)$ & $1579(32.6 \%)$ & $333(6.9 \%)$ & $9(0.19 \%)$ & $28(0.58 \%)$ & $2(0.04 \%)$ & $0(0 \%)$ \\
\hline Congo & 4406 & $2658(60.3 \%)$ & $1485(33.7 \%)$ & $227(5.2 \%)$ & $1(0.02 \%)$ & $22(0.50 \%)$ & $0(0 \%)$ & $13(0.30 \%)$ \\
\hline Danube & 5847 & $2593(44.3 \%)$ & $2289(39.1 \%)$ & $769(13.2 \%)$ & $16(0.27 \%)$ & $162(2.77 \%)$ & $6(0.10 \%)$ & $12(0.21 \%)$ \\
\hline Ganges-Brahmaputra & 3053 & $1790(58.6 \%)$ & $990(32.4 \%)$ & $256(8.4 \%)$ & $5(0.16 \%)$ & $9(0.29 \%)$ & $3(0.10 \%)$ & $0(0 \%)$ \\
\hline Yangtze & 5457 & $2369(43.4 \%)$ & $2174(39.8 \%)$ & $741(13.6 \%)$ & $9(0.16 \%)$ & $152(2.79 \%)$ & $4(0.07 \%)$ & $8(0.15 \%)$ \\
\hline Lena & 4638 & $2913(62.8 \%)$ & $1297(28.0 \%)$ & $374(8.1 \%)$ & $10(0.22 \%)$ & $24(0.52 \%)$ & $2(0.04 \%)$ & $18(0.39 \%)$ \\
\hline Mekong & 5298 & $2653(50.1 \%)$ & $2034(38.4 \%)$ & $521(9.8 \%)$ & $16(0.30 \%)$ & $65(1.23 \%)$ & $0(0 \%)$ & $9(0.17 \%)$ \\
\hline Mississippi & 5236 & $2594(49.5 \%)$ & $1922(36.7 \%)$ & $621(11.9 \%)$ & $3(0.06 \%)$ & $88(1.68 \%)$ & $1(0.02 \%)$ & $7(0.13 \%)$ \\
\hline Paraná & 6818 & $3222(47.3 \%)$ & $2594(38.0 \%)$ & $718(10.5 \%)$ & $124(1.82 \%)$ & $140(2.05 \%)$ & $4(0.06 \%)$ & $16(0.23 \%)$ \\
\hline St. Lawrence & 5865 & $3089(52.7 \%)$ & $1980(33.8 \%)$ & $644(11.0 \%)$ & $52(0.89 \%)$ & $81(1.38 \%)$ & $0(0 \%)$ & $19(0.32 \%)$ \\
\hline
\end{tabular}


Table 3.2 Molecular parameters of global river DOM derived from assigned molecular formulae. Intensity weighted average values are displayed for molecular weight $\left(\mathrm{m} / \mathrm{z}_{\mathrm{wa}}\right)$, number of carbon $\left(\mathrm{C}_{\mathrm{wa}}\right)$, hydrogen $\left(\mathrm{H}_{\mathrm{wa}}\right)$, oxygen $\left(\mathrm{O}_{\mathrm{wa}}\right)$, nitrogen $\left(\mathrm{N}_{\mathrm{wa}}\right)$, sulfur $\left(\mathrm{S}_{\mathrm{wa}}\right)$ and phosphorous atoms $\left(\mathrm{P}_{\mathrm{wa}}\right)$, hydrogen to carbon ratio $\left(\mathrm{H} / \mathrm{C}_{\mathrm{wa}}\right)$, oxygen to carbon ratio $(\mathrm{O} / \mathrm{C})$, modified aromaticity index $(\mathrm{AI}-\mathrm{mod}$ wa) and double bond equivalent (DBE $\mathrm{wa}_{\mathrm{w}}$ ).

\begin{tabular}{|c|c|c|c|c|c|c|c|c|c|c|c|}
\hline River & $\mathrm{m} / \mathrm{z}_{\mathrm{wa}}$ & $\mathrm{C}_{\mathrm{wa}}$ & $\mathrm{H}_{\mathrm{wa}}$ & $\mathrm{O}_{\mathrm{wa}}$ & $\mathrm{N}_{\mathrm{wa}}$ & $\mathrm{S}_{\mathrm{wa}}$ & $\mathrm{P}_{\mathrm{wa}}$ & $\mathrm{H} / \mathrm{C}_{\mathrm{wa}}$ & $\mathrm{O} / \mathrm{C}_{\mathrm{wa}}$ & AI-mod ${ }_{w a}$ & $\mathrm{DBE}_{\mathrm{wa}}$ \\
\hline Amazon & 290.89 & 14.17 & 15.22 & 6.50 & 0.12 & 0.02 & 0.0010 & 0.80 & 0.34 & 0.29 & 7.37 \\
\hline Congo & 293.03 & 14.12 & 14.85 & 6.69 & 0.13 & 0.01 & 0.0006 & 0.79 & 0.36 & 0.30 & 7.52 \\
\hline Danube & 292.98 & 14.06 & 16.50 & 6.44 & 0.21 & 0.07 & 0.0012 & 0.91 & 0.36 & 0.24 & 6.69 \\
\hline Ganges-Brahmaputra & 262.40 & 13.08 & 15.95 & 5.33 & 0.13 & 0.09 & 0.0007 & 0.91 & 0.30 & 0.23 & 5.91 \\
\hline Yangtze & 286.78 & 13.89 & 16.63 & 6.15 & 0.22 & 0.08 & 0.0006 & 0.93 & 0.35 & 0.24 & 6.47 \\
\hline Lena & 284.43 & 13.70 & 15.68 & 6.46 & 0.07 & 0.02 & 0.0008 & 0.87 & 0.36 & 0.25 & 6.66 \\
\hline Mekong & 287.69 & 13.98 & 15.89 & 6.32 & 0.19 & 0.03 & 0.0008 & 0.89 & 0.36 & 0.27 & 6.91 \\
\hline Mississippi & 290.08 & 13.97 & 16.43 & 6.41 & 0.19 & 0.05 & 0.0004 & 0.93 & 0.36 & 0.25 & 6.63 \\
\hline Paraná & 292.21 & 14.09 & 16.12 & 6.47 & 0.20 & 0.04 & 0.0042 & 0.87 & 0.35 & 0.26 & 6.89 \\
\hline St. Lawrence & 291.73 & 13.93 & 16.14 & 6.62 & 0.13 & 0.04 & 0.0019 & 0.90 & 0.37 & 0.25 & 6.71 \\
\hline
\end{tabular}


(PC1) explained 55.4\% of the variance and was significantly positively correlated with $\mathrm{m} / \mathrm{Zwa}_{\mathrm{wa}}(\mathrm{R}=0.81, \mathrm{p}<0.01), \mathrm{O} / \mathrm{C}_{\mathrm{wa}}(\mathrm{R}=0.65, \mathrm{p}<0.05)$ and AI-modwa $(\mathrm{R}=0.87$, $\mathrm{p}<0.001$; Figure 3.2). Molecular formulae enriched in $\mathrm{O}$ and depleted in $\mathrm{H}$ with increased AI-mod reflect terrestrial inputs from plant-derived biomacromolecules such as lignins, tannins and carboxyl-rich acyclic molecules..$^{24,28,43,45}$ Molecular formulae depleted in $\mathrm{O}$ and enriched in $\mathrm{H}$ with lower AI-mod may be derived from autochthonous sources $^{25,44}$ and are generally categorized into biolabile compound classes including carbohydrates, proteins and lipids. ${ }^{24,28}$ However, these types of compounds have also been identified in soil solutions where they reflect allochthonous sources and are thought to be derived from secondary plant metabolites and/or soil microbes. ${ }^{30,46}$ Principle component 1 was also significantly negatively correlated with $H / C_{w a}(R=-0.76$, $\mathrm{p}<0.05)$ and $\mathrm{S}_{\mathrm{wa}}(\mathrm{R}=-0.89, \mathrm{p}<0.001)$, suggesting that, as CHOS contributions to the DOM signature increased, the $\mathrm{H} / \mathrm{C}_{\mathrm{wa}}$ also increased. A relative enrichment in Scontaining formulae with high $\mathrm{H} / \mathrm{C}$ ratios has been previously linked to DOM sourced from waste water effluent. ${ }^{19}$ Therefore, the relationship between these two molecular parameters along PC1 may reflect the relative contribution of effluent $\mathrm{OM}$ to the total DOM signature. Principle component 2 explained $25.6 \%$ of the variance and was significantly positively correlated with $\mathrm{N}_{\mathrm{wa}}(\mathrm{R}=0.77, \mathrm{p}<0.01)$. Increased contributions of organic $\mathrm{N}$ to riverine DOM have been linked to cropland runoff $\mathrm{f}^{12,13,17}$ and increased instream primary productivity triggered by anthropogenic nutrient inputs. ${ }^{20,47}$ Although it would be speculative to assign specific DOM sources or diagenetic trends along PC1 or PC2, the wide distribution of global rivers within the PCA graphical space (Figure 3.2) 
elucidated statistical differences among DOM compositions which may be linked to watershed characteristics or land use.

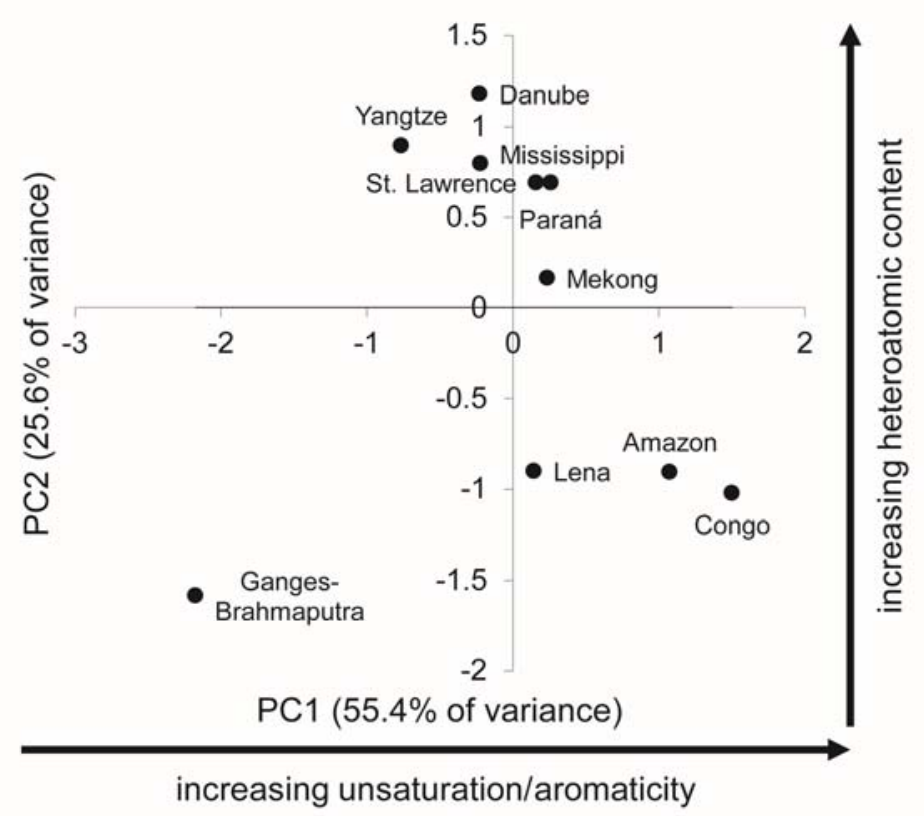

Figure 3.2 Principle component analysis of intensity weighted average values (molecular DOM characteristics) listed in Table 3.2 for global river DOM.

\subsubsection{Linking DOM molecular signatures to watershed land cover and source material}

A cluster analysis was performed using the log-normalized intensity of detected masses common to all large river DOM samples to compare and contrast DOM quality more effectively among the fluvial systems (Appendix 3.3). The degree of similarity between riverine DOM was derived from the comparison of relative peak intensities, therefore the clustering can be directly related to the distances between rivers in Figure 3.2 and to the intensity weighted mean molecular parameters described in Table 3.2. Amazon, Congo and Lena River DOM exhibited the least degree of similarity with the other seven rivers (Appendix 3.3). These fluvial systems had DOM enriched in CHO 
compounds (Table 3.1) and had low N, S and P content (Table 3.2). The Amazon, Congo and Lena Rivers each drain heavily forested watersheds with limited regions of agricultural development (Appendix 3.1) where the lack of anthropogenic inputs may explain the depletion of heteroatoms (Table 3.2). Although the DOM of these terrestrially-dominated rivers share some similarities, a large geochemical distinction was observed between DOM from the high latitude Lena River and the equatorially-located Amazon and Congo Rivers (Appendix 3.3). The Lena River basin is positioned within the tundra/taiga biomes and is primarily underlain by permafrost. ${ }^{48}$ The Lena River receives little autochthonous DOM input, ${ }^{48}$ therefore its pronounced terrigenous DOM signature likely reflected predominant sources from soil organic matter (SOM) and/or soil microbial inputs. DOM from the Amazon and Congo Rivers exhibited the highest $\mathrm{m} / \mathrm{Z}_{\mathrm{wa}}$ and AI-mod $\mathrm{wa}_{\mathrm{w}}$ (Table 3.2), which was reflected in their close clustering to one another and separation from the Lena River (Appendix 3.3). Large contributions from terrestrial DOM components such as lignins, polyphenols and condensed aromatics have been observed previously for these tropical rivers, ${ }^{49,50}$ which likely shifted their overall DOM compositions to increased average molecular weights and degrees of aromaticity compared to the other global rivers located at higher and lower latitudes (Table 3.2).

Although Ganges-Brahmaputra River DOM was generally clustered with other anthropogenically-influenced rivers identified as having $>30 \%$ of basin area characterized as urban and cropland (Appendix 3.3), it exhibited a unique molecular signature compared to all other samples (Table 3.2). Ganges-Brahmaputra River DOM was strongly depleted in high molecular weight, aromatic, oxidized compounds as evidenced by its comparatively low $\mathrm{m} / \mathrm{Z}_{\mathrm{wa}}$, high $\mathrm{H} / \mathrm{C}_{\mathrm{wa}}$ and low $\mathrm{O} / \mathrm{C}_{\mathrm{wa}}$ ratios (Table 3.2). 
The upper reaches of the Ganges-Brahmaputra River basin are characterized by a cold and arid climate with minimal vegetation cover. ${ }^{51}$ Disperse vegetation and the absence of accumulated soil organic layers associated with the steepness of Himalayan slopes within the upper reaches of the Ganges-Brahmaputra River watershed likely results in minimal inputs from terrestrial OM to the mainstem. The low amount of terrigenous DOM inputs may provide one explanation for the lower contribution of large, aromatic, humic-like components to the Ganges-Brahmaputra molecular composition (Table 3.2). Although, the Ganges-Brahmaputra River is known to be one of the major contributors of suspended sediments to the ocean, ${ }^{52}$ the construction of dams within the drainage basin may result in the settling of these particulates and facilitate in-stream DOM processes, such as photodegradation ${ }^{49}$ and primary production, which could result in the observed O-depleted, low molecular weight signature. Downstream reaches of the GangesBrahmaputra River are highly populated and much of the regional municipal and industrial waste waters are discharged directly into the river. ${ }^{53}$ Thus, it can also be suggested that relatively high $\mathrm{H} / \mathrm{C}_{\mathrm{wa}}$ and $\mathrm{S}_{\mathrm{wa}}$ and low $\mathrm{m} / \mathrm{Z}_{\mathrm{wa}}$ (Table 3.2) may reflect increased aliphatic inputs from these anthropogenic waste streams. ${ }^{19}$

The Danube and Yangtze Rivers were similar in overall DOM composition (Appendix 3.3) and exhibited enrichments in $\mathrm{N}_{w a}, \mathrm{~S}_{w a}$ and $\mathrm{H} / \mathrm{C}_{\mathrm{wa}}$ (Table 3.2). Both the Danube and Yangtze Rivers have watersheds with large human populations and some of the largest proportions of cropland cover (Appendix 3.1). While DON concentrations have been shown to be positively correlated with percentage of agricultural land cover within a catchment area, ${ }^{13,17}$ enrichments in $\mathrm{CHON}$ and $\mathrm{CHOS}$ formulae have been identified in waste water ${ }^{19}$ and septic-impacted ${ }^{54}$ aquatic systems. Enrichment in the 
heteroatomic DOM signal suggests that anthropogenic inputs to the Danube and Yangtze watersheds have altered in-stream DOM composition, thereby suppressing the terrestrial DOM signature observed for less impacted rivers such as the Amazon (Table 3.2). Catchments of the Mekong, Mississippi, Paraná and St. Lawrence Rivers are characterized by intermediate degrees of forest, urban and cropland cover (Appendix 3.1). Therefore, their DOM compositions were generally similar and consequently clustered with one another (Appendix 3.3). However, the Paraná and St. Lawrence Rivers were distinguished in their unique expression of increased $\mathrm{P}_{\mathrm{wa}}$ (Table 3.2). High concentrations of soluble organic P recorded for urbanized watersheds,${ }^{13}$ may explain in part, the abundance of CHOP formulae in the St. Lawrence River (Table 3.1) since its watershed has the highest proportion of urban land cover (Appendix 3.1). Lakes connected to St. Lawrence River have been characterized as having an increased presence of heteroatomic formulae in their DOM signatures ${ }^{32}$ which may be attributed to autochthonous DOM enriched during the long water residence time in the Great Lakes systems. ${ }^{55,56}$ Although the Paraná River watershed is not necessarily characterized by extensive lake and/or wetland cover (Appendix 3.1), it drains portions of the Pantanal (the largest subtropical wetland in the world) and features a series of large reservoirs (including the Itaipu Reservoire, the largest in South America). The lacustrine zone of reservoirs typically has higher water clarity and increased nutrient inputs from inflowing tributaries and can therefore support significant inputs from algal biomass. ${ }^{57}$ Thus, the relatively large contribution of $\mathrm{CHOP}$ to the molecular composition of DOM from the Paraná River may come from similar lake-derived DOM sources as for the St. Lawrence River, and/or be generated in adjacent river floodplains and lake habitats which can be 
flushed into the main stem during periods of high flow. ${ }^{58}$ Although the exact sources of some of these heteroatomic contributions are only speculative, mass spectral patterns have emerged which possibly link human activities to increased organic nutrient inputs to rivers.

\subsubsection{Visualizing characteristic compound classes among world river DOM}

Van Krevelen diagrams have been widely used to visualize complex DOM mixtures from $\mathrm{H} / \mathrm{C}$ and $\mathrm{O} / \mathrm{C}$ ratios of molecular formulae assigned to individual mass spectral peaks. ${ }^{27,49,59}$ Individual van Krevelen distributions of formulae identified in each global river are included in the Supporting Information (Appendix 3.4). Of all formulae assigned to peaks detected by ultrahigh-resolution mass spectral analysis $(\mathrm{n}=7838)$, approximately $33 \%(n=2559)$ were shared among all river DOM samples. The H/C of shared formulae was distributed between 0.5 and 1.6 while the $\mathrm{O} / \mathrm{C}$ of shared formulae spanned from 0.15 to 0.8 (Figure 3.3a). The formulae with heteroatoms occupied a relatively limited region in the Van Krevelen diagram with a high $\mathrm{H} / \mathrm{C}$ ratio for $\mathrm{CHOS}-$ formulae (Figure 3.3a). The $\mathrm{H} / \mathrm{C}$ and $\mathrm{O} / \mathrm{C}$ ratios of these shared formulae suggest that global rivers, despite their distribution across a wide range of climatic regions with varying land use characteristics, share a common and relatively cohesive pool of DOM molecules (Figure 3.3a). The commonality of DOM formulae has been previously observed in lakes, ${ }^{32,60}$ headwater streams ${ }^{61}$ and throughout other aquatic systems. ${ }^{62}$ The ubiquity of this pool of riverine DOM compounds can be explained by similar OM sources and diagenetic processing that influence in-stream DOM as it is mobilized through the fluvial system. ${ }^{9,10}$ The removal of labile DOM components by microbial 
processing ${ }^{59}$ or photodegradation ${ }^{49}$ has been suggested to result in the accumulation of a similar pool of refractory molecules. ${ }^{61}$ Therefore the ubiquitous DOM signature observed here may reflect the preferential accumulation of certain group of recalcitrant compounds in the downstream reaches of world river systems. It is important to mention, that this study focused on the refractory DOM pool (see Supporting Information).
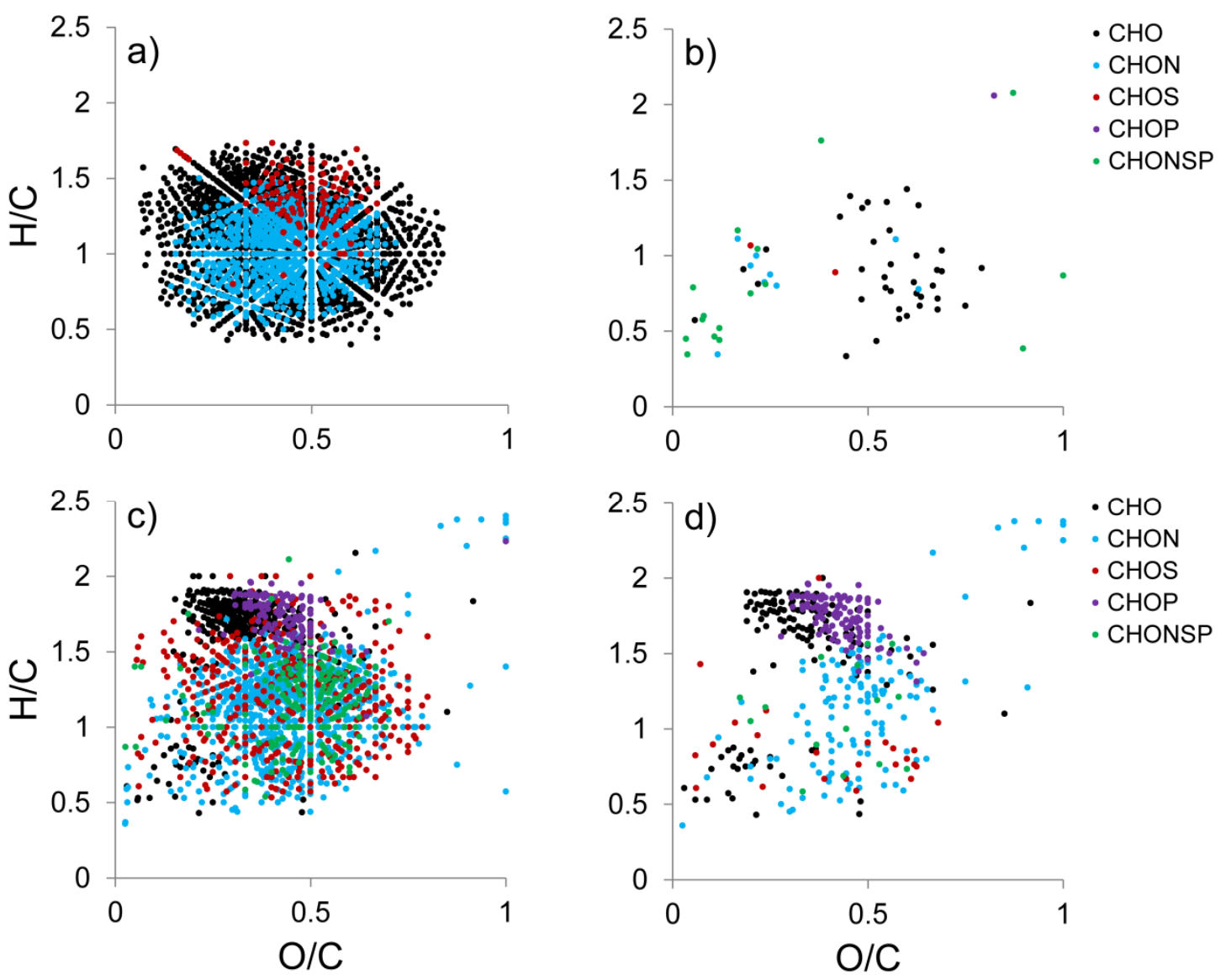

Figure 3.3 Van Krevelen diagrams of molecular formulae (a) common among all global river DOM, (b) identified in one or more of the "natural" rivers, which includes the Amazon, Congo and Lena, (c) identified in one or more of the "anthropogenicallyimpacted" rivers, which includes the Danube, Ganges-Brahmaputra, Yangtze, Mekong, Mississippi, Parana and St. Lawrence and (d) unique to the Paraná and/or St. Lawrence Rivers. Formula include $\mathrm{CHO}$ (black), CHON (blue), CHOS (red), CHOP (purple) and CHONS (green). 
Although there is considerable molecular similarity among this suite of DOM samples (Figure 3.3a), approximately $67 \%(n=5279)$ of total assigned molecular formulae were not ubiquitous. Approximately 67\% (3535 of 5279) of these "uncommon" formulae were determined to be heteroatomic in nature. The percentage is high in contrast to the proportion of heteroatomic formulae in the common DOM pool, which was only $35 \%$ ( 895 of 2559 ). The heteroatomic contributions to DOM have been previously discussed for a variety of systems, ${ }^{19,32-34,60}$ however the present study focused primarily on how $\mathrm{N}, \mathrm{S}$ and $\mathrm{P}$ contributions to DOM were linked to land use and possible organic source materials. The ten rivers were each assigned to one of two groups ("anthropogenically-impacted" or "natural") according to the clustering pattern observed in Appendix 3.3. The Danube, Ganges-Brahmaputra, Yangtze, Mekong, Mississippi, Paraná and St. Lawrence Rivers, all of which have $>30 \%$ area of urban and cropland in their watersheds (Appendix 3.1), compose a group of "anthropogenically-impacted" systems. Whereas, the Amazon, Congo and Lena Rivers have watersheds with large proportions of forest and grassland cover (Appendix 3.1) and therefore compose a group of "natural" systems. The DOM from these rivers, which are less influenced by human disturbance, had fewer detected peaks and fewer assigned formulae than nearly all other systems (except the Ganges-Brahmaputra; Table 3.1). The limited molecular diversity of the Amazon, Congo and Lena River DOM was reflected in the low number of formulae found to be unique to their molecular signatures (Figure 3.3b). However, hundreds of formulae were determined to be unique to one or more rivers in the "anthropogenicallyimpacted" fluvial group where their DOM compositions generally exhibited high molecular diversity (Figure 3.3c). These formulae were predominantly heteroatomic in 
nature and most were classified as highly unsaturated aliphatics. The majority of these compounds fell outside of the protein-like region along the $\mathrm{H} / \mathrm{C}$ axis $(\mathrm{H} / \mathrm{C}>1.5$; Figure 3.3c), suggesting that this heteroatomic pool of DOM may not necessarily reflect autochthonous inputs from primary production. Instead, the CHOS and $\mathrm{CHON}$ formulae identified among these seven "anthropogenically-impacted" rivers were more comparable to compounds found in abundance in waste water effluent ${ }^{19}$ and septic-impacted groundwaters. ${ }^{54}$ The presence of such heteroatomic DOM compoents may therefore serve as an indicator for aquatic systems receiving waste water inputs. The cluster of $\mathrm{CHO}$ compounds that falls within the $\mathrm{O} / \mathrm{C}<0.6$ and $\mathrm{H} / \mathrm{C}>1.7$ van Krevelen space (Figure 3.3c) has been previously described as being aliphatic-type molecules possibly sourced from microbial biomass. ${ }^{26,44}$ The $\mathrm{CHON}$ and CHOP compounds observed here have similar molecular features to those identified in some lacustrine DOM, ${ }^{32,33}$ and may be indicative of either degraded proteins ${ }^{31,63}$ or autochthonous DOM inputs from primary production that occurs in lake-influenced rivers, such as the Paraná and St. Lawrence Rivers. ${ }^{56}$ The unique contribution of CHOP and other DOM components from these two lacustrine-impacted systems to the "anthropogenically-impacted" molecular signature is highlighted in Figure 3.3d. Overall, this comparison suggested that anthropogenicallysourced inputs to inland waters may increase the overall molecular diversity of DOM and that the heteroatomic signature of human-impacted inland waters is persistent in large river systems. 

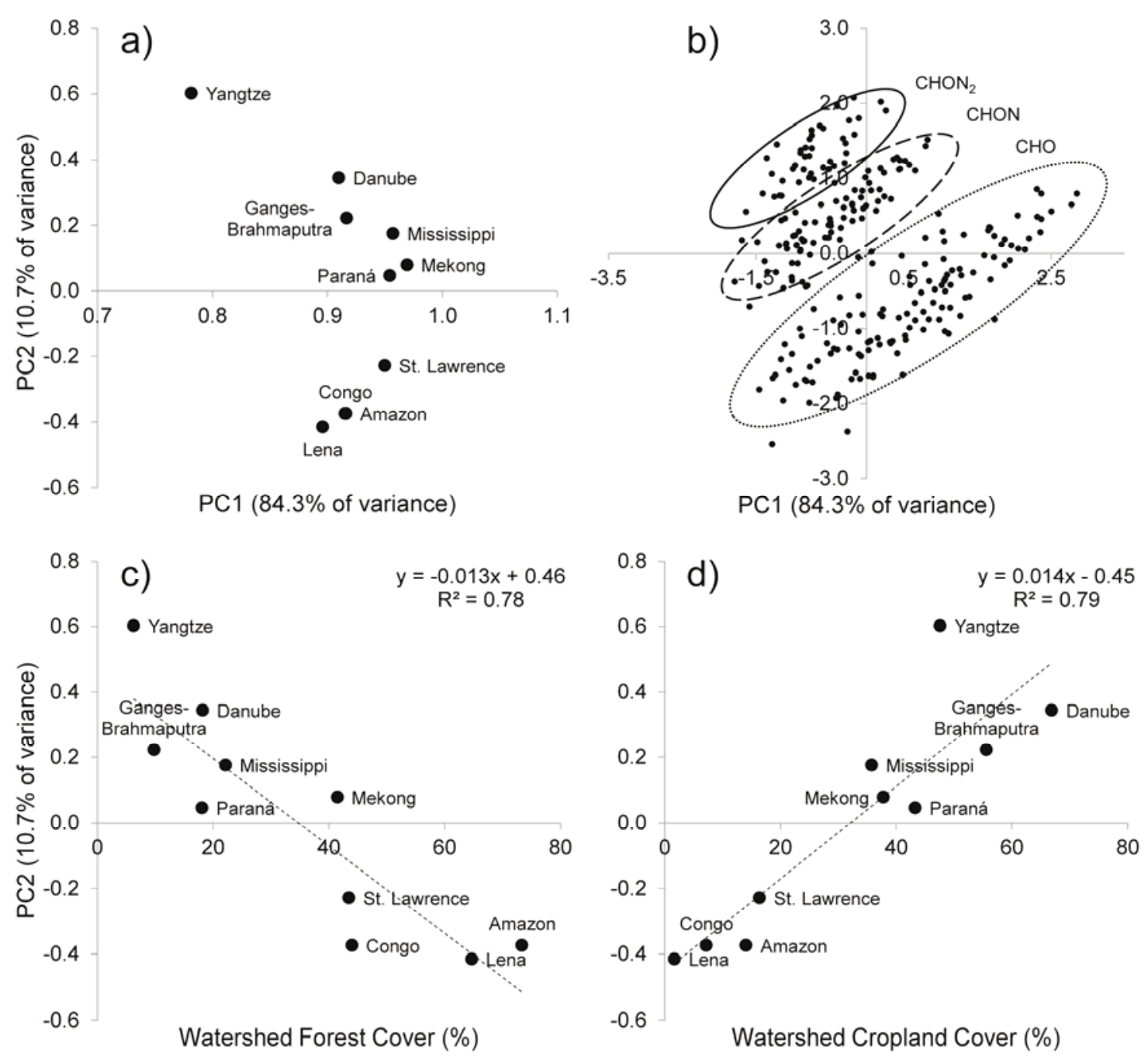

Figure 3.4 Principle component analysis of log-normalized dissolved black carbon (AImod $>0.66$ ) peak intensities common to all global river DOM which includes the (a) loading plot and (b) score plot and correlations between PC2 and proportion of watershed (c) forest cover and (d) cropland cover.

\subsubsection{Correlation between land use and dissolved black nitrogen}

The pool of combustion-derived molecules commonly associated with riverine DOM, also known as dissolved black carbon (DBC), has been determined to be ubiquitous in river systems around the world. ${ }^{36}$ Initially considered to be a refractory 
group of molecules, DBC is highly photoreactive ${ }^{49}$ and can include N-containing molecular formulas previously reported as dissolved black nitrogen (DBN) ${ }^{34}$ In order to investigate possible influences of land use on the relative abundance of DBC and DBN in rivers, a PCA was carried out using the log-normalized peak intensities with assigned polycondensed aromatic formulae (AI-mod $\geq 0.67)^{28}$ common to all studied rivers (Figure 3.4). Figure 3.4a depicts the loading plot where PC1 (84.3\% of variance) was determined to be strongly correlated with mean relative peak intensity $(\mathrm{R}=0.99$, $\mathrm{p}<0.001$ ). All rivers were distributed similarly along PC1 (Figure 3.4a), which suggested that the pyrogenic DOM signature was generally similar across all rivers. Although PC1 explained $84.3 \%$ of the variability in the data, no significant correlations were observed $(\mathrm{Rs}<0.1)$ between PC1 and neither any of the molecular parameters nor land-use characteristics. However, PC2 (10.7\% of variance) provided an additional degree of separation regarding heteroatom contributions. Within the PCA score plot, it was observed that the DBC formulae arranged themselves into three distinct clusters (Figure 3.4b). The cluster that fell lowest along PC2 represented DBC formulae that did not contain $\mathrm{N}$ (CHO only). The intermediate cluster included condensed aromatic formulae with one $\mathrm{N}$ atom $(\mathrm{CHON})$ and the cluster that fell highest along PC2 represented formulae with two $\mathrm{N}$ atoms $\left(\mathrm{CHON}_{2}\right)$. As $\mathrm{PC} 2$ was significantly positively correlated with number of $\mathrm{N}$ atoms within each molecular formulae $(\mathrm{N}=0-2 ; \mathrm{R}=0.79$, $\mathrm{p}<0.001$ ), rivers with more positive PC2 values had greater relative contributions of pyrogenic $\mathrm{CHON}$ and $\mathrm{CHON}_{2}$ to their DOM pool (Figure 3.4a). On the basis of the assessment, the Yangtze River received more significant DBN inputs compared to rivers such as the Lena, Amazon and Congo, which exhibited pyrogenic OM signatures 
depleted in DBN (Figure 3.4a). The PC2 value was also shown to be significantly negatively correlated with basin forest cover (Figure $3.4 \mathrm{c} ; \mathrm{R}=-0.89, \mathrm{p}<0.001$ ) and positively correlated with the proportion of watershed cropland cover (Figure 3.4d; $\mathrm{R}=0.89, \mathrm{p}<0.001)$. Charcoal generated by the incomplete combustion of grassy biomass has been shown to be enriched in $\mathrm{N}^{64,65}$ and can leach greater amounts of DBN than wood-derived charcoal. ${ }^{34}$ The suggestion that DBN is enriched in rivers receiving pyrogenic inputs from cropland is also supported by the fact that ca. $8-11 \%$ of global fires are due to agricultural practices. ${ }^{66}$ Forested landscapes are dominated by trees and other woody plants that are rich in biomacromolecules such as lignin and cellulose, which generate N-depleted DBC upon burning. ${ }^{34,64}$ Therefore, although wildfire activity is ubiquitous across landscapes, ${ }^{67}$ it is hypothesized that the leaching of charcoal components generated from the burning of agricultural biomass may release greater amounts of DBN to inland waters compared to char produced from fires that occur in woody, forested landscapes. Recent studies have shown that wildfires appear to have little immediate effect on bulk in-stream DBC concentrations. ${ }^{68,69}$ However, since it has been suggested that the mobilization and release of DBC may occur over longer timescales lasting decades to hundreds of years, ${ }^{70,71}$ the export of DBN from burned watersheds may continue to impact downstream DOM quality and nutrient cycling for an extended period of time.

\subsection{Conclusions}

In summary, ultrahigh-resolution FT-ICR-MS was employed to determine how the heteroatomic DOM contributions to large, global rivers varied with land use and 
watershed geomorphology. Although a considerable proportion of DOM formulae was common to all river systems, this study revealed that the heteroatomic DOM components drove much of the differentiation between molecular signatures. Heteroatomic formulae, specifically CHON and CHOS, were more abundant in rivers that receive agricultural, waste water and other anthropogenic inputs. The persistence of such anthropogenicallyderived, heteroatomic compounds in lower reaches of global rivers may have major implications for the cycling of nutrients such as $\mathrm{N}, \mathrm{S}$ and $\mathrm{P}$ and their ultimate oceanic fate. Although the DOM samples analyzed here were sourced from a suite of major rivers located across the globe, each mass spectrum provides only a snapshot of downstream DOM composition at a single point in time for each fluvial system. However, trends between land use and in-stream DOM quality were clearly established, which suggested that the dependence of DOM composition on watershed characteristics is quite robust. Future studies need to evaluate how DOM signatures are impacted both spatially and temporally within a watershed to understand how hydrology, climatic disturbance, wildfires and other environmental drivers influence DOM composition within large drainage basins. As the world population continues to rise, urban sprawl increases and natural lands are converted to agriculture, the composition and reactivity of riverine DOM is expected to continue to change. Combined with ongoing global warming trends and an increasing need of storing water through the construction of reservoirs throughout the globe, long term effects of such changes in the quality of a major oceanic carbon source might be significant and its potential consequences remain largely unknown. 


\section{References}

1. Cole, J. J.; Prairie, Y. T.; Caraco, N. F.; McDowell, W. H.; Tranvik, L. J.; Striegl, R. G.; Duarte, C. M.; Kortelainen, P.; Downing J. A.; Middelburg, J. J.; Melack J. Plumbing the global carbon cycle: Integrating inland waters into the terrestrial carbon budget. Ecosystems 2007, 10, 171-184.

2. Battin, T. J.; Kaplan, L. A.; Findlay, S.; Hopkinson, C. S.; Marti, E.; Packman, A. I.; Newbold, J. D.; Sabater, F. Biophysical controls on organic carbon fluxes in fluvial networks. Nat. Geosci. 2008, 1, 95-100.

3. Degens, E. T., Kempe, S., Richey, J. E., Eds. Biogeochemistry of Major World Rivers SCOPE 42; John Wiley and Sons, Inc.: New York, 1991.

4. Jaffé, R.; McKnight, D.; Maie, N.; Cory, R.; McDowell, W. H.; Campbell, J. L. Spatial and temporal variations in DOM composition in ecosystems: The importance of long-term monitoring of optical properties. J. Geophys. Res. 2008, 113, G04032, doi:10.1029/2008JG000683.

5. Sanderman, J.; Lohse, K. A.; Baldock, J. A.; Amundson, R. Linking soils and streams: Sources and chemistry of dissolved organic matter in a small coastal watershed. Water Resour. Res. 2009, 45, W03418, doi:10.1029/2008WR006977.

6. Cory, R. M.; Ward, C. P.; Crump, B. C.; Kling, G. W. Sunlight controls water column processing of carbon in arctic fresh waters. Science 2014, 345, 925-928.

7. Kang, P.-G.; Mitchell, M. J. Bioavailability and size fractionation of dissolved organic carbon, nitrogen and sulfur at the Arbutus Lake watershed, Adirondack Mountains, NY. Biogeochemistry 2013, 115, 213-234.

8. Vannote, R. L.; Minshall, G. W.; Cummins, K. W.; Sedell, J. R.; Cushing, C. E. The river continuum concept. Can. J. Fish. Aquat. Sci. 1980, 37, 130-137.

9. Hedges, J. I.; Mayorga, E.; Tsamakis, E.; McClain, M. E.; Aufdenkampe, A.; Quay, P.; Richey, J. E.; Benner, R.; Opsahl, S.; Black, B.; Pimentel, T.; Quintanilla, J.; Maurice, L. Organic matter in Bolivian tributaries of the Amazon River: A comparison to the lower mainstream. Limnol. Oceanogr. 2000, 45 (7), 1449-1466.

10. Richey, J. E.; et al. Case Study 1: Integrated Analysis of a Humid Tropical Region - The Amazon Basin. In Vegetation, Water, Humans and the Climate; Kabat, P., Claussen, M., Dirmeyer, P. A., Gash, J. H. C., de Guenni, L. B., Meybeck, M., Pielke, R. A., Vörösmarty, C. I., Hutjes, R. W. A., Lütkemeier, S., Eds.; SpringerVerlag: Berlin Heidelberg 2004; pp 415-528 
11. Scott, D.; Harvey, J.; Alexander, R.; Schwarz, G. Dominance of organic nitrogen from headwater streams to large rivers across the conterminous United States. Global Biogeochem. Cy. 2007, 21, GB1003, doi:10.1029/2006GB002730.

12. Wilson, H. F.; Xenopoulos, M. A. Effects of agricultural land use on the composition of fluvial dissolved organic matter. Nat. Geosci. 2009, 2, 37-41.

13. Mattson, T.; Kortelainen, P.; Laubel, A.; Evans, D.; Pujo-Pay, M.; Räike, A.; Conan, P. Export of dissolved organic matter in relation to land use along a European climatic gradient. Sci. Total Environ. 2009, 407, 1967-1976.

14. Hedges, J. I.; Cowie, G. L.; Richey, J. E.; Quay, P. D.; Benner, R.; Strom, M.; Forsberg, B. R. Origins and processing of organic matter in the Amazon River as indicated by carbohydrates and amino acids. Limnology and Oceanography 1994, 39 (4), 743-761.

15. Bertilsson, S., Jones, J. B. Supply of dissolved organic matter to aquatic ecosystems: Autochthonous sources. In Aquatic Ecosystems; Findlay, S. E. G., Sinsabaugh, R. L., Eds.; Academic Press: San Diego 2003; pp. 3-19.

16. Hilton, J.; O’Hare, M.; Bowes, M. J.; Jones, J. I. How green is my river? A new paradigm of eutrophication in rivers. Sci. Total Environ. 2006, 365, 66-83.

17. Mattson, T.; Kortelainen, P.; Räike, A. Export of DOM from boreal catchments: Impacts of land use cover and climate. Biogeochemistry 2005, 76, 373-394.

18. Aitkenhead-Peterson, J. A., McDowell, W. H., Neff, J. C. Sources, production and regulation of allochthonous dissolved organic matter inputs to surface waters. In Aquatic Ecosystems; Findlay, S. E. G., Sinsabaugh, R. L., Eds.; Academic Press: San Diego 2003; pp. 28-30.

19. Gonsior, M.; Zwartjes, M.; Cooper, W. J.; Song, W.; Ishida, K. P.; Tseng, L. Y.; Jeung, M. K.; Rosso, D.; Hertkorn, N.; Schmitt-Kopplin, P. Molecular characterization of effluent organic matter identified by ultrahigh resolution mass spectrometry. Water Res. 2011, 45, 2943-2953.

20. Williams, C. J.; Yamashita, Y.; Wilson, H. F.; Jaffé, R.; Xenopoulos, M. A. Unraveling the role of land use and microbial activity in shaping dissolved organic matter characteristics. Limnol. Oceanogr. 2010, 55 (3), 1159-1171.

21. Lu Y.; Bauer J. E.; Canuel E. A.; Yamashita Y.; Chambers R. M.; Jaffé, R. Photochemical and microbial alteration of dissolved organic matter in temperate headwater streams associated with different land use. J. Geophys. Res.-Biogeo. 2013, 118, 1-15. 
22. Dittmar, T.; Paeng, J. A heat-induced molecular signature in marine dissolved organic matter. Nat. Geosci. 2009, 2, 175-179.

23. Kujawinski, E. B. Electrospray ionization Fourier transform ion cyclotron resonance mass spectrometry (ESI FT-ICR MS): Characterization of complex environmental mixtures. Environ. Forensics 2002, 3, 207-216.

24. Sleighter, R. L.; Hatcher, P .G. The application of electrospray ionization coupled to ultrahigh resolution mass spectrometry for the molecular characterization of natural organic matter. J. Mass Spectrom. 2007, 42, 559-574.

25. Stenson, A. C.; Marshall, A. G.; Cooper, W. T. Exact masses and chemical formulas of individual Suwannee River fulvic acids from ultrahigh resolution electrospray ionization Fourier transform resonance ion cyclotron mass spectra. Anal. Chem. 2003, 75, 1275-1284.

26. Koch, B. P.; Witt, M.; Engbrodt, R.; Dittmar, T.; Kattner, G. Molecular formulae of marine and terrigenous dissolved organic matter detected by electrospray ionization Fourier transform ion cyclotron resonance mass spectrometry. Geochim. Cosmochim. Ac. 2005, 69 (13), 3299-3308.

27. Kim, S.; Kramer, R. W.; Hatcher, P. G. Graphical method for analysis of ultrahigh-resolution broadband mass spectra of natural organic matter, the Van Krevelen diagram. Anal. Chem. 2003, 75, 5336-5344.

28. Koch, B. P.; Dittmar, T. From mass to structure: An aromaticity index for highresolution mass data of natural organic matter. Rapid Commun. Mass Spectrom. 2006, 20, 926-932.

29. Šantl-Temkiv, T.; Finster, K.; Dittmar, T.; Hansen, B. M.; Thyrhaug, R.; Nielsen, N. W.; Karlson, U. G. Hailstones: A window into the microbial and chemical inventory of a storm cloud. PLoS One 2013, 8 (1), e53550. doi:10.1371/journal.pone.0053550.

30. Riedel, T.; Iden, S.; Geilich, J.; Wiedner, K.; Durner, W.; Biester, H. Changes in the molecular composition of organic matter leached from an agricultural topsoil following addition of biomass-derived black carbon (biochar). Org. Geochem. 2014, 69, 52-60.

31. Schmidt, F.; Elvert, M.; Koch, B. P.; Witt, M.; Hinrichs, K.-U. Molecular characterization of dissolved organic matter in pore water of continental shelf sediments. Geochim. Cosmochim. Ac. 2009, 73, 3337-3358. 
32. Minor, E. C.; Steinbring, C. J.; Longnecker, K.; Kujawinski, E. B. Characterization of dissolved organic matter in Lake Superior and its watershed using ultrahigh resolution mass spectrometry. Org. Geochem. 2012, 43, 1-11.

33. Spencer, R. G. M.; Guo, W.; Raymond, P. A.; Dittmar, T.; Hood, E.; Fellman, J.; Stubbins, A. Source and biolability of ancient dissolved organic matter in glacier and lake ecosystems on the Tibetan Plateau. Geochim. Cosmochim. Ac. 2014, 142, 64-74.

34. Wagner, S.; Dittmar, T.; Jaffé, R. Molecular characterization of dissolved black nitrogen via electrospray ionization Fourier transform ion cyclotron resonance mass spectrometry. Org. Geochem. 2015, 79, 21-30.

35. Pohlabeln, A.; Dittmar, T. Novel insights into the molecular structure of nonvolatile marine dissolved organic sulfur. Mar. Chem. 2015, 168, 86-94.

36. Jaffé, R.; Ding, Y.; Niggemann, J.; Vähätalo, A. V.; Stubbins, A.; Spencer, R. G. M.; Campbell, J.; Dittmar, T. Global charcoal mobilization from soils via dissolution and riverine transport to oceans. Science 2013, 340, 345-347.

37. Xiao, Y.-H.; Sara-Aho, T.; Hartikainen, H.; Vähätalo, A. V. Contribution of ferric iron to light absorption by chromophoric dissolved organic matter. Limnol. Oceanogr. 2013, 58 (2), 653-662.

38. Lalonde, K.; Vähätalo, A. V.; Gélinas, Y. Revisiting the disappearance of terrestrial dissolved organic matter in the ocean: $\mathrm{A} \delta^{13} \mathrm{C}$ study. Biogeosciences 2014, 11, 3707-3719.

39. Dittmar, T.; Koch, B.; Hertkorn, N.; Kattner, G. A simple and efficient method for the solid-phase extraction of dissolved organic matter (SPE-DOM) from seawater. Limnol. Oceanogr.: Methods 2008, 6, 230-235.

40. Riedel, T.; Biester, H.; Dittmar, T. Molecular fractionation of dissolved organic matter with metal salts. Environ. Sci. Technol. 2012, 46, 4419-4426.

41. Koch, B. P.; Dittmar, T.; Witt, M.; Kattner, G. Fundamentals of molecular formulae assignment to ultrahigh resolution mass data of natural organic matter. Anal. Chem. 2007, 79, 1758-1763.

42. Riedel, T.; Dittmar, T. A method detection limit for the analysis of natural organic matter via Fourier transform ion cyclotron resonance mass spectrometry. Anal. Chem. 2014, 86, 8376-8382. 
43. Hertkorn, N.; Benner, R.; Frommberger, M.; Schmitt-Kopplin, P.; Witt, M.; Kaiser, k.; Kettrup, A.; Hedges, J. I. Characterization of a major refractory component of marine dissolved organic matter. Geochim. Cosmochim. Ac. 2006, 70, 2990-3010.

44. Sleighter, R. L.; Hatcher, P .G. Molecular characterization of dissolved organic matter (DOM) along a river to ocean transect of the lower Chesapeake Bay by ultrahigh resolution electrospray ionization Fourier transform ion cyclotron resonance mass spectrometry. Mar. Chem. 2008, 110, 140-152.

45. Hertkorn, N.; Frommberger, M.; Witt, M.; Koch, B. P.; Schmitt-Kopplin, P.; Perdue, E. M. Natural organic matter and the event horizon of mass spectrometry. Anal. Chem. 2008, 90, 8908-8919.

46. Ohno, T.; He, Z.; Sleighter, R. L.; Honeycutt, C. W.; Hatcher, P. G. Ultrahigh resolution mass spectrometry and indicator species analysis to identify marker components of soil- and plant biomass-derived organic matter fractions. Environ. Sci. Technol. 2010, 44, 8594-8600.

47. Boyer, E. W.; Goodale, C. L.; Jaworski, N. A.; Howarth, R. W. Anthropogenic nitrogen sources and relationships to riverine nitrogen export in the northeastern U.S.A. Biogeochemistry 2002, 57-58, 137-169.

48. Lara, R. J.; Rachold, V.; Kattner, G.; Hubberten, H. W.; Guggenberger, G.; Skoog, A.; Thomas, D. N. Dissolved organic matter and nutrients in the Lena River, Siberian Arctic: Characteristics and distribution. Mar. Chem. 1998, 59, 301-309.

49. Stubbins, A.; Spencer, R. G. M.; Chen, H.; Hatcher, P. G.; Mopper, K.; Hernes, P. J.; Mwamba, V. L.; Mangangu, A. M.; Wabakanghanzi, J. N.; Six, J. Illuminated darkness, Molecular signatures of Congo River dissolved organic matter and its photochemical alternation as revealed by ultrahigh resolution precision mass spectrometry. Limnol. Oceanogr. 2010, 55 (4), 1467-1477.

50. Ward, N. D.; Keil, R. G.; Medeiros, P . M.; Brito, D. C.; Cunha, A. C.; Dittmar, T.; Yager, P. L.; Krusche, A V.; Richey, J. E. Degradation of terrestrially derived macromolecules in the Amazon River. Nat. Geosci. 2013, 6, 530-533.

51. Galy, V.; Eglinton, T. Protracted storage of biospheric carbon in the GangesBrahmaputra basin. Nat. Geosci. 2011, 4, 843-847.

52. Galy, V.; France-Lanord, C.; Beyssac, O.; Faure, P.; Kudrass, H.; Palhol, F. Efficient organic carbon burial in the Bengal fan sustained by the Himalayan erosional system. Nat. Geosci. 2007, 450, 407-411. 
53. Mishra, A. Assessment of water quality using principle component analysis: A case study of the river Ganges. J. Water Chem. Tech. 2010, 32 (4), 277-234.

54. Arnold, W. A.; Longnecker, K.; Kroeger, K. D.; Kujawinski, E. B. Molecular signature of organic nitrogen in septic-impacted groundwater. Environ. Sci. Process. Impacts 2014, 16 (10), 2400-2407.

55. Beltran, R., Botts, L., Brown, L., Clarke, T., Cowell, D., Fuller, K., Krushelnicki, B. Introduction: The great lakes. In The Great Lakes: An Environmental Atlas and Resource Book; Fuller, K., Shear, H., Wittig, J., Eds.; Government of Canada and United States Environmental Protection Agency: Chicago 1995; pp. 3-5.

56. Hanley, K. W.; Wollhein, W. M.; Salisbury, J.; Huntington, T.; Aiken, G. Controls on dissolved organic carbon quality and chemical character in temperate rivers of North America. Global Biogeochem. Cy. 2013, 27, 492-504.

57. Cooke, G. D.; Kennedy, R. H. Managing drinking water supplies. Lake Reserv. Manage. 2001, 17 (3), 157-174.

58. Roberto, M. C.; Santana, N. F.; Thomaz, S. M. Limnology in the Upper Paraná River floodplain: Large-scale spatial and temporal patterns, and the influence of reservoirs. Braz. J. Biol. 2009, 69, 717-725.

59. Sleighter, R. L.; Cory, R. M.; Kaplan, L. A.; Abdulla, H. A. N.; Hatcher, P. G. A coupled geochemical and biogeochemical approach to characterize the bioreactivity of dissolved organic matter from a headwater stream. J. Geophys. Res. Biogeosci. 2014, 119, 1520-1537.

60. Kellerman, A. M.; Dittmar, T.; Kothawala, D. N.; Tranvik, L. J. Chemodiversity of dissolved organic matter in lakes driven by climate and hydrology. Nat.

Commun. 2014, 5:3804, DOI: 10.1038/ncomms4804.

61. Jaffé, R.; Yamashita, Y.; Maie, N.; Cooper, W. T.; Dittmar, T.; Dodds, W. K.; Jones, J. B.; Myoshi, T.; Ortiz-Zayas, J. R.; Podgorski, D. C.; Watanabe, A. Dissolved organic matter in headwater streams: Compositional variability across climatic regions in North America. Geochim. Cosmochim. Ac. 2012, 94, 95-108.

62. Roth, V.-N.; Dittmar, T.; Gaupp, R.; Gleixner, G. Ecosystem-specific composition of dissolved organic matter. Vadose Zone J. 2014, 13, doi:10.2136/vzj2013.09.0162. 
63. Kujawinski, E. B.; Del Vecchio, R.; Blough, N. V.; Klein, G. C.; Marshall, A. G. Probing molecular-level transformations of dissolved organic matter: Insights on photochemical degradation and protozoan modification of DOM from electrospray ionization Fourier transform ion cyclotron resonance mass spectrometry. Mar. Chem. 2004, 92, 23-37.

64. Knicker, H. How does fire affect the nature and stability of soil organic nitrogen and carbon? A review. Biogeochemistry 2007, 85, 91-118.

65. Knicker, H. "Black nitrogen" - An important fraction in determining the recalcitrance of charcoal. Org. Geochem. 2010, 41, 947-950.

66. Korontzi, S.; McCarty, J.; Loboda, T.; Kumar, S.; Justice, C. Global distribution of agricultural fires in croplands from 3 years of Moderate Resolution Imaging Spectroradiometer (MODIS) data. Global Biogeochem. Cy. 2006. 20, GB2021, doi:10.1029/2005GB002529.

67. Flannigan, M. D.; Krawchuck, M. A.; de Groot, W. J.; Wotton, B. M.; Gowman, L. M. Implications of changing climate for global wildland fire. Int. J. of Wildland Fire 2009, 18, 483-507.

68. Ding, Y.; Yamashita, Y.; Dodds, W. K.; Jaffé, R. Dissolved black carbon in grassland streams: Is there an effect of recent fire history? Chemosphere 2013, 90, 2557-2562.

69. Wagner, S.; Cawley, K. M.; Rosario-Ortiz, F. L.; Jaffé, R. In-stream sources and links between particulate and dissolved black carbon following a wildfire. Biogeochem. 2015, doi: 10.1007/s10533-015-0088-1

70. Singh, N.; Abiven, S.; Torn, M. S.; Schmidt, M. W. I. Fire-derived organic carbon in soil turns over on a centennial scale. Biogeosciences 2012, 9, 2847-2857.

71. Dittmar, T.; de Rezende, C. E.; Manecki, M.; Niggemann, J.; Ovalle, A. R. C.; Stubbins, A.; Bernardes, M. C. Continuous flux of dissolved black carbon from a vanished tropical forest biome. Nat. Geosci. 2012, 5, 618-622. 
CHAPTER IV

\section{IN-STREAM SOURCES AND LINKS BETWEEN PARTICULATE AND DISSOLVED BLACK CARBON FOLLOWING A WILDFIRE}

(Modified from Wagner et al., 2015, Biogeochemistry) 


\subsection{Abstract}

The occurrence of wildfires is expected to increase with the progression of climate change. These natural burn events can drastically alter the geomorphology and hydrology of affected areas and are one of the primary sources of black carbon (BC) in the environment. Black C can be mobilized from soils and charcoal in fire-affected watersheds, potentially impacting downstream water quality. In June of 2012, the High Park Fire burned a large portion of the Cache La Poudre River watershed located in the Colorado Rocky Mountains. Seasonal riverine export of BC in both the dissolved (DBC) and particulate (PBC) phase was compared between burned and unburned sections of the watershed during the year following the High Park Fire. There was little difference in overall DBC concentration between sites, however seasonal changes in DBC quality reflected a shift in hydrology and associated DBC source between peak and base flow conditions. Particulate BC export was substantially larger in fire-affected areas of the watershed during periods of overland flow. These findings suggest that export processes of $\mathrm{BC}$ in the particulate and dissolved phase are decoupled in burned watersheds and that, in addition to $\mathrm{DBC}$, the export of $\mathrm{PBC}$ could be a significant contributor to the cycling of charcoal in freshwater ecosystems.

\subsection{Introduction}

The increased incidence and potential severity of wildfires in recent times has been associated with climate change and these natural burn events are expected to increase with continued climate change (Flannigan et al. 2009; Krawchuk et al. 2009). Mountainous regions of the western United States have been experiencing warmer 
springs and drier summers in recent years and these conditions prime the area for longer and more intense wildfires (Westerling et al. 2006). Wildfires significantly alter landscapes by changing the hydrology and geomorphology of the burned area. The most notable effects of fire include loss of litter and vegetation cover and destabilization of soils, the combination of which results in increased surface erosion during times of overland flow on hillslopes (Shakesby and Doerr 2006 and references therein). Rivers that drain fire-affected regions are greatly impacted by burn events, as they experience increased streamflow (Loáiciga et al. 2001) and receive significantly greater sediment yields (Moody and Martin 2001; Reneau et al. 2007) in years following a wildfire. The intensity and frequency of post-fire rainfall events trigger erosion and sediment transport which can significantly impact the water quality of inland freshwater systems (Lane et al. 2006; Moody and Martin 2009).

Wildfires transfer significant amounts of $\mathrm{C}$ to the atmosphere in the form of $\mathrm{CO}_{2}$ through the burning of biomass (Flannigan et al. 2009). Fires also generate large amounts of charcoal, or pyrogenic $\mathrm{C}(\mathrm{PyC})$, during the incomplete combustion of vegetation and soil organic material (Goldberg 1985). Pyrogenic C falls along a combustion continuum ranging from slightly charred biomass to soot particles (Hedges et al. 2000; Masiello 2004) and is a heterogeneous mixture of molecules characterized by their fused aromatic ring structures (Preston and Schmidt 2006). The highly condensed aromatic component derived from high temperature combustion of biomass is referred to as black carbon (BC) and represents the thermally refractory portion of PyC (Preston and Schmidt 2006). Black C was thought to be highly resistant to degradation processes and has been considered to be a C sink when stably incorporated into the soil matrix (Liang et al. 2008). However, 
recent research has shown that $\mathrm{BC}$ turnover rates in soils are much shorter than previously considered, providing evidence that $\mathrm{BC}$ is susceptible to degradation and other loss processes (Singh et al. 2012). The majority of PyC produced by wildfires is deposited close to the burn site and can thus be subsequently incorporated into soils or transported via fluvial systems (Forbes et al. 2006; Saiz et al. 2014). It has recently been estimated that only about $17 \%$ of the BC produced during Colorado wildfires can be transferred from the litter layer to upper soil horizons (Boot et al. 2014). While a significant amount to BC may be removed through surface runoff, the stabilization of a portion of PyC in soils would provide a steady source of BC to adjacent fluvial systems. It has been proposed that such aged, sub-surface PyC stocks may provide the main source of $\mathrm{BC}$ in rivers (Dittmar et al. 2012, Ding et al. 2013).

Black C incorporated into soils following a burn event can undergo degradative/aging processes (Czimczik and Masiello 2007). Several environmental drivers appear to control the rate of $\mathrm{BC}$ mineralization and degradation in soils. Oxidation of PyC was more favorable with increasing medium annual temperature (Cheng et al. 2008) and under alternating wet-dry environmental conditions (Nguyen and Lehmann 2009). In some studies, abiotic processes appear to be the predominant mode of BC oxidation during short periods of time (Cheng et al. 2006; Bruun et al. 2008). However, biodegradation of $\mathrm{BC}$ has also been shown to occur more favorably under environmental conditions where nitrogen is present (Hilscher and Knicker 2011; LeCroy et al. 2013). A pool of freshly-generated BC can become concentrated in upper organic soil horizons post-fire (Preston and Schmidt 2006). Over time, a portion of this BC can be partiallyoxidized and transferred to deeper layers of soil (Knicker et al. 2008; Boot et al. 2014) 
where it is stabilized by minerals (Glaser et al. 2000; Czimczik and Masiello 2007).

Although further research is still needed to elucidate the dominant factors controlling BC oxidation in soils, it has been commonly observed that these aging processes do happen, resulting in $\mathrm{BC}$ with increased oxygen content (Lehmann et al. 2005; Knicker et al. 2006; Nguyen et al. 2010).

The export of BC in the dissolved phase (DBC) from fire-affected watersheds has been studied on a global scale, where it is found to closely correlate with bulk dissolved organic carbon (DOC; Jaffé et al. 2013). In addition to this highly polycondensed, more refractory dissolved form of $\mathrm{BC}$, more soluble and labile char-derived pyrogenic products have also been reported in aquatic systems as a result of char leaching (Norwood et al. 2013). Interestingly, recent fire activity does not appear to immediately impact in-stream DBC concentrations (Ding et al. 2013; Myers-Pigg et al. 2015), however DBC can continue to be measured in rivers decades after major fire activity (Dittmar et al. 2012). The delayed release of $\mathrm{DBC}$ indicates that $\mathrm{BC}$ may first need to undergo biotic and/or abiotic oxidation processes in soils in order to increase the number of O-containing functionalities and overall polarity for it to become soluble enough to be transferred to the dissolved phase (Abiven et al. 2011). Once DBC enters a river, it can be photodegraded by exposure to sunlight (Stubbins et al. 2012) and may be susceptible to removal processes such as flocculation or adsorption that influence other portions of the hydrophobic, aromatic pool of dissolved organic matter (DOM; Uher et al. 2001; Kothawala et al. 2012).

Studies addressing BC mobilization in aquatic systems have focused primarily on water soluble forms (e.g. Jaffé et al. 2013; Norwood et al., 2013), however very little is 
currently known about $\mathrm{BC}$ mobilization in the particulate phase (PBC). Particulate $\mathrm{BC}$ comprises a small portion of suspended solids in lakes (Zigah et al. 2012) and sinking particles in the ocean (Coppola et al. 2014; Yang and Guo 2014) where the presence of PBC is primarily attributed to adsorption of DBC to particulate matter. It is likely that wildfire-derived $\mathrm{PBC}$ can also be exported directly to inland waters in the form of charcoal particulates. However, studies regarding changes in riverine concentrations of PBC in response to recent fire activity have been limited. It has been established that changes in land cover following a fire result in increased in-stream suspended sediment loads in years immediately following the burn event (Moody and Martin 2001; Reneau et al. 2007). A considerable portion of PyC is deposited within the burned area (Forbes et al. 2006; Alexis et al. 2010; Saiz et al. 2014), and can be quickly redistributed within the watershed by wind and surface runoff (Cerdá and Doerr 2008). Boot et al. (2014) have suggested that the bulk of BC may be lost from wildfire-impacted watersheds through soil erosion and overland runoff. Therefore, it is likely that BC export in fire-affected rivers may occur mainly in the particulate phase rather than the dissolved phase.

The main objectives of this research were (1) to determine if the apparent coupling between DOC and DBC that occurs globally (Jaffé et al. 2013) is maintained throughout the season in an alpine river receiving inputs from both recently burned and unburned regions of the watershed; (2) to measure the seasonal changes in quantity and quality of $\mathrm{DBC}$ and $\mathrm{PBC}$ and link $\mathrm{BC}$ in these two phases to pyrogenic source material; (3) to assess how wildfire activity impacts the in-stream dynamics of and relationship between total suspended solids (TSS) and PBC; (4) to estimate and compare the total seasonal fluxes of $\mathrm{BC}$ in both the particulate and dissolved phases. The current study is 
the first time tandem measurements were taken for the export of both $\mathrm{DBC}$ and $\mathrm{PBC}$ in fluvial systems.

\subsection{Methods}

\subsubsection{Site description}

During June of 2012, the High Park Fire burned $350 \mathrm{~km}^{2}$ of the Cache La Poudre River (from here on will be abbreviated as the Poudre River) watershed (total area is $4900 \mathrm{~km}^{2}$ ) located in Colorado's Front Range just west of Fort Collins (Colorado, USA). The Poudre River watershed is characterized by vegetation that includes stands of ponderosa pine, lodge pole pine and Douglas fir. Despite $<10 \%$ of its watershed being consumed by the High Park Fire, effects of the burn on Poudre River water quality were evident. Water discharge data was continuously collected by the U.S. Geological Survey (USGS) in cooperation with the city of Fort Collins. Three locations along the Poudre River transect were selected for sample collection (Fig. 4.1) and included an unburned, reference site located upstream from the fire-affected area (PBR), a site located just within the perimeter of the burned area where the main stem and South Fork of the Poudre River merge (PSF) and a site located just upstream from the confluence of the North Fork and the Poudre River main stem (PNF). The PNF site receives riverine inputs from the majority of the burned area and is therefore described as the most fire-affected site. 


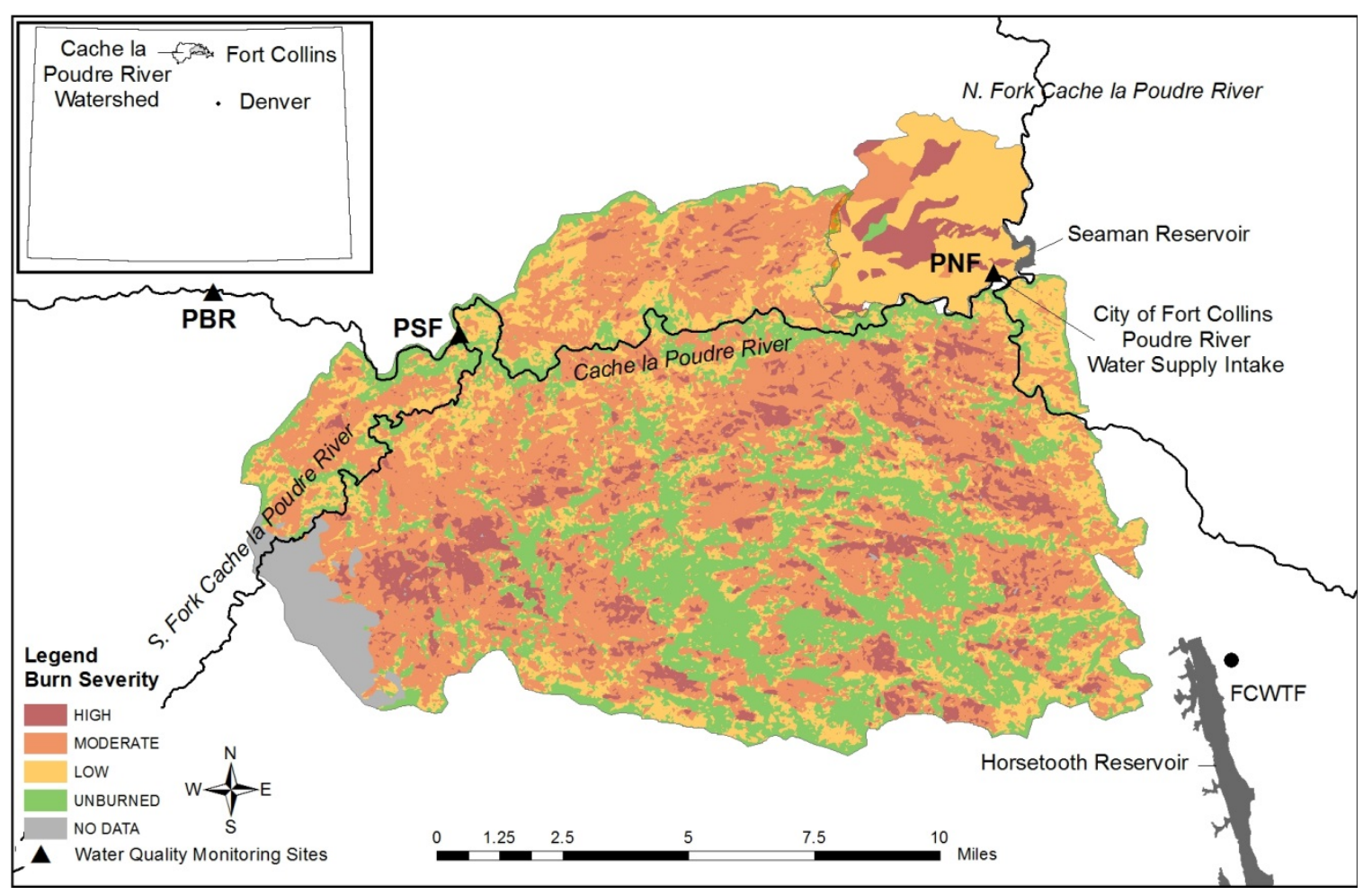

Figure 4.1 Map of the High Park Fire burn site. Sampling locations PBR, PSF and PNF represented an unburned reference site, moderately fire-affected site and heavily fireaffected site, respectively

\subsubsection{Measurement of TSS and DOC}

Water samples were collected biweekly from each site (PBR, PSF, PNF) from March through August of 2013, approximately 1 year after the High Park Fire. Surface water was collected in pre-cleaned HDPE bottles or combusted glass bottles and kept chilled in a dark cooler until arriving at the University of Colorado at Boulder (CU Boulder) laboratory. Total suspended solids was measured by pre-recording the GFF filter mass $(0.7 \mu \mathrm{m}$ pore size $)$ and passing a known volume of sample, previously homogenized by agitation, through the pre-weighed filter. Filters were then dried at 
$105^{\circ} \mathrm{C}$ for $1-2 \mathrm{~h}$, cooled and weighed. The TSS concentration was determined by

dividing the mass of particulates on the filter by the total volume of stream water passed through the filter. Filtrates were collected in pre-cleaned vessels and stored at $4{ }^{\circ} \mathrm{C}$ until DOC analysis and solid phase extraction (SPE) of DOM. Dissolved OC values were measured using a non-purgeable organic carbon and the high temperature combustion method on a Shimadzu TOC-V analyzer (Shimadzu Corp., Japan) at the Kiowa Laboratory, CU Boulder.

\subsubsection{Determination of $D B C$ and PBC via the BPCA method}

Both DBC and PBC were quantified using the benzenepolycarboxylic acid (BPCA) method previously described by Dittmar (2008) and optimized by Ding et al. (2013). For the determination of DBC, DOM was first extracted by SPE (Dittmar et al. 2008) and aliquots of the DOM-containing $\mathrm{MeOH}$ elute were added to $2 \mathrm{~mL}$ glass ampules and dried under $\mathrm{N}_{2}$ for complete evaporation of $\mathrm{MeOH}$. Concentrated HNO3 $(0.5 \mathrm{~mL})$ was added to each ampule, which were then flame-sealed and DOM oxidized for $6 \mathrm{~h}$ at $160{ }^{\circ} \mathrm{C}$. After oxidation, the concentrated $\mathrm{HNO} 3$ was dried under $\mathrm{N}_{2}$ at $50{ }^{\circ} \mathrm{C}$ and the BPCA-containing residue was re-dissolved in mobile phase for analysis by high pressure liquid chromatography (HPLC; Dittmar 2008).

For the measurement of PBC, procedures carried out for DBC were scaled up to accommodate the oxidation of larger amounts of particulate organic matter. Additional clean-up steps were also required to remove metals and other compounds present in particulates that may interfere with BPCA analysis (Schneider et al. 2010, 2011). Glass fiber filters containing a known amount of suspended solids were transferred directly to 
$20 \mathrm{~mL}$ glass ampules and $2 \mathrm{~mL}$ of concentrated $\mathrm{HNO} 3$ was subsequently added. Ampules were heat-sealed and particulates were oxidized under conditions described previously. Contents of the ampules were then passed through a pre-rinsed $0.7 \mu \mathrm{m}$ GFF filter and the filtrate was then passed over a cation exchange resin. The eluent was collected, freezedried and re-dissolved in HPLC mobile phase. HPLC analysis of BPCAs was carried out using a Sunfire C18 reversed phase column $(3.5 \mu \mathrm{m}, 2.1 \times 150 \mathrm{~mm}$; Waters Corporation). Separation and quantification of BPCAs generated from both DBC and PBC was carried out by employing a gradient elution method with mobile phase A (4 mM tetrabutylammonium bromide, $50 \mathrm{mM}$ sodium acetate, $10 \% \mathrm{MeOH}$ ) and mobile phase $\mathrm{B}$ $(100 \% \mathrm{MeOH})$ as described in detail by Dittmar (2008).

\subsubsection{Statistical methods}

The significance of the linear relationship between two parameters was determined using the Pearson's product-moment correlation coefficient (IBM SPSS Statistics Version 20, IBM Corp.). Principle component analysis (PCA) was carried out using the relative abundance (\%) of BPCAs (IBM SPSS Statistics Version 20, IBM Corp.). 
Table 4.1 Black carbon, DOC and TSS data for all three Poudre River sites throughout the sampling period

\begin{tabular}{|c|c|c|c|c|c|c|c|c|c|c|c|c|c|c|c|c|c|}
\hline \multirow[b]{2}{*}{ Sampling Date } & \multicolumn{3}{|c|}{$\begin{array}{c}\mathrm{DOC} \\
(\mathrm{mg}-\mathrm{C} / \mathrm{L})\end{array}$} & \multicolumn{3}{|c|}{$\begin{array}{c}\mathrm{DBC} \\
(\mathrm{mg}-\mathrm{C} / \mathrm{L})\end{array}$} & \multicolumn{2}{|c|}{$\begin{array}{c}\text { TSS } \\
\text { (mg-dry weight/L) }\end{array}$} & \multicolumn{2}{|c|}{$\begin{array}{c}\mathrm{PBC} \\
(\mathrm{mg}-\mathrm{C} / \mathrm{L})\end{array}$} & \multicolumn{3}{|c|}{$\begin{array}{c}\text { B5CA:B4CA } \\
\text { (DBC) }\end{array}$} & \multicolumn{2}{|c|}{$\begin{array}{c}\text { B5CA:B4CA } \\
(\mathrm{PBC})\end{array}$} & \multicolumn{2}{|c|}{$\begin{array}{c}\text { PBC:TSS } \\
\text { (g-C/kg-dry weight) }\end{array}$} \\
\hline & PBR & PSF & PNF & PBR & PSF & PNF & PBR & PNF & PBR & PNF & PBR & PSF & PNF & PBR & PNF & PBR & PNF \\
\hline March 26 & 2.68 & 2.35 & 2.25 & 0.12 & 0.13 & 0.080 & 5.1 & 13.3 & n.c. & n.c. & 0.77 & 0.87 & 0.75 & n.c. & n.c. & n.c. & n.c. \\
\hline April 20 & 1.56 & 1.76 & 2.09 & 0.047 & 0.066 & 0.089 & n.c. & n.c. & n.c. & n.c. & 0.73 & 0.73 & 0.75 & n.c. & n.c. & n.c. & n.c. \\
\hline May 4 & 4.41 & 5.49 & 6.43 & 0.17 & 0.27 & 0.34 & 1.7 & 241 & n.c. & n.c. & 0.79 & 0.83 & 0.69 & n.c. & n.c. & n.c. & n.c. \\
\hline May 14 & 8.41 & 7.87 & 8.41 & 0.30 & 0.33 & 0.34 & 25.3 & 528 & 0.019 & 5.5 & 0.83 & 0.86 & 0.74 & 0.25 & 0.89 & 0.76 & 10 \\
\hline June 1 & 5.86 & 6.03 & 6.35 & 0.34 & 0.34 & 0.25 & 4.9 & 32.0 & 0.007 & 0.17 & 0.83 & 0.87 & 0.85 & 0.31 & 0.85 & 1.4 & 5.2 \\
\hline June 14 & 5.00 & 5.08 & 4.90 & 0.29 & 0.30 & 0.24 & 10.6 & 27.0 & 0.008 & 0.034 & 0.97 & 0.93 & 0.94 & 0.25 & 0.74 & 0.73 & 1.3 \\
\hline June 29 & 2.66 & 2.81 & 2.86 & 0.17 & 0.17 & 0.14 & 3.4 & 24.6 & 0.006 & 0.11 & 0.97 & 1.1 & 0.95 & 0.38 & 0.82 & 1.8 & 4.5 \\
\hline July 14 & 2.51 & 2.63 & 2.97 & 0.12 & 0.10 & 0.18 & 23.6 & 110 & 0.012 & 1.0 & 1.0 & 0.9 & 1.0 & 0.41 & 0.90 & 0.50 & 9.3 \\
\hline July 29 & 2.16 & 2.27 & 2.88 & 0.14 & 0.15 & 0.19 & 15.9 & 337 & 0.009 & 2.3 & 1.2 & 1.1 & 1.0 & 0.24 & 0.86 & 0.56 & 7.0 \\
\hline August 24 & 2.69 & 2.46 & 2.52 & 0.14 & 0.14 & 0.16 & 2.3 & 62.7 & 0.005 & 0.56 & 1.0 & 1.0 & 1.0 & 0.59 & 0.86 & 2.2 & 9.0 \\
\hline
\end{tabular}

BPCA ratios (B5:B4) were calculated based on relative BPCA distributions. The abbreviation n.c. denotes where data was not

collected due to lack of sample 


\subsection{Results}

\subsubsection{Bulk DOC and DBC concentrations}

Measurements of DOC and DBC for all locations during the sampling period are outlined in Table 4.1. Seasonal DOC concentrations were generally comparable among all sites between March and August (Fig. 4.2a). Dissolved OC was lowest on the April 20 sampling date across all sites $(1.80 \pm 0.027 \mathrm{ppm})$ when the river was at base flow conditions. The DOC concentrations increased during spring snow melt and peaked on May 14 at all sampling sites $(8.23 \pm 0.31 \mathrm{ppm})$, approximately 1 month prior to peak water discharge. As discharge increased through early summer, DOC concentrations decreased and returned to near-base flow concentrations by late June (Fig. 4.2a).
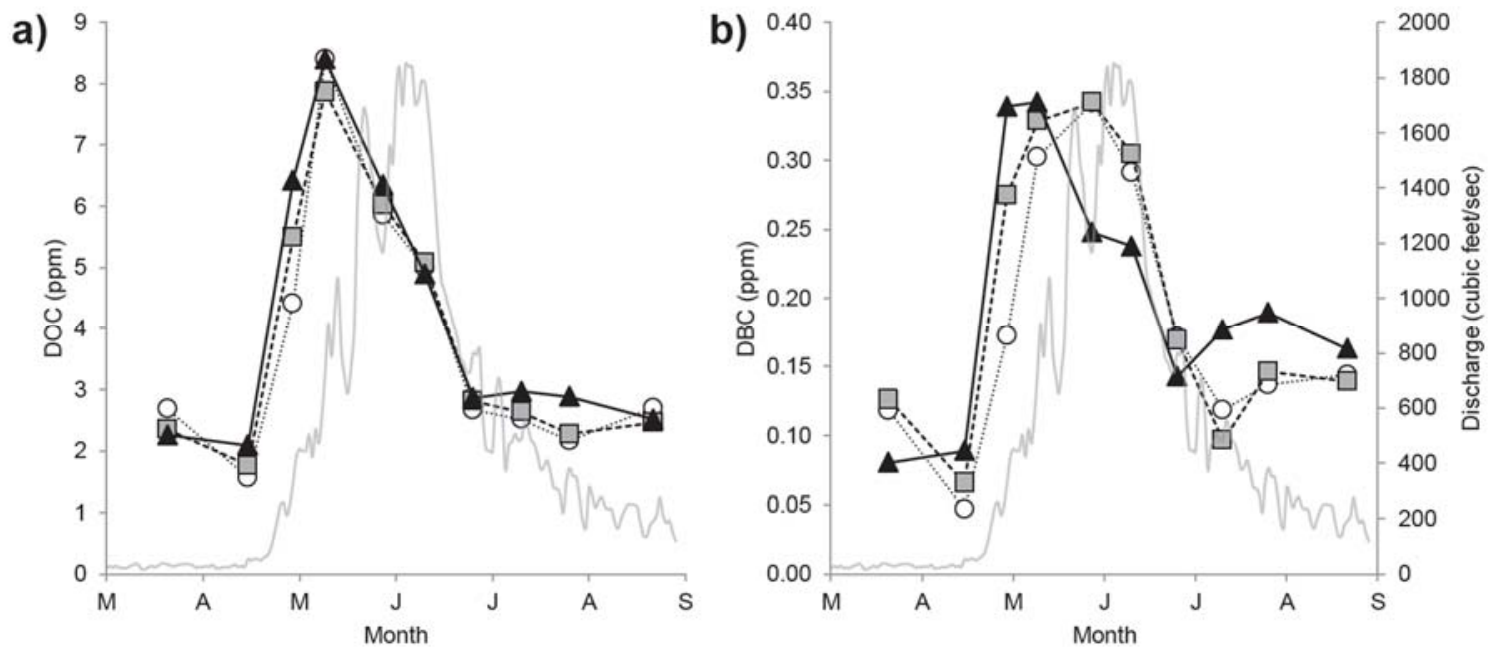

Figure 4.2 Seasonal distribution of water discharge rates and bulk DOC (a) and DBC (b) concentrations for burned (PSF grey squares; PNF black triangles) and unburned (PBR open circles) sites along the Poudre River transect 
Although DOC and DBC concentrations were overall strongly correlated throughout the sampling period $\left(\mathrm{R}^{2}=0.83, \mathrm{p}<0.01\right)$, variations in the seasonal distribution of bulk DBC were detected among the sites (Fig. 4.2b). Dissolved BC concentrations were lowest under base flow conditions, averaging $0.067 \pm 0.021 \mathrm{ppm}$ across each of the three sampling locations on April 20. However, slight differences in DBC export between the burned and unburned sites became apparent as discharge rates increased with spring melt. PNF exhibited the highest DBC concentration in early May (0.34 ppm). Dissolved BC at this fire-affected location subsequently decreased with increasing water discharge, but concentrations continued to remain elevated compared to PBR and PSF during the summer months (Fig. 4.2b). Despite being moderately influenced by the High Park Fire, seasonal DBC concentrations at PSF were generally similar to that of PBR throughout the sampling period. DBC at PBR and PSF peaked on June 1 (0.34 and $0.34 \mathrm{ppm}$, respectively), approximately 1 month after DBC concentrations peaked at PNF (Fig. 4.2b).

\subsubsection{Bulk TSS and PBC concentrations}

The TSS and PBC concentrations determined for PBR and PNF are also described in Table 4.1. Analysis of the particulate data focused on the two sites that represented burned (PNF) and unburned (PBR) end-members. Particulate samples were not available for April 20, therefore TSS and PBC were not determined. The TSS measured at PBR was variable $(10.3 \pm 9.2 \mathrm{ppm})$, but remained at concentrations significantly lower than those determined for PNF throughout the season (Fig. 4.3a, $\mathrm{p}<0.05$ ). A bimodal 
distribution for TSS at PNF was clearly evident and concentrations ranged from $13.3 \mathrm{ppm}$ during base flow to 528 ppm during spring melt and 337 ppm in late summer (Fig. 4.3a).
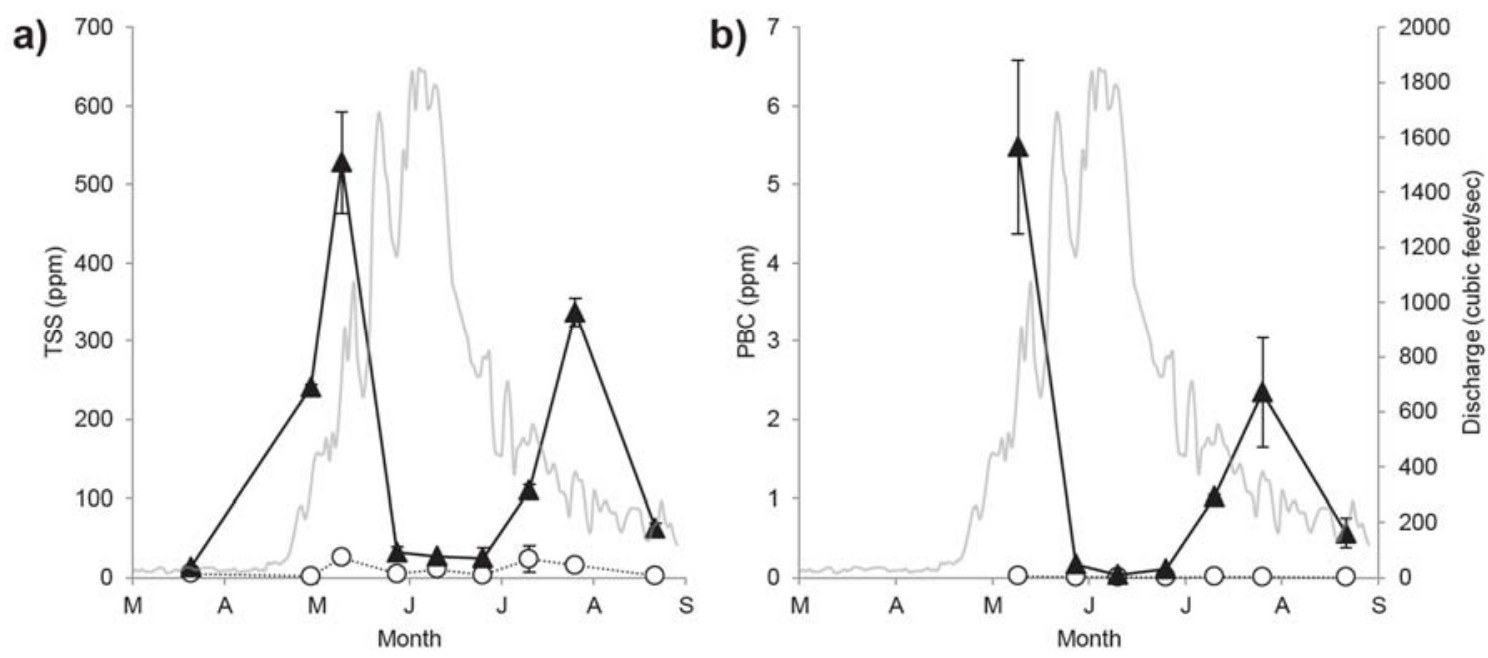

Figure 4.3 Seasonal distribution of water discharge rates and bulk TSS (a) and PBC (b) concentrations for fire-affected site PNF (black triangles) and unburned reference site PBR (open circles)

The seasonal distribution of TSS positively correlated with PBC at both PBR $\left(\mathrm{R}^{2}=0.79, \mathrm{p}<0.01\right)$ and PNF $\left(\mathrm{R}^{2}=0.96, \mathrm{p}<0.01\right) . \mathrm{PBC}$ was not determined for March 26 and May 4 collections because not enough particulate material was available to carry out BPCA analysis. The seasonal concentrations of PBC at PBR were variable $(0.009 \pm$ $0.005 \mathrm{ppm}$ ), but consistently remained lower than PBC concentrations measured for fireaffected PNF (Fig. 4.3b). The bimodal distribution of PBC at PNF exhibited a similar pattern to that of TSS, where concentrations initially peaked at $5.5 \mathrm{ppm}$ during spring melt, again at $1.0 \mathrm{ppm}$ during the late summer months and dropped as low as $0.034 \mathrm{ppm}$ during peak water discharge (Fig. 4.3b). Particulate organic carbon was not determined 
for TSS since sample amounts were limited. The seasonally averaged proportion of PBC to the dry weight of TSS (PBC:TSS) for PBR $(1.1 \pm 0.7 \mathrm{~g} \mathrm{C} / \mathrm{kg}$ dry weight) was significantly less than PBC:TSS for PNF $(6.6 \pm 3.2 \mathrm{~g} \mathrm{C} / \mathrm{kg}$ dry weight, $\mathrm{p}<0.01$, Table 4.1).

\subsubsection{Quality of PBC and DBC based on BPCA composition}

Seasonal averages indicated that BC particulates collected at the fire-affected PNF site were significantly more enriched in B5CA and B6CA than those collected from PBR (Fig. 4.4a; $\mathrm{p}<0.01$ ). Relative BPCA percentages for PBC at PNF had seasonal averages of $11.3 \pm 1.2,36.8 \pm 1.1,31.7 \pm 1.5$ and $20.2 \pm 1.8 \%$ for B3CAs, B4CAs, B5CA and B6CA, respectively. The B6CA marker was not detected in any of the PBR particulate samples. The contribution of B3CAs, B4CAs and B5CA to PBC measured at PBR were $23.1 \pm 2.1,57.4 \pm 53.3$ and $19.5 \pm 4.4 \%$, respectively. Ratios of BPCAs were used to describe the overall condensed aromaticity of $\mathrm{BC}$. Ratios including proportions of B6CA could not be used as this particular BPCA marker was not detected in PBC determined for samples from PBR. Therefore, the ratio of B5CA to B4CAs (B5:B4) was chosen to compare the quality of $\mathrm{BC}$ samples within this data set. The $\mathrm{B} 5$ :B4 ratio for $\mathrm{PBC}$ measured at PNF $(0.85 \pm 0.05)$ was significantly greater than that of PBR $(0.35 \pm 0.13$, $\mathrm{p}<0.001)$. The distribution of B5:B4 did not vary significantly during the sampling period at PNF $(p=0.58)$ or PBR ( $p=0.09$; Fig. $4.4 b)$.

Contrary to PBC, the seasonal mean BPCA distributions for DBC among PBR, PSF and PNF did not significantly differ from one another ( $p>0.05$; Fig. 4.5a). The average relative BPCA percentages across all sites for the entire sampling period were 
$12.9 \pm 1.8,40.8 \pm 3.7,36.2 \pm 2.5$ and $10.1 \pm 3.1 \%$ for B3CAs, B4CAs, B5CA and

B6CA, respectively. Despite the overall similarity in BPCA composition when taken as a seasonal average, a clear trend in increasing B5:B4 ratio emerged when BPCA distribution was plotted over time (Fig. 4.5b). Such a seasonal shift in B5:B4 was common among all sites.
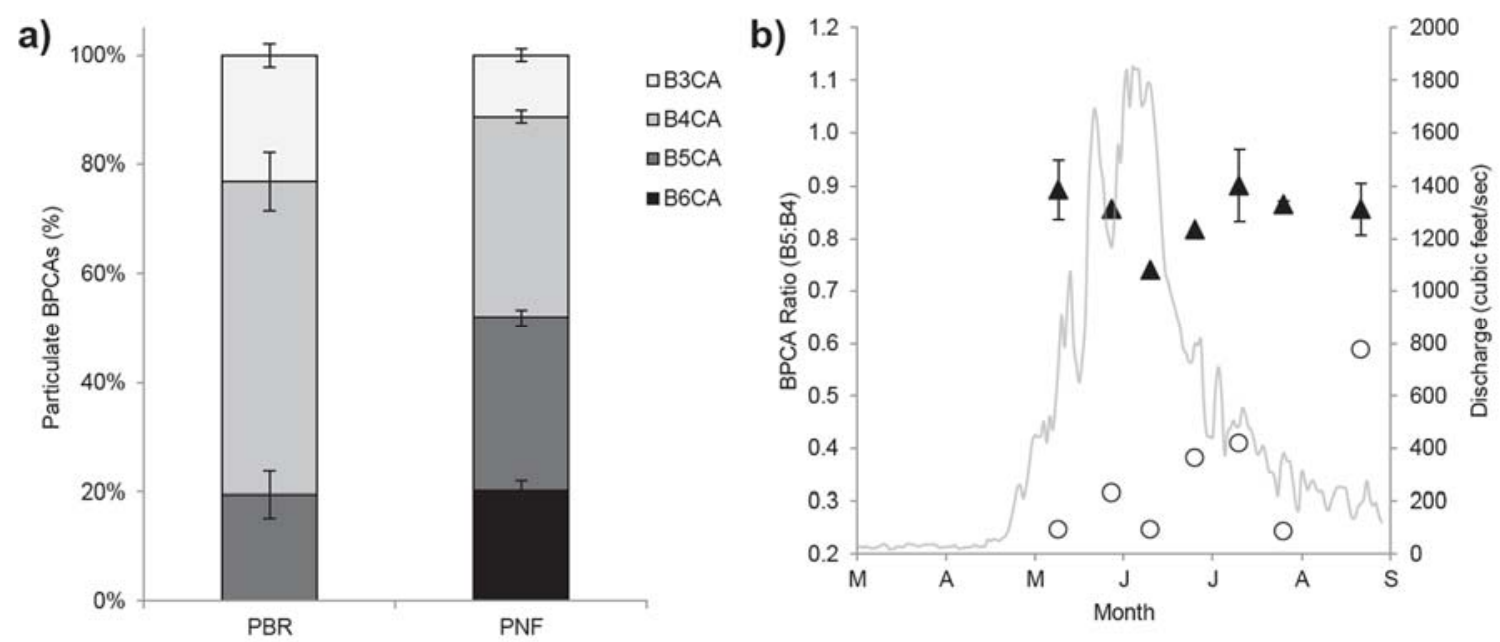

Figure 4.4 Seasonally-averaged PBC BPCA distributions for PBR and PNF (a) and the seasonal distribution of PBC quality (B5:B4) at PBR (open circles) and PNF (black triangles) (b). Error bars represent $1 \mathrm{SD}$ of the mean

In order to elucidate the drivers of this observed seasonal change in DBC quality, a principal component analysis (PCA) was carried out. The loading plot indicated a clear separation of BPCAs along principal component 1 (PC1) and principal component 2 (PC2) which explained $66.4 \%$ and $28.3 \%$ of the variance, respectively (Fig. 4.6a). When the scores were plotted according to sampling site, no clustering was observed (Fig. 4.6b). A lack of spatial trend was expected, as the shift in BPCA composition was 
common and similar among all sampling sites. When plotted according to sampling date, the scores followed a clear counterclockwise trend which supported the hypothesis that BPCA distribution underwent a seasonal shift (Fig. 4.6c). When the scores were plotted according to high and low water discharge, where the rates were categorized as being greater than or less than $500 \mathrm{ft}^{3} / \mathrm{s}$, respectively, a distinct separation along PC2 became apparent (Fig. 4.6d). Principle component 1 correlated most strongly with DBC quality (e.g., BPCA ratio B5:B4; $\mathrm{R}^{2}=0.95, \mathrm{p}<0.01$; Fig. 4.6e) and $\mathrm{PC} 2$ correlated with water discharge $\left(R^{2}=0.36, p<0.01 ;\right.$ Fig. 4.6f $)$.
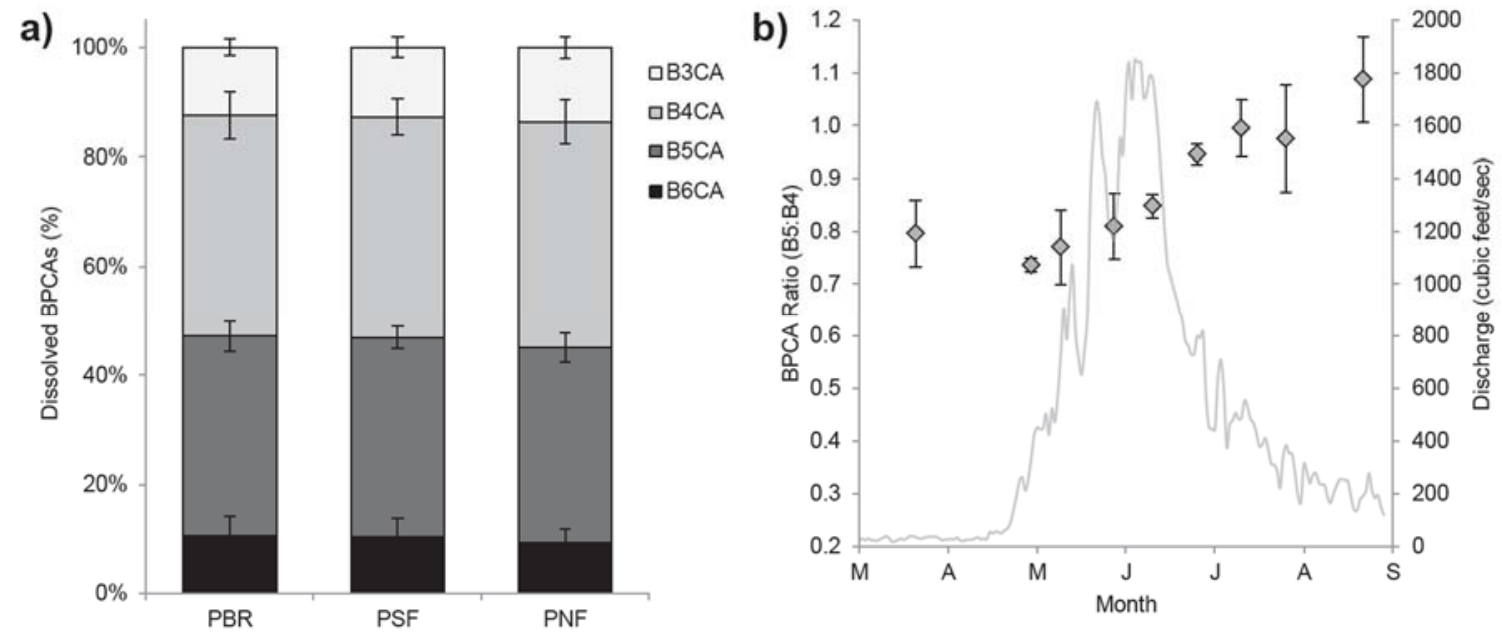

Figure 4.5 Seasonally-averaged DBC BPCA distributions for PBR, PSF and PNF (a) and the seasonal distribution of DBC quality (B5:B4) averaged across each of the three sampling sites (grey diamonds) (b). Error bars represent $1 \mathrm{SD}$ of the mean 
a)

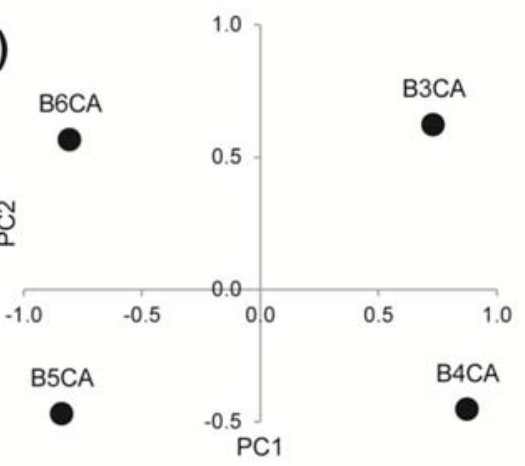

c)

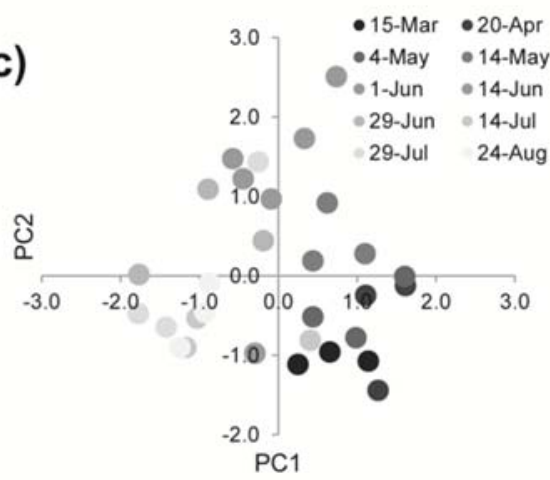

e)

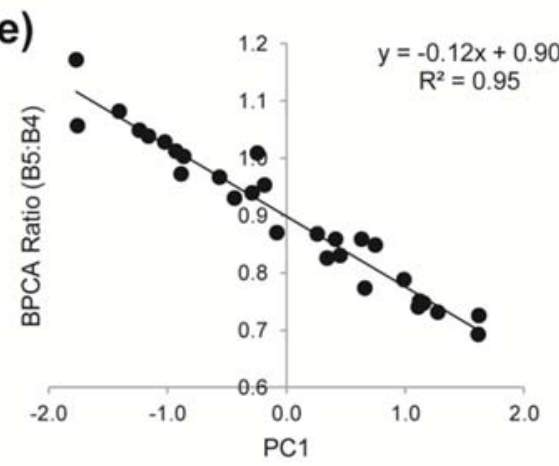

b)
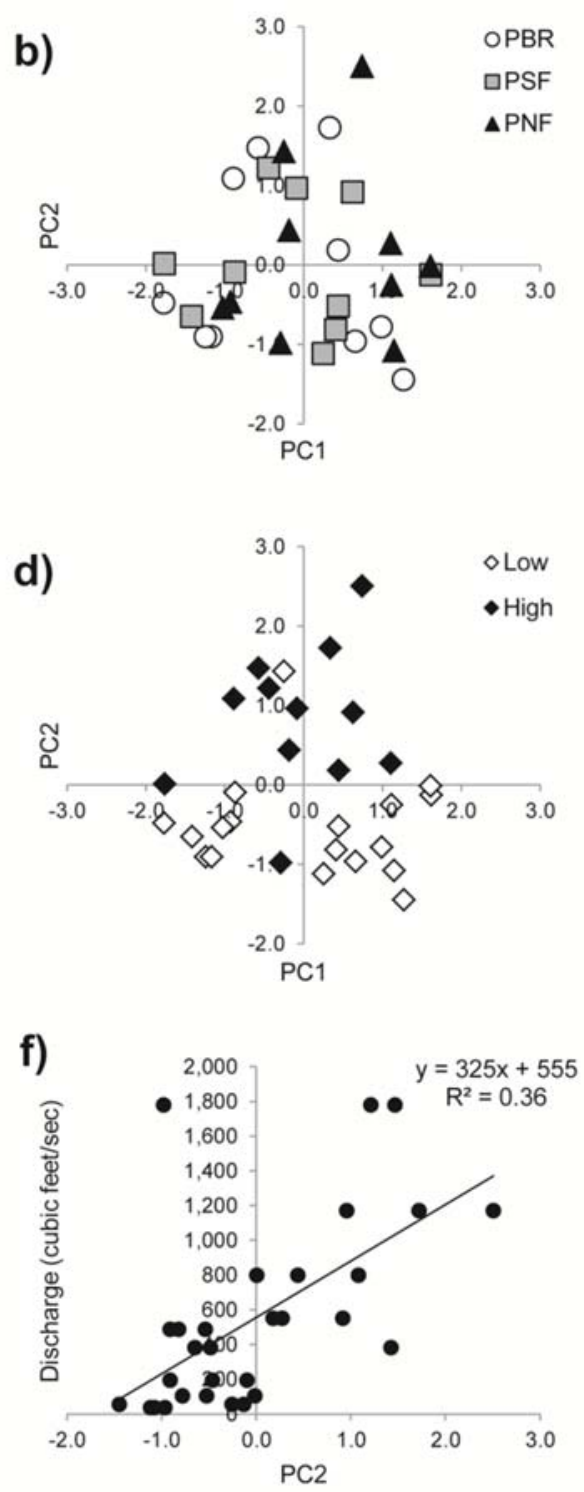

Figure 4.6 PCA where loadings included the relative proportion of DBC BPCAs at all sampling sites throughout the season (a). Scores were plotted by sampling site (b), collection date (c) and water discharge where low and high flow represent rates below and above $500 \mathrm{ft}^{3} / \mathrm{s}(\mathrm{d})$. Principle component 1 (PC1) explains $66.4 \%$ of the variance and correlates with DBC quality (B5:B4) (e) whereas principle component 2 (PC2) explains $28.3 \%$ of the variance and correlates with water discharge (f) 


\subsubsection{BC fluxes in particulate and dissolved phase}

Flux values could only be calculated for PNF, as this is the sampling site where water discharge data was collected. Fluxes of $\mathrm{BC}$ in both the particulate and dissolved phase do not remain constant throughout the year (Fig. 4.7). Dissolved BC fluxes were lowest $(0.01 \mathrm{Mg} \mathrm{C} /$ day) during early spring base flow conditions and peaked (0.61 Mg C/day) in June with increased water discharge. Particulate BC flux values for March 26 and May 4, for which actual data were not available, were estimated using the strong regression between TSS and $\mathrm{PBC}\left(\mathrm{PBC}=0.0098 \times \mathrm{TSS}-0.1718, \mathrm{R}^{2}=0.96\right.$, $\mathrm{p}<0.001)$. Particulate BC fluxes remained low during base flow and peak discharge $(0.3$ $\pm 0.2 \mathrm{Mg} \mathrm{C} /$ day) but increased by an order of magnitude during spring melt and late summer rain events $(2.5 \pm 0.4 \mathrm{Mg} \mathrm{C} /$ day $)$.

\subsection{Discussion}

\subsubsection{Controls on bulk DOC and DBC export}

Dissolved BC was shown to be strongly correlated with DOC in the Poudre River throughout the sampling period (Fig. 4.2). The DBC-DOC relationship is shared among global rivers, and suggests that $\mathrm{DBC}$ and $\mathrm{DOC}$ mobilization processes are somehow linked in fluvial systems (Jaffé et al. 2013). During winter and early spring, the watershed was still predominantly snow-covered and the river was fed primarily by groundwater. Seasonal DOC and DBC concentrations were lowest under these base flow conditions. In-stream DOC and DBC concentrations increased rapidly with the onset of spring snow melt. As the water table rises and overland flow increases, DOC from recently-deposited organic material is flushed from the upper soil horizons into adjacent river systems 
(Boyer et al. 1997; Lambert et al. 2011). Although there appeared to be no significant difference in DOC between burned and unburned sites throughout the season, samples collected on May 4 exhibited a detectable low-to-high concentration gradient from PBR to PNF (Fig. 4.2a). This pattern was also observed with regards to DBC (Fig. 4.2b), suggesting a "snapshot" of local hydrology may have been captured which seemed to occur for only a brief period of time during spring snowmelt. The Poudre River sampling sites fell along an elevation gradient, where PBR and PNF are located at the highest and lowest elevations, respectively. It has been shown that the onset of snowmelt at lower elevations can occur earlier in the season (Clow 2010). Early snowmelt could have resulted in the premature flushing of surface soils at lower elevations, which could presumably have been linked to increased riverine DOC and associated DBC at PSF and PNF during that time period. DOC in alpine streams typically reaches peak concentrations prior to peak water discharge and decreases with increasing snowmelt as the soluble pool of DOC from soils is exhausted and diluted in-stream (Hornberger et al. 1994). This trend was also observed for the Poudre River, where DOC concentrations peaked approximately 1 month prior to peak water discharge (Fig. 4.2a).

Despite being positively correlated with one another, DBC concentrations were distributed slightly differently than that of DOC throughout the season. Compared to DBC concentrations determined for PSF and PBR, DBC measured at PNF peaked approximately 1 month earlier and dropped more rapidly with increasing water discharge (Fig. 4.2b). According to Stoof et al. (2012), fire has been shown to increase streamflow volumes resulting from vegetation removal and increased soil repellency. Poudre River discharge rates were only obtained at the downstream burn site, PNF. Therefore, water 
discharge measured at PNF may have been greater than actual streamflow rates occurring simultaneously at PBR or PSF due to the presence of smaller tributaries that likely contribute to flow downstream of PSF. If the bulk of DBC inputs occurred upstream of the fire affected area, then the perceived drop in DBC concentration between PBR and PNF for samples collected on June 1 and June 14 (Table 4.1; Fig. 4.2b) can be attributed to downstream dilution of DBC during peak discharge. In late summer, when discharge drops to near-base flow rates, DBC concentrations at PNF remain elevated compared to PBR and PSF (Fig. 4.2b). Pyrogenic C incorporated into surface soils immediately following a wildfire has been characterized as generally being smaller in size and having increased functionality (Czimczik et al. 2003), which suggests that a portion of freshlygenerated BC could be soluble (Preston and Schmidt 2006; Abiven et al. 2011). Small, but detectable, inputs of DBC derived from the High Park Fire could have contributed to the slightly increased DBC concentrations at PNF until fall and winter base flow conditions were reached. In agreement with other studies (Smith et al. 2011; Ding et al. 2013), it appears that recent fire activity does not significantly affect peak concentrations or total seasonal export of DOC and DBC in rivers associated with such watersheds. While the data presented here suggests that the bulk export of DBC from downstream, lower elevation burned areas occurs earlier in the season compared to unburned, upper elevation sites, the overall contribution of DBC from the burned watershed seems to be minimal. However, it is important to note that this study was performed 1 year after the actual fire event. It is thus possible that soluble DBC from freshly generated char could have been exported prior to sampling. 


\subsubsection{DBC and PBC source material}

Pyrogenic C represents a large pool of heat-altered molecules where various methods can be employed to gain quantitative and qualitative information for charred biomass along different regions of the combustion continuum (Masiello 2004). For example, extracted anhydrosugars have been used to reveal possible fuel sources of biomass burned at low temperatures (Myers-Pigg et al. 2015), whereas thermo-chemical oxidation methods quantify more thermally refractory portions of PyC (Roth et al. 2012). The BPCA method specifically detects polycondensed aromatic compounds and generates molecular information that is related to the source, formation conditions and overall quality of BC derived from high temperature combustion (Schneider et al. 2010; Abiven et al. 2011). Black C oxidation products that yield greater proportions of B5CA and $\mathrm{B} 6 \mathrm{CA}$ indicate that the original aromatic structure was larger and more polycondensed in nature (Brodowski et al. 2005; Dittmar 2008; Ziolkowski et al. 2011). The seasonally averaged BPCA distributions determined for DBC was statistically similar between all three sampling sites (Fig. 4.5a). Comparable BPCA compositions between burned and unburned locations suggested that the bulk of DBC was mainly sourced upstream, above the fire-affected area and/or from charcoal generated during previous historical fire events in the area. The data is in agreement with reports that $\mathrm{BC}$ stocks in the Poudre River watershed are higher in deeper soil horizons compared to surface soils, and that this deeper, aged BC from historical fires, had a more condensed aromatic structure compared to recently generated BC from the High Park Fire (Boot et al. 2014). The absence of increased DOC and DBC at the downstream PNF site compared to the control site (Fig. 2) further supported this hypothesis, indicating that there may 
have been minimal DOM input or removal between the burned and unburned endmembers during the sampling period studied. The water residence time between PBR and PNF is also quite short (approximately $6 \mathrm{~h}$ during spring snowmelt). Therefore, there is also little opportunity for significant in-stream geochemical processing of DOC and DBC (e.g., sorption, dissolution, decomposition, etc.) that would considerably alter DBC quantity and/or quality. However, the data presented here cover only a portion of the annual hydrograph (March-August) and thus do not imply that potential differences between the control and fire-impacted sites or between periods before and after the fire do not exist.

The B5CA and B6CA biomarkers contributed approximately $50 \%$ of the BPCAs for DBC measured at all sites (Fig. 4.5a), which suggests that large, more polycondensed aromatic molecules are exported to the Poudre River in the dissolved phase. As BC ages and undergoes oxidation in soils, carboxylic functionalities are introduced, increasing the overall polarity and solubility of BC molecules (Knicker 2011). Abiven et al. (2011) observed increased contributions of larger, condensed aromatic molecules in DBC leached from aged and oxidized charcoal. Thus, the prevalence of B5CA and B6CA suggested that DBC in the Poudre River was primarily derived from an older PyC source, and received only minimal inputs from freshly-generated charcoal produced by the High Park Fire. Although seasonally-averaged BPCA compositions indicated a shared DBC source among the sampling sites, it was apparent that this source may have in part shifted between peak and base flow conditions.

The ratio of $\mathrm{B} 5 \mathrm{CA}$ to $\mathrm{B} 4 \mathrm{CAs}(\mathrm{B} 5: \mathrm{B} 4)$ has been used previously to express the overall degree of BC condensation (Stubbins et al. 2012). Dissolved BC experiences a 
seasonal shift from low to high $\mathrm{B} 5$ :B4, indicating a change in DBC quality between the spring and summer months (Fig. 4.5b). The shift in DBC quality was observed for all sampling sites, and therefore cannot necessarily be attributed to the recent fire activity that affected PSF and PNF. PCA was implemented to uncover the possible environmental controls that influenced BPCA composition during the course of the sampling period (Fig. 4.6). Dissolved BC quality correlates strongly with PC1, indicating a shift in DBC source strengths between the spring and summer months (Fig. 4.6e). Principle component 2 was determined to be significantly correlated with water discharge rates measured at the downstream sampling site, which suggested that seasonal hydrology played a role in the quality of exported DBC (Fig. 4.6f). In Rocky Mountain streams, it has been previously established that DOC composition is controlled by different flow paths of water entering the river (Sanderman et al. 2009). During base flow, the Poudre River received inputs from slow-moving groundwater that percolated through deep soil horizons before entering the stream. However, during times of increased runoff, such as spring snow melt and summer storm events, faster-moving flow paths through the upper soil horizons linked mobile DBC and DOC in organic-rich surface layers to the river main stem. It has been observed that aged and partially-oxidized BC can become enriched in deeper soil layers (Knicker et al. 2008; Boot et al. 2014) and stabilized in the mineral phase (Glaser et al. 2000; Czimczik and Masiello 2007). Although it has been shown that, compared to fresh charcoal, aged BC leaches DBC that generates greater proportions of B5CA and B6CA (Abiven et al. 2011), Kothawala et al. (2012) showed that larger aromatic compounds can be largely retained in mineral-rich soils, which suggests that smaller DBC molecules yielding lower B5:B4 ratios could have been 
preferentially released from deeper soil horizons during base flow. The relatively slow rates of groundwater flow may have allowed for the equilibration time needed for sorption of larger DBC molecules to deep mineral soils, resulting in the preferential export of DBC with comparatively small molecular structures. In contrast, large runoff events, such as storm activity or snow melt, likely resulted in quick surface flow that may not have allowed for the sorption/desorption mechanisms of DBC that are suggested to have occurred during base flow. A large pool of relatively fresh $\mathrm{BC}$ can become concentrated in the upper organic soil horizon (Preston and Schmidt 2006). The fast flushing of DBC in these surface soils does not likely discriminate in the export of large and small aromatic molecules. Therefore, it is hypothesized that increased contributions of $\mathrm{B} 5 \mathrm{CA}$ and $\mathrm{B} 6 \mathrm{CA}$ to the $\mathrm{BPCA}$ signature later in the season can be attributed to the additional mobilization of relatively large $\mathrm{DBC}$ molecules from organic surface soils (including soil pore water) during times of increased discharge (Fig. 4.5b). The export of larger DBC structures will have likely dominated the BPCA signature until the system returned to base flow conditions. Dissolved BC quality has been linked to hydrology in other climatic regions, such as tropical forests (Dittmar et al. 2012) and Arctic rivers (Guggenberger et al. 2008), suggesting that this seasonal shift in DBC source between fresh BC incorporated into surface soils and partially aged BC enriched in deeper soil horizons may occur on a global scale.

The presence of PBC, albeit at much lower concentrations than at the downstream fire-impacted site, at the unburned reference site was initially thought to have been sourced from atmospheric deposition of soot from anthropogenic sources or from airborne charcoal generated by the High Park Fire. However, PBC from these particular 
sources are expected to have increased contributions of B5CA and B6CA (Roth et al. 2012). Enrichments in B5CA and B6CA were not observed for PBR, which exhibited a BPCA signature that was relatively depleted in such oxidation products (Fig. 4.4a). Recently, the photoflocculation of terrestrial organic matter has been suggested under specific environmental conditions (i.e. high DOC, high iron content and low $\mathrm{pH}$ ) where photochemically-flocculated particulate organic was suggested to become enriched in condensed aromatic functionalities (Chen et al. 2014). However, the molecular size and degree of conjugation of these photoflocculated aromatics has yet to be characterized as $\mathrm{BC}$ using the BPCA method. In addition, the lack of a direct link between DBC and PBC in the Poudre River may suggest that the potential photo-production of condensed aromatic components could be less important in natural fluvial settings than what has been observed under laboratory conditions (Chen et al. 2014). Sánchez-García et al. (2013) noted a reduced contribution of B6CA for BC measured in near-shore coastal shelf sediments when compared to BC in sediments collected from within the central river plume. A relative depletion in B6CA suggests that diagenetic degradation processes and associated aging may result in a less condensed PBC signature and that this material at PBR may be relic PBC from historic events. However, the exact reasons for these observations remain to be resolved.

\subsubsection{Controls on bulk TSS and PBC export}

The riverine export of TSS and PBC at PNF, both of which exhibited a clear bimodal distribution throughout the season, was substantially larger compared to measurements at the unburned PBR site (Fig. 4.3). Particulate BC and TSS at PBR was 
variable, but exhibited no clear seasonal trend (Fig. 4.3). Wildfires reduce vegetation cover and destabilize soils, which increases the susceptibility of the burned area to surface erosion (Johansen et al. 2001; Smith et al. 2011). The initial peaks in TSS and PBC coincided with spring snowmelt, when increasing river discharge mobilized sediments deposited within the main stem during the previous season and overland runoff flushed large amounts of fire-affected soils and associated charcoal into the river. Total suspended solids and PBC concentrations quickly dropped, becoming diluted as discharge rates increased, and exhausted the erodible pool of soils and PyC. The second peak in TSS and PBC that occurred during mid-summer was attributed to multiple storm events that were documented during the first 2 weeks of July (Fig. 4.3). Previous work has shown similar trends in increased TSS mobilization during spring melt and summer storm events in watersheds affected by recent wildfire activity (Moody and Martin 2001). Moody and Martin (2001) suggested that pyrogenic material can be deposited in "alluvial fans" in areas where lower-order tributaries connect to higher-order streams. Significant deposits of charcoal were visibly evident at the shoreline of the Poudre River in the burned section of the watershed, showing a clear size selection, changing from coarse char particles to fine, black, particulate matter with increasing distance from the river channel. Such a size distribution pattern agrees with the mobilization and transport of fine $\mathrm{PBC}$ during increased river discharge events as this fire-derived organic matter is then flushed into the main river during times of increased runoff, such as summer storm events which typically occur later in the season (Moody and Martin 2001). In some studies, it has been shown that charcoal may be transferred preferentially down a slope, further increasing the connectivity between $\mathrm{PBC}$ and riverine export (Florsheim et al. 1991; 
Rumpel et al. 2006). Contrary to DBC, the export of PBC in the Poudre River was clearly influenced by the High Park Fire, where particulate charcoal and thermally-altered soils were physically transported along the main stem during increased spring streamflow and periods of overland runoff.

The contribution of PBC to TSS was also significantly increased in areas where the Poudre River drained fire-affected regions of the watershed (Table 4.1). The proportion of PBC to dry TSS was, on average, up to six times greater in areas where the river received pyrogenic inputs from the High Park Fire (Table 4.1), which reflects the direct and immediate post-burn contribution of charred particulates to the Poudre River. Despite the significantly increased contributions of PBC to TSS in fire-affected waters, the proportion of PBC to TSS was expected to be even larger due to large amounts of visible suspended char at the PNF site. However, it was hypothesized that perhaps only a small percentage of TSS is organic in nature and that a considerable portion of the visibly-detected charcoal may be slightly charred biomass, which is mildly thermallyaltered but lacking a polycondensed aromatic structure, thereby falling outside the BPCA detection window (Masiello 2004; Alexis et al. 2010; Masiello and Louchouarn 2013). The BPCA method detects only the polycondensed aromatic portion of fire-derived organic matter and therefore primarily reflects $\mathrm{PyC}$ inputs derived from high temperature combustion. Pairing this technique with others, such as extracted anhydrosugars for low temperature PyC (Myers-Pigg et al. 2015), would allow for a more complete understanding of $\mathrm{PyC}$ composition and mobility across larger regions of the combustion continuum (Masiello 2004). 


\subsubsection{Decoupling of PBC and DBC export in fire-affected rivers}

Flux measurements for the export of $\mathrm{PBC}$ and $\mathrm{DBC}$ were only calculated for the PNF site, as this was the location closest to the gage station. Fluxes of PBC and DBC varied throughout the season and appeared to operate on different timescales (Fig. 4.7). This variation in $\mathrm{BC}$ export further strengthened the hypothesis that both sources and mobilization processes for $\mathrm{BC}$ in the particulate and dissolved phases were decoupled in the Poudre River watershed. Flushing events, such as spring snow melt and summer storm activity, triggered overland flow and the physical transport of particulate $\mathrm{PyC}$ within the river main stem, which significantly increased the flux of PBC to rates 16 times greater than that of DBC (Table 4.2). However, during times of peak discharge, when seasonally high DBC concentrations are compounded by increased streamflow rates, the export of riverine $\mathrm{BC}$ occurred primarily in the dissolved phase and reached fluxes approximately 7 times that of PBC (Table 4.2), which provides additional support for the observed link between streamflow and DBC export where the mobilization of soluble PyC is influenced by watershed dynamics. The area under each seasonal flux curve (Fig. 4.7), was integrated in order to estimate and directly compare the total amount of $\mathrm{BC}$ exported as both PBC (148 Mg BC) and DBC (38 Mg BC). On the basis of these approximations, the total seasonal export of PBC exceeded that of DBC by a factor of four during the sampling period. 
Table 4.2 Water discharge rates and calculated black carbon flux measurements for the PNF sampling site

\begin{tabular}{lccc}
\hline Sampling Date & $\begin{array}{c}\text { Discharge } \\
\left(\mathrm{ft}^{3} / \mathrm{sec}\right)\end{array}$ & $\begin{array}{c}\text { Flux PBC } \\
(\mathrm{Mg}-\mathrm{C} / \text { day })\end{array}$ & $\begin{array}{c}\text { Flux DBC } \\
(\mathrm{Mg}-\mathrm{C} / \text { day })\end{array}$ \\
\hline March 26 & 34 & $0.00^{*}$ & 0.01 \\
May 4 & 46 & $0.25^{*}$ & 0.04 \\
May 14 & 199 & 2.7 & 0.17 \\
June 1 & 474 & 0.19 & 0.29 \\
June 14 & 1054 & 0.09 & 0.61 \\
June 29 & 1721 & 0.46 & 0.60 \\
July 14 & 795 & 2.0 & 0.34 \\
July 29 & 483 & 2.8 & 0.22 \\
August 24 & 378 & 0.52 & 0.15 \\
\hline
\end{tabular}

* Some values were extrapolated based on the strong regression between PBC and TSS; $\mathrm{PBC}=0.0098 \times \mathrm{TSS}-0.1718, \mathrm{R}^{2}=0.96, \mathrm{p}<0.001$

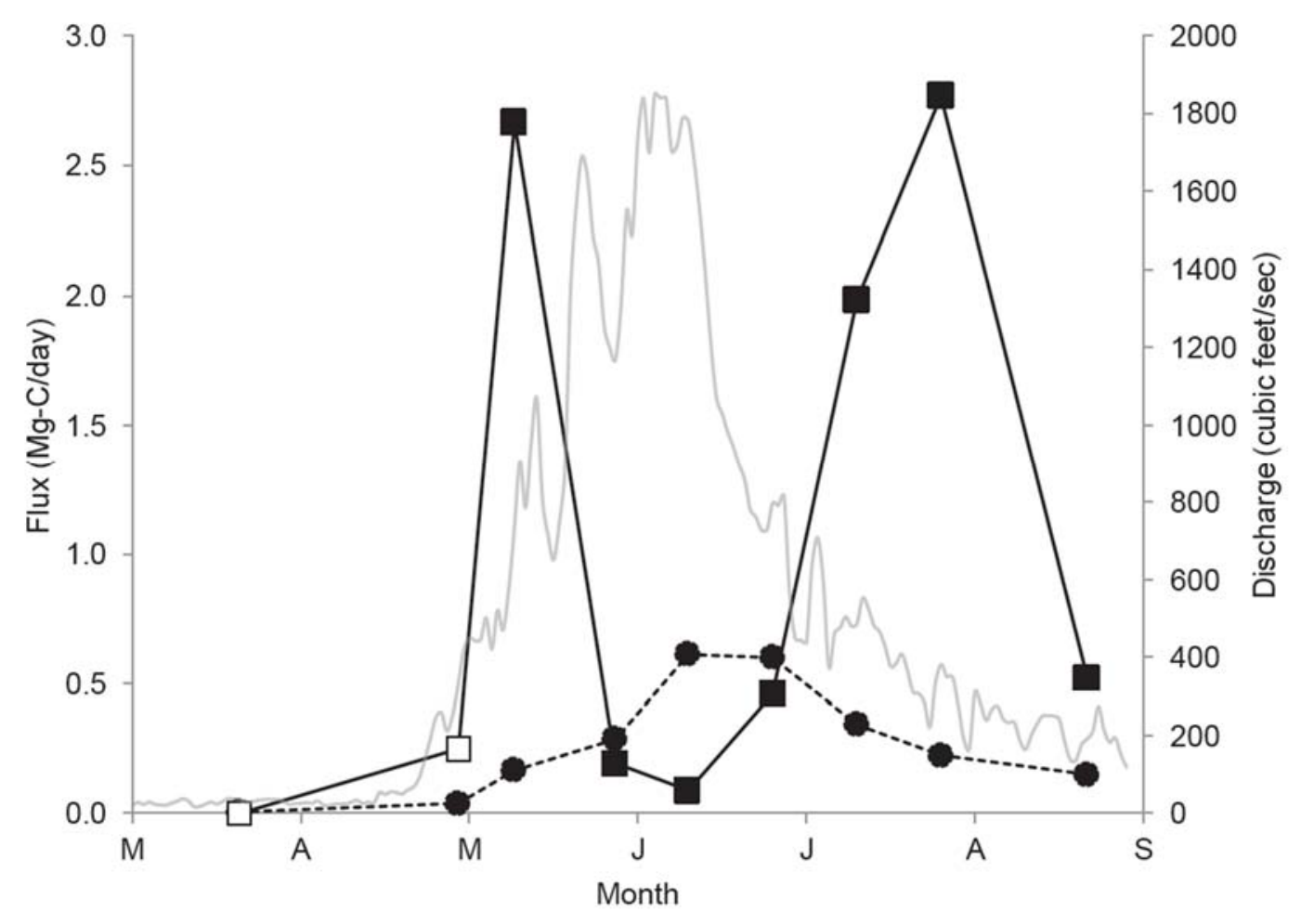

Figure 4.7 Seasonal fluxes for DBC (black circles) and PBC (black squares) at the fireaffected PNF sampling site. PBC flux rates for March 26 and May 4 (open squares) were estimated using the strong regression between $\mathrm{PBC}$ and TSS 
The scope of this study was limited considering that data was only available for the 2013 sampling season, thereby missing what may have been a key time for BC export in 2012, during the immediate post-fire period. It is known that fresh char can leach a significant amount of DBC (Abiven et al. 2011; Wagner et al. 2015), which suggests that an initial pulse of DBC exported immediately after the High Park Fire may have been missed. Since there was not a considerable difference in DBC between burned and unburned locations, it was concluded that any immediate influence the fire may have had on $\mathrm{DBC}$ during the first year is nearly undetectable during the following season. However, DBC export in the Poudre River may ultimately increase as the new pool of charcoal generated from the High Park Fire becomes incorporated into the soil and is slowly oxidized before being released into the river, a process that could last hundreds of years (Dittmar et al. 2012; Singh et al. 2012). Contrary to DBC, the riverine export of PBC was significantly impacted by recent wildfire activity on what appears to be a much shorter timescale. Fires result in increased erosion (Johansen et al. 2001; Smith et al. 2011) where the preferential translocation of BC downslope is possible (Rumpel et al. 2006). Previous work by Lane et al. (2006) indicated a tenfold increase and a threefold increase in TSS during the first and second years following a wildfire, respectively, which suggests that fluxes of TSS and PBC may have been more than three times greater in 2012 than those measured during the 2013 sampling period. Despite the initially dramatic increase in riverine PBC export following the High Park Fire, it is suggested that PBC fluxes will be reduced each subsequent year in response to vegetation recovery and soil re-stabilization (Lane et al. 2006) until pre-fire concentrations are reached. The apparent decoupling between DBC and PBC in the Poudre River is supported by the 
hypothesis that dissolved and particulate organic matter in fluvial systems is likely derived from different sources (Raymond and Bauer 2001). Although it has been suggested that the bulk of High Park Fire BC is removed from the landscape via surface erosion (Boot et al. 2014), the time deferred release of DBC from the deeper, aged $\mathrm{BC}$ stocks, and from ageing char from this fire event may ultimately become a greater, longer term contribution to the riverine $\mathrm{BC}$ pool in the Poudre River system.

\subsection{Conclusions}

Dissolved BC fluxes in the Poudre River watershed were not substantially increased post-fire, which suggests that the oxidation and aging of $\mathrm{BC}$ to enhance its solubility is a prerequisite to its export in the dissolved phase. However, the High Park Fire significantly increased PBC export as freshly-generated charcoal entered the Poudre River during spring melt and times of the year when overland flow was prominent. These findings suggest that (1) the export processes of $\mathrm{PBC}$ and $\mathrm{DBC}$ are decoupled in systems recently impacted by fires and (2) although it is not known if there was an initial pulse of DBC released shortly after the fire event, the release of DBC is likely to occur over longer timescales than PBC derived from the same burn event. During the sampling period discussed here, the seasonal flux of $\mathrm{PBC}$ in the Poudre River exceeded that of DBC four-fold. The riverine export of $\mathrm{BC}$ in the particulate phase appears to be a significant, yet previously unquantified, mechanism for BC removal from watersheds directly affected by fires.

Since the occurrence of wildfires is expected to increase in the coming decades as a result of climate change (Krawchuk et al. 2009), fluxes of PBC via inland waters may 
also increase. However, extrapolating global fluxes of PBC from the data shown here would be highly speculative, as PBC export appears to be strongly influenced by geomorphology and hydrology of the specific, burnt catchment area. Nevertheless, relationships between post-fire $\mathrm{DBC}$ and $\mathrm{PBC}$ should be further explored in order to properly assess short- and long-term effects of wildfires on the dynamics of aquatic BC and its contribution to the biogeochemical cycling of charcoal. 


\section{References}

Abiven S, Hengartner P, Schneider MPW, Singh N, Schmidt MWI (2011) Pyrogenic carbon soluble fraction is larger and more aromatic in aged charcoal than in fresh charcoal. Soil Biol Biochem 43:1615-1617

Alexis MA, Rumpel C, Knicker H, Leifeld J, Rasse D, Péchot N, Bardoux G, Mariotti A (2010) Thermal alteration of organic matter during a shrubland fire: a field study. Org Geochem 41:690-697

Boot CM, Haddix M, Paustian K, Cotrufo MF (2014) Distribution of black carbon in Ponderosa pine litter and soils following the High Park wildfire. Biogeosci Discuss 11:16799-16824

Boyer EW, Hornberger GM, Bencala KE, McKnight DM (1997) Response characteristics of DOC flushing in an alpine catchment. Hydrol Process 11:1635-1647

Brodowski S, Amelung W, Haumaier L, Abetz C, Zech W (2005) Morphological and chemical properties of black carbon in physical soil fractions as revealed by scanning electron microscopy and energy-dispersive X-ray spectroscopy. Geoderma 128:116-129

Bruun S, Jensen ES, Jensen LS (2008) Microbial mineralization and assimilation of black carbon: dependency on degree of thermal alteration. Org Geochem 39:839-845

Cerdá A, Doerr SH (2008) The effect of ash and needle cover on surface runoff and erosion in the immediate post-fire period. Catena 74:256-263

Chen H, Abdulla HAN, Sanders RL, Myneni SCB, Mopper K, Hatcher PG (2014) Production of black carbon-like and aliphatic molecules from terrestrial dissolved organic matter in the presence of sunlight and iron. Environ Sci Technol 1:399-404

Cheng C-H, Lehmann J, Thies JE, Burton SD, Engelhard MH (2006) Oxidation of black carbon by biotic and abiotic processes. Org Geochem 37:1477-1488

Cheng C-H, Lehmann J, Thies JE, Burton SD (2008) Stability of black carbon in soils across a climatic gradient. J Geophys Res 113:G02027. doi:10.1029/2007JG000642

Clow DW (2010) Changes in the timing of snowmelt and streamflow in Colorado: a response to recent warming. J Clim 23:2293-2306

Coppola AI, Ziolkowski LA, Masiello CA, Druffel ERM (2014) Aged black carbon in marine sediments and sinking particles. Geophys Res Lett 41:2427-2433

Czimczik CI, Masiello CA (2007) Controls on black carbon in soils. Glob Biogeochem Cycles 21:GC3005. doi:10.1029/2006GB002798 
Czimczik CI, Preston CM, Schmidt MWI, Schulze ED (2003) How surface fire in Siberian Scots pine forests affects soil organic carbon in the forest floor: stocks, molecular structure, and conversion to black carbon (charcoal). Glob Biogeochem Cycles 17:1020. doi:10.1029/2002GB001956

Ding Y, Yamashita Y, Dodds WK, Jaffé R (2013) Dissolved black carbon in grassland streams: Is there an effect of recent fire history? Chemosphere 90:2557-2562

Dittmar T (2008) The molecular level determination of black carbon in marine dissolved organic matter. Org Geochem 39:396-407

Dittmar T, Koch B, Hertkorn N, Kattner G (2008) A simple and efficient method for the solid-phase extraction of dissolved organic matter (SPE-DOM) from seawater. Limnol Oceanogr 6:230-235

Dittmar T, de Rezende CE, Manecki M, Niggemann J, Ovalle ARC, Stubbins A, Bernardes MC (2012) Continuous flux of dissolved organic carbon from a vanished tropical forest biome. Nat Geosci 5:618-622

Flannigan MD, Krawchuk MA, de Groot WJ, Wotton BM, Gowman LM (2009) Implications of changing climate for global wildland fire. Int J Wildland Fire 18:483-507

Florsheim JL, Keller EA, Best DW (1991) Fluvial sediment transport in response to moderate storm flows following chaparral wildfire, Ventura County, southern California. Geol Soc Am Bull 103:504-511

Forbes MS, Raison RJ, Skjemstad JO (2006) Formation, transformation and transport of black carbon (charcoal) in terrestrial and aquatic ecosystems. Sci Total Environ 370:190 206

Glaser B, Balashov E, Haumaier L, Guggenberger G, Zech W (2000) Black carbon in density fractions of anthropogenic soils of the Brazilian Amazon region. Org Geochem 31:669-678

Goldberg E (1985) Black carbon in the environment. Wiley, New York

Guggenberger G, Rodionov A, Shibistova O, Grabe M, Kasansky OA, Fuchs H, Mikeyeva N, Zrazhevskaya G, Flessa H (2008) Storage and mobility of black carbon in permafrost soils of the forest tundra ecotone in Northern Siberia. Glob Change Biol $14: 1367-1381$ 
Hedges JI, Eglinton G, Hatcher PG, Kirchman DL, Arnosti C, Derenne S, Evershed RP, Kögel-Knaber I, de Leew JW, Littke R, Michaelis W, Rullkötter J (2000) The molecularly-uncharacterized component of nonliving organic matter in natural environments. Org Geochem 31:945-958

Hilscher A, Knicker H (2011) Carbon and nitrogen degradation on molecular scale of grass-derived pyrogenic organic material during 28 months of incubation in soil. Soil Biol Biochem 43:261-270

Hornberger GM, Bencala KE, McKnight DM (1994) Hydrological controls on dissolved organic carbon during snowmelt in the Snake River near Montezuma, Colorado.

Biogeochemistry 25:147-165

Jaffé R, Ding Y, Niggeman J, Vähätalo AV, Stubbins A, Spencer RGM, Campbell J, Dittmar T (2013) Global charcoal mobilization via dissolution and riverine transport to the oceans. Science 340:345-347

Johansen MP, Hakonson TE, Breshears DD (2001) Post-fire runoff and erosion from rainfall simulation: contrasting forests with shrublands and grasslands. Hydrol Process $15: 2953-2965$

Knicker H (2011) Soil organic N-an under-rated player for C sequestration in soils? Soil Biol Biochem 43:1118-1129

Knicker H, Almendros G, González-Vila FJ, González-Pérez JA, Polvillo O (2006) Characteristic alterations of quantity and quality of soil organic matter caused by forest fires in continental Mediterranean ecosystems: a solid-state 13C NMR study. Eur J Soil Sci 57:558-569

Knicker H, Hilscher A, González-Vila FJ, Almendros G (2008) A new conceptual model for the structural properties of char produced during vegetation fires. Org Geochem 39:935-939

Kothawala DN, Roehm C, Blodau C, Moore TR (2012) Selective adsorption of dissolved organic matter to mineral soils. Geoderma 189-190:334-342

Krawchuk MA, Moritz MA, Parisien M-A, Van Dorn J, Hayhoe K (2009) Global pyrogeography: the current and future distribution of wildfire. PLoS One 4:e5102

Lambert T, Pierson-Wickmann A-C, Gruau G, Thibault J-N, Jaffrezic A (2011) Carbon isotopes as tracers of dissolved organic carbon sources and water pathways in headwater catchments. J Hydrol 402:228-238 
Lane PNJ, Sheridan GJ, Noske PJ (2006) Changes in sediment loads and discharge from small mountain catchments following wildfire in south eastern Australia. J Hydrol $331: 495-510$

LeCroy C, Masiello CA, Rudgers JA, Hockaday WC, Silberg JJ (2013) Nitrogen, biochar, and mycorrhizae: alteration of the symbiosis and oxidation of the char surface. Soil Biol Biochem 58:248-254

Lehmann J, Liang B, Solomon D, Lerotic M, Luizão F, Kinyangi J, Schäfer T, Wirick S, Jacobsen C (2005) Near-edge X-ray absorption fine structure (NEXAFS) spectroscopy for mapping nano-scale distribution of organic carbon forms in soil: application to black carbon particles. Global Biogeochem Cycles 19:GB1013. doi:10.1029/2004GB002435

Liang B, Lehmann J, Solomon D, Sohi S, Thies JE, Skjemstad JO, Luizão FJ, Engelhard MH, Neves EG, Wirick S (2008) Stability of biomass-derived black carbon in soils. Geochim Cosmochim Acta 72:6069-6078

Loáiciga HA, Pedreros D, Roberts D (2001) Wildfire-streamflow interactions in a chapparal watershed. Adv Environ Res 5:295-305

Masiello CA (2004) New directions in black carbon organic geochemistry. Mar Chem 92:201-213

Masiello CA, Louchouarn P (2013) Fire in the ocean. Science 340:287-288

Moody JA, Martin DA (2001) Initial hydrologic and geomorphic response following a wildfire in the Colorado Front Range. Earth Surf Process Land 26:1049-1070

Moody JA, Martin DA (2009) Synthesis of sediment yields after wildland fire in different rainfall regimes in the western United States. Int J Wildland Fire 18:96-115

Myers-Pigg AN, Louchouarn P, Amon RMW, Prokushkin A, Pierce K, Rubtsov A (2015) Labile pyrogenic dissolved organic carbon in major Siberian Arctic rivers: implications for wildfire-stream metabolic linkages. Geophys Res Lett. doi:10.1002/ 2014GL062762

Nguyen BT, Lehmann J (2009) Black carbon decomposition under varying water regimes. Org Geochem 40:846-853

Nguyen BT, Lehmann J, Hockaday WC, Joseph S, Masiello CA (2010) Temperature sensitivity of black carbon decomposition and oxidation. Environ Sci Technol 44:3324 3331 
Norwood MJP, Louchouarn P, Kou LJ, Harvey OR (2013) Characterization and biodegradation of water-soluble biomarkers and organic carbon extracted from low temperature chars. Org Geochem 56:111-119

Preston CM, Schmidt MWI (2006) Black (pyrogenic) carbon: a synthesis of current knowledge and uncertainties with special consideration of boreal regions. Biogeosciences $3: 397-420$

Raymond P, Bauer JE (2001) Use of 14C and 13C natural abundances for evaluating riverine, estuarine and coastal DOC and $\mathrm{POC}$ sources and cycling: a review and synthesis. Org Geochem 32:469-485

Reneau SL, Katzman D, Kuyumjian GA, Lavine A, Malmon DV (2007) Sediment delivery after a wildfire. Geology 35:151-154

Roth PJ, Lehndorff E, Brodowski S, Bornemann L, Sánchez-García L, Gustafsson Ö, Amelung W (2012) Differentiation of charcoal, soot and diagenetic carbon in soil: method comparison and perspectives. Org Geochem 46:66-75

Rumpel C, Chaplot V, Planchon O, Bernadou J, Valentin C, Mariotti A (2006) Preferential erosion of black carbon on steep slopes with slash and burn agriculture. Catena 65:30-40

Saiz G, Wynn JG, Wurster CM, Goodrick I, Nelson PN, Bird MI (2014) Pyrogenic carbon from tropical savanna burning: production and stable isotope composition. Biogeosci Discuss 11:15149-15183

Sánchez-García L, de Andrés JR, Gélinas Y, Schmidt MWI, Louchouarn P (2013) Different pools of black carbon in sediments from the Gulf of Cádiz (SW Spain): method comparison and spatial distribution. Mar Chem 151:13-22

Sanderman J, Lohse KA, Baldock JA, Amundson R (2009) Linking soils and streams: sources and chemistry of dissolved organic matter in a small coastal watershed. Water Resour Res 45:W03418. doi:10.1029/2008WR006977

Schneider MPW, Hilf M, Vogt UF, Schmidt MWI (2010) The benzene polycarboxylic acid (BPCA) pattern of wood pyrolyzed between $200{ }^{\circ} \mathrm{C}$ and $1000{ }^{\circ} \mathrm{C}$. Org Geochem 41:1082-1088

Schneider MPW, Smittenberg RH, Dittmar T, Schmidt MWI (2011) Comparison of gas with liquid chromatography for the determination of benzenepolycarboxylic acids as molecular tracers of black carbon. Org Geochem 42:275-282

Shakesby RA, Doerr SH (2006) Wildfire as a hydrological and geomorphological agent. Earth Sci Rev 74:269-307 
Singh N, Abiven S, Torn MS, Schmidt MWI (2012) Fire-derived organic carbon in soil turns over on a centennial scale. Biogeosciences 9:2847-2857

Smith HG, Sheridan GJ, Lane PNJ, Nyman P, Haydon S (2011) Wildfire effects on water quality in forest catchments: a review with implications for water supply. J Hydrol 396:170-192

Stoof CR, Vervoort RW, Iwema J, van den Elsen E, Ferreira AJD, Ritsema CJ (2012) Hydrological response of a small catchment burned by experimental fire. Hydrol Earth Syst Sci 16:267-285

Stubbins A, Niggemann J, Dittmar T (2012) Photo-lability of deep ocean dissolved black carbon. Biogeosciences 9:1661-1670

Uher G, Hughes C, Henry G, Upstill-Goddard RC (2001) Non-conservative mixing behavior of colored dissolved organic matter in a humic-rich, turbid estuary. Geophys Res Lett 28:3309-3312

Wagner S, Dittmar T, Jaffé R (2015) Molecular characterization of dissolved black nitrogen by electrospray ionization Fourier transform ion cyclotron resonance mass spectrometry. Org Geochem 79:21-30

Westerling AL, Hidalgo HG, Cayan DR, Swetnam TW (2006) Warming and earlier spring increase western U.S. forest wildfire activity. Science 313:940-943

Yang W, Guo L (2014) Abundance, distribution and isotopic composition of particulate black carbon in the northern Gulf of Mexico. Geophys Res Lett 41:7619-7625

Zigah PK, Minor EC, Werne JP (2012) Radiocarbon and stable-isotope geochemistry of organic and inorganic carbon in Lake Superior. Global Biogeochem Cycles 26:GB1023. doi:10.1029/2011GB004132

Ziolkowski LA, Chamberlin AR, Greaves J, Druffel ERM (2011) Quantification of black carbon in marine systems using the benzene polycarboxylic acid method: a mechanistic and yield study. Limnol Oceanogr 9:140-149 


\section{CHAPTER V}

\section{EFFECT OF PHOTODEGRADATION ON MOLECULAR SIZE DISTRIBUTION AND QUALITY OF DISSOLVED BLACK CARBON}

(Modified from Wagner and Jaffé, 2015, Organic Geochemistry) 


\subsection{Abstract}

The effect of photodegradation on the molecular size distribution and composition of dissolved black carbon (DBC) were explored using a surface water dissolved organic matter (DOM) sample from a terrigenous-influenced, fire-impacted Everglades area canal. The original and photodegraded DOM samples were fractionated by size exclusion chromatography and DBC was quantified by benzenepolycarboxylic acid analysis. Size fractionation revealed that DBC was unequally distributed along the DOM molecular weight (MW) continuum, and was preferentially associated with high MW (HMW) fractions. The photo-decomposition of HMW DBC generated less condensed DBC photo-products that preferentially re-associated with, and became enriched in, low MW(LMW) DOM size fractions. The patterns observed indicated that size of the conjugated aromatic ring structure may drive the association of DBC compounds with different DOM MW fractions. The HMW DBC was also more photo-labile than LMW DBC, which suggests that that DBC associated with DOM over a range of size fractions may not exhibit the same degree of photo-reactivity, thereby resulting in different environmental fates for pyrogenic OM.

\subsection{Introduction}

Photo-reactivity of dissolved organic matter (DOM) in surface waters has a significant impact on the composition and quantity of dissolved organic carbon (DOC) transported through aquatic systems (Chen and Jaffé, 2014). Dissolved black carbon (DBC), the soluble portion of pyrogenic OM, is characterized by its polycondensed aromatic ring structure and typically generated by high temperature combustion processes 
(Schneider et al., 2010). Dissolved BC is ubiquitous in aquatic environments (Dittmar, 2008; Jaffé et al., 2013) and highly susceptible to photo-transformation (Stubbins et al., 2010 2012). While DBC has been shown to correlate with bulk DOC on a global scale (Jaffé et al., 2013), the exact physical and chemical drivers controlling DBC-DOC interaction remain elusive.

Size exclusion chromatography (SEC) is a useful tool for gaining compositional and structural information across the molecular weight (MW) continuum of DOM. Elution conditions have been developed for the distinct separation of different size fractions (Peuravuori and Pihlaja, 2004), while maintaining the supramolecular structural integrity of DOM (Piccolo, 2001; Simpson et al., 2002; Romera-Castillo et al., 2014). Generally, high MW (HMW) fractions are enriched in aromatic, carboxyl-rich, humic substances, whereas low MW (LMW) fractions are typically enriched in smaller, more labile compounds such as aliphatics, sugars and amino acids (Woods et al., 2010). Condensed aromatic DOM components have been shown to co-vary with humic-type substances (Stubbins et al., 2014). It was hypothesized that the fused ring structures characteristic of DBC enables its interaction with humic-like DOM in HMW fractions by way of weak intermolecular forces (Perminova et al., 1999), supporting the new paradigm whereby DOM consists of variable-sized assemblies of smaller heterogeneous molecules (Piccolo, 2001; Simpson et al., 2002). The photo-reactivity of DBC is similar to that of the chromophoric DOM pool (CDOM; Stubbins et al., 2012). Previous work has shown that CDOM can be diminished through photo-bleaching, a process that has also been linked to reductions in apparent MW (Lou and Xie, 2006; Helms et al., 2008). 
Therefore, the light absorbance of DOM size fractions was also measured to provide complementary support for observed DBC photodegradation processes.

There is no information on the molecular size distribution of DBC. The goal of the present study was to establish with which MW fractions DBC is primarily associated and how the distribution may be affected after photo-exposure. Dissolved BC is highly photo-reactive (Stubbins et al., 2010; 2012), so it is of interest to gain insight into how it is specifically altered within the MW continuum during this degradation process. Thus, the effect of photo-irradiation on DBC concentration and quality across the MW continuum of a terrestrially-derived DOM sample collected in south Florida was investigated.

\subsection{Material and Methods}

Surface water (20 1) was collected from the Everglades area Hillsboro Canal (Florida, USA) during October of 2011 and filtered through pre-combusted 0.7 um GFF filters. Ultrafiltration (UF) does not significantly alter the MW distribution of DOM (Peuravuori and Pihlaja, 2004). Therefore, UF (1 kDa cutoff membrane) was employed to pre-concentrate the DOM approximately ten-fold to a final DOC concentration of 160 ppm in order to obtain mg quantities of size-fractionated DOC. A $250 \mathrm{ml}$ aliquot of UFconcentrated DOM was transferred to a pre-combusted 11 quartz Erlenmeyer flask fitted with a quartz cap and placed in a Suntest XLS ${ }^{+}$solar simulator fitted with bulbs that mimic the irradiance of natural sunlight and set to $765 / \mathrm{m}$ for $72 \mathrm{~h}$ (sunlight dose is $c a .12$ summer days in south Florida; Chen and Jaffé, 2014). Both the original and irradiated DOM samples were stored at $4{ }^{\circ} \mathrm{C}$ until size fractionation. 
The DOM MW fractionation was achieved with preparative scale SEC following methods described by Peuravuori and Pihlaja (2004). High pressure liquid chromatography (HPLC; Thermo Scientific Surveyor Plus system) was used for separation. Approximately 160 SEC separations were carried out for both the original and photodegraded DOM concentrate in order to recover mg amounts of DOC per fraction for DBC quantification. Size fractions were collected in pre-combusted glass test tubes using an LKB Bromma 2211 Superrac fraction collector, combined into precleaned Nalgene bottles and stored at $4{ }^{\circ} \mathrm{C}$. Absorption data were collected ( 250 to 800 $\mathrm{nm}$ ) using a Varian Cary 50 Bio UV-visible spectrophotometer with a $1 \mathrm{~cm}$ quartz cuvette. CDOM was calculated by converting absorbance at $254 \mathrm{~nm}$ to the Napierian absorbance coefficient (a $254 / \mathrm{m}$; Hu et al., 2002).

The DOC concentration of whole DOM samples was measured using a Shimadzu TOC-V-CSH analyzer. Size fractionated DOC could not be measured directly because of DOC interference from residual SEC NaOAc buffer (Peuravuori and Pihlaja, 2004). Concentration of DOC has been shown to correlate strongly with CDOM in freshwater systems (Spencer et al., 2012). The CDOM (absorbance at $254 \mathrm{~nm}$ ) was continually measured during SEC and used to determine DOM size fraction cutoffs (Fig. 4.1). Thus, SEC peak areas corresponded to the relative proportion of CDOM in each size fraction. The concentration of DOC per fraction was estimated by multiplying the total mass of DOC injected by the ratio of the fraction peak area to the total peak area of all fractions with the assumption of a linear correlation between CDOM and DOC. The estimated mass of DOC per fraction was then divided by the total fraction volume to obtain approximate DOC concentrations for each fraction. Dissolved OM was isolated and 
desalted via solid phase extraction for DBC analysis using the method described by Dittmar et al. (2008).

Dissolved BC was quantified using the benzene polycarboxylic acid (BPCA) method, which detects polycondensed aromatic compounds generated primarily during high temperature combustion processes (Schneider et al., 2010). Briefly, concentrated $\mathrm{HNO}_{3}$ was added to dry DOM $\left(<1 \mathrm{mg}\right.$ DOC) and oxidized for $6 \mathrm{~h}$ at $160{ }^{\circ} \mathrm{C}$ (Ding et al., 2013). Post-oxidation, $\mathrm{HNO}_{3}$ was dried under $\mathrm{N}_{2}$ and the $\mathrm{BPCA}$-containing residue was re-dissolved in mobile phase for direct HPLC separation and quantification. The HPLC elution conditions and calculation of DBC values have been previously described in detail by Dittmar (2008). The BPCAs for each sample were measured in triplicate (CV $<5 \%)$.

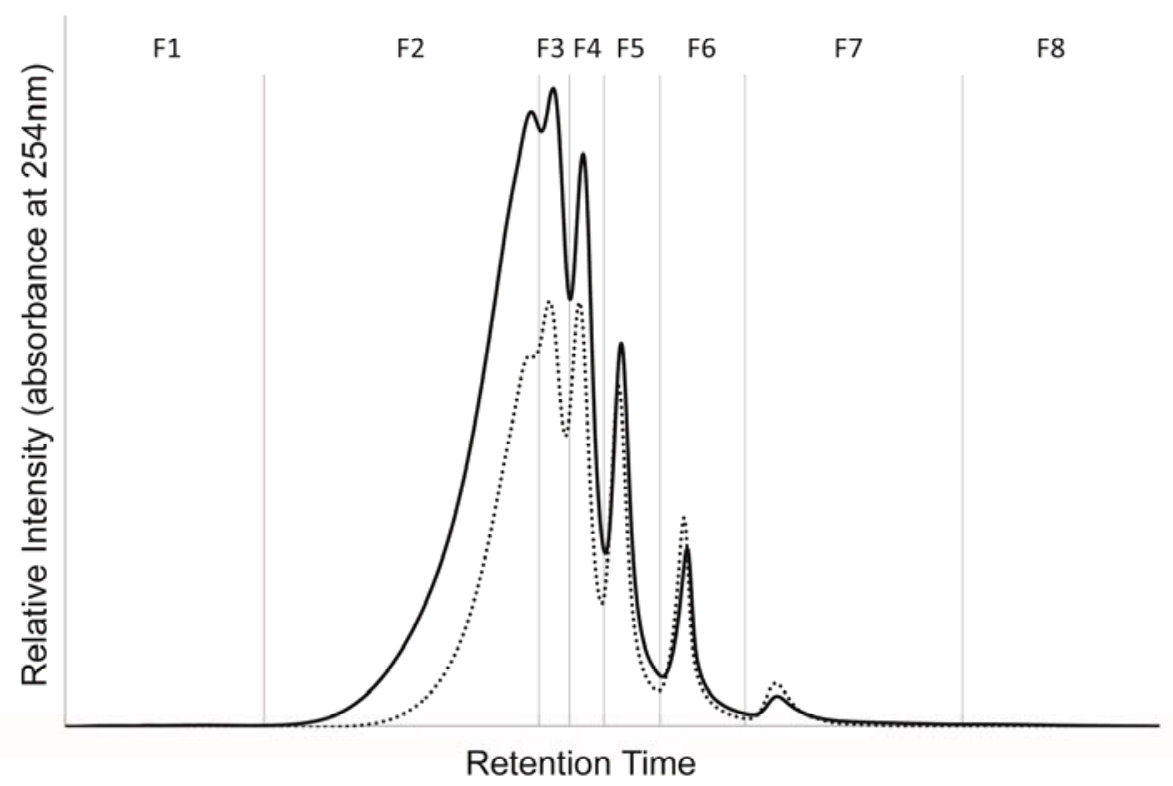

Figure 5.1 SEC fractionation (F1 - F8) of Everglades area DOM before (solid line) and after (dashed line) photo-exposure. Vertical grey lines indicate size fraction cut offs. 


\subsection{Results and Discussion}

Eight distinct MW fractions (F1 - F8) were isolated for both the original and photo-exposed DOM (Fig. 5.1). Dissolved OC, DBC and CDOM for whole water and size fractionated DOM both before and after photo-exposure are reported in Table 5.1. While it is known that SEC separation of DOM is not necessarily solely determined by molecular mass (Štulík et al., 2003), previous studies have reported clear trends in MW distribution that demonstrate a general decrease in apparent molecular size from early- to late-eluting peaks (e.g., Peuravuori and Pihlaja, 2004). Thus, F2 - F4 and F5 - F7 are referred to here as HMW and LMW DOM fractions, respectively. Dissolved BC was not detectable in F1 and F8 using the BPCA method. Absorbance measurements collected for these fractions were also low, which indicated that F1 and F8 contained very little, if any, CDOM (Table 5.1; see also Romera-Castillo et al., 2014).

Photodegradation significantly reduced concentrations of DOC, DBC and CDOM in whole DOM after 3 days irradiation ( $\mathrm{p}<0.05$; Table 5.1). Dissolved BC was removed preferentially vs. bulk DOC, as evidenced by the significant decrease in DBC:DOC ratio for whole DOM ( $\mathrm{p}<0.05$; Table 5.1). The proportion of CDOM removed with photodegradation was similar to the proportional loss of DBC (Table 5.1). Therefore, a photo-sensitivity gradient of $\mathrm{DBC}=\mathrm{CDOM}>\mathrm{DOC}$ is suggested for this Everglades area DOM sample. A tight coupling between CDOM and DBC during photodegradation has been suggested by Stubbins et al. (2012), so it is not surprising that size-fractionated DBC concentration also correlated significantly with CDOM here $(p<0.05)$. 
Table 5.1 Summary of data for whole and size-fractionated DOM before and after photo-exposure.

\begin{tabular}{ccccccc}
\hline Sample & Fraction & $\mathrm{a}_{254}(/ \mathrm{m})^{\mathrm{a}}$ & ${\text { DBC }(\mathrm{ppm})^{\mathrm{b}}}^{\text {Def }(\mathrm{ppm})^{\mathrm{c}}}$ & $\begin{array}{c}\text { DBC:DOC } \\
(\mathrm{mg}-\mathrm{C} \%)\end{array}$ & B5:B4 $^{\mathrm{d}}$ \\
\hline Photo & Whole & 1650 & $37.53 \pm 0.32$ & $164.09 \pm 2.00$ & $22.9 \pm 0.3$ & $1.6 \pm 0.1$ \\
& F1 & 0.9 & ND & 0.01 & - & - \\
& F2 & 20.6 & 0.42 & 4.80 & 8.8 & 2.0 \\
& F3 & 66.1 & 1.74 & 9.10 & 19.1 & 1.8 \\
& F4 & 42.3 & 0.77 & 6.09 & 12.6 & 1.6 \\
& F5 & 18.1 & 0.29 & 2.60 & 11.2 & 1.3 \\
& F6 & 6.6 & 0.08 & 0.80 & 10.2 & 1.0 \\
After & F7 & 2.2 & 0.01 & 0.25 & 4.9 & 0.9 \\
& F8 & 1.1 & ND & 0.01 & - & - \\
& Fhole & 1190 & $27.44 \pm 0.14$ & $145.76 \pm 2.07$ & $18.8 \pm 0.3$ & $1.7 \pm 0.1$ \\
& F2 & 0.8 & ND & 0.00 & - & - \\
& F3 & 53.9 & 0.13 & 1.58 & 8.2 & 1.7 \\
& F4 & 43.6 & 1.42 & 8.75 & 16.2 & 2.0 \\
& F5 & 23.5 & 0.41 & 3.33 & 12.3 & 1.4 \\
& F6 & 10.0 & 0.11 & 1.05 & 10.7 & 1.0 \\
& F7 & 3.4 & 0.01 & 0.19 & 6.6 & 0.8 \\
& F8 & 0.9 & ND & 0.01 & - & - \\
\hline
\end{tabular}

aAbsorbance measured at $254 \mathrm{~nm}$ is expressed in Napierian absorbance coefficients; ${ }^{b} \mathrm{DBC}$ was quantified using the BPCA method; ${ }^{\mathrm{c}} \mathrm{DOC}$ concentrations were derived from $\mathrm{a}_{254} ;{ }^{\mathrm{d}} \mathrm{B} 5: \mathrm{B} 4$ is the ratio of $\mathrm{B} 5 \mathrm{CA}$ to $\mathrm{B} 4 \mathrm{CAs}$

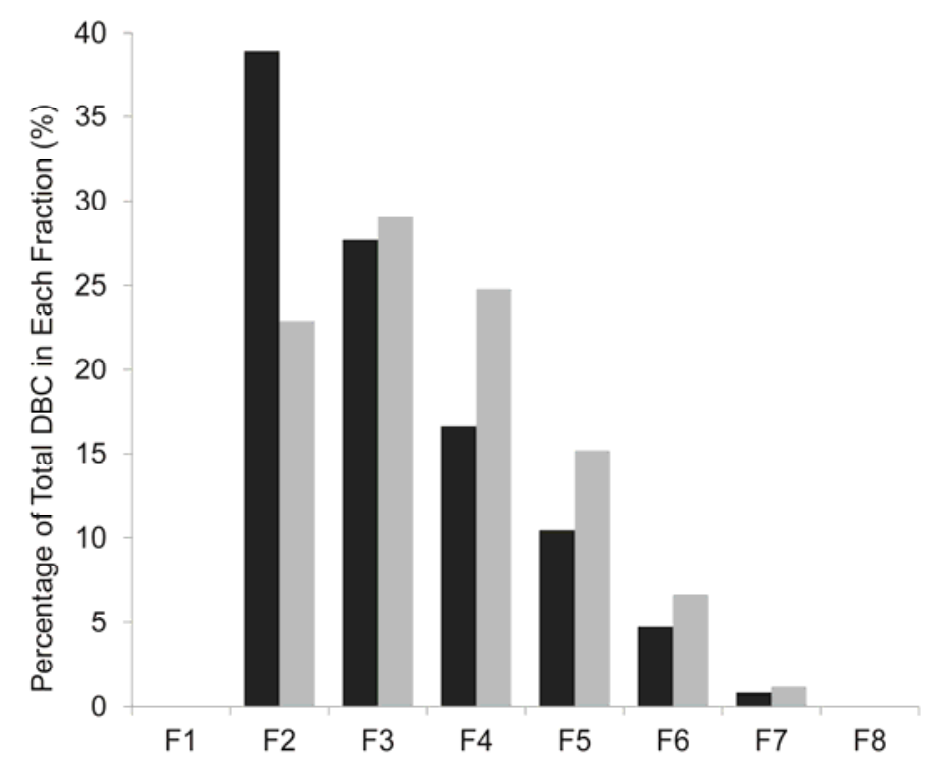

Figure 5.2 Relative proportion of DBC in each DOM size fraction before (black bars) and after (gray bars) photodegradation. BPCAs were measured in triplicate $(\mathrm{CV}<5 \%)$ 
Dissolved BC was preferentially associated with DOM in HMW size fractions as evidenced by relatively high DBC:DOC ratios for F2 and F3 (Table 5.1). The decrease in DBC concentration in these HMW fractions after photo-irradiation was coupled with an increase in DBC concentration in LMW fractions (Table 5.1). The apparent photoinduced shift in DBC relative abundance from HMW to LMW fractions (Fig. 5.2) could be the result of a combination of oxidation to $\mathrm{CO}_{2}$ via photo-mineralization (Ward et al., 2014) of HMW DBC or a structural photo-alteration (Stubbins et al., 2010), resulting in DBC to form more thermodynamically stable re-associations with DOM in LMW fractions. Bulk DOC significantly decreased when the DOM was exposed to sunlight (Table 5.1), which indicated that a portion of DOC was lost via photo-mineralization to $\mathrm{CO}_{2}$. Although it has been shown that a small portion of DBC can also be photomineralized to $\mathrm{CO}_{2}$, the majority of DBC becomes only partially oxidized, generating photo-products (Ward et al., 2014) that may or may not be detectable with the BPCA method (Ziolkowski et al., 2011). However, since an increase in both CDOM concentration and DBC concentration was observed for LMW fractions after photodegradation (Table 5.1), it is suggested that smaller aromatic photo-products were indeed generated from the decomposition of CDOM and DBC in HMW fractions for this particular DOM sample. Although the present study is corroborated by previous observations where $\mathrm{DBC}$ is preferentially removed through photo-reactive processes vs. bulk DOC (Stubbins et al., 2012; Ward et al., 2014), it was also discovered that DBC is associated with HMW fractions is more photo-labile than DBC in LMW fractions (Fig. 5.2). The $\mathrm{DBC}$ molecules with large polycondensed aromatic rings generate more BPCAs with 5 and 6 carboxylic groups (B5CA and B6CA) than B3CAs and B4CAs 
during oxidation (Dittmar, 2008; Ziolkowski et al., 2011). By using relative BPCA distributions, such as the ratio of B5CA to B4CAs (B5:B4; Table 5.1), the quality of DBC was compared among whole and size fractionated DOM samples. The ratio generally decreased with increasing size fraction and the pattern was not found to be considerably altered after photo-exposure (Table 5.1). The trend indicated that not only was the DBC abundance unevenly distributed among size fractions, but also that DBC molecules with larger ring systems continued to be associated with DOM of larger apparent MW regardless of short term photo-reactive processes.

Despite the significant reduction in bulk DBC and an apparent shift in the distribution of DBC from HMW to LMW fractions after 3 days irradiation, the B5:B4 ratio for whole water $\mathrm{DBC}$ was not significantly altered $(\mathrm{p}>0.05$; Table 5.1$)$. After photodegradation, $>76 \%$ of the DBC still remained in F2 to F4 (Fig. 5.2). The observed result suggests that, even after short-term photo-exposure, the quality of whole water DBC was still controlled mainly by the DBC associated with HMW fractions, which exhibited consistently higher B5:B4 values than DBC in LMW fractions (Table 5.1). Therefore, the relative proportion of BPCAs for whole water DBC did not seem to change significantly after three days of irradiation $(p>0.05)$. The primary objective of this study was to assess short-term DBC photo-reactivity along the DOM MW continuum. Assuming DBC would continue to be preferentially removed from HMW fractions, the BPCA composition of whole water DBC is expected to more closely resemble that of the photo-resistant DBC pool in LMW DOM fractions after long exposure times (e.g., weeks to months). 
The selective photo-removal of HMW DBC may generate a LMW DBC pool with potentially increased bioavailability (Bruun et al., 2008). The microbial processing of LMW DBC could be enhanced by the interactive priming effects of labile compounds found in smaller DOM size fractions (Woods et al., 2010). Considering that cometabolism effects have been observed between black carbon and labile $\mathrm{C}$ sources in soil (Hamer et al., 2004), such priming could also occur for DBC. Although it has not been described before, the mineralization of DBC may be enhanced via synergistic photo-oxidation and biodegradation processes, much like those observed for terrigenous DOM (Chen and Jaffé, 2014). These interactive degradation processes may reduce the otherwise relatively long turnover rates of pyrogenic DOM. 


\section{References}

Bruun, S., Jensen, E.S., Jensen, L.S., 2008. Microbial mineralization and assimilation of black carbon: Dependency on degree of thermal alteration. Organic Geochemistry 39, 839-845.

Chen, M., Jaffé, R., 2014.Photo- and bio-reactivity patterns of dissolved organic matter from biomass and soil leachates and surface waters in a subtropical wetland. Water Research 61, 181-190.

Ding, Y., Yamashita, Y., Dodds, W. K., Jaffé, R., 2013. Dissolved black carbon in grassland streams: Is there an effect of recent fire history? Chemosphere 90,2557-2562.

Dittmar, T., 2008. The molecular level determination of black carbon in marine dissolved organic matter. Organic Geochemistry 39, 396-407.

Dittmar, T., Koch, B., Hertkorn, N., Kattner, G., 2008, A simple and efficient method for the solid-phase extraction of dissolved organic matter (SPE-DOM)from seawater. Limnology and Oceanography: Methods 6, 230-235.

Hamer, U., Marschner, B., Brodowski, S., Amelung, W., 2004. Interactive priming of black carbon and glucose mineralization. Organic Geochemistry 35, 823-830.

Helms, J.R., Stubbins, A., Ritchie, J.D., Minor, E.C., Kieber, D.J., Mopper, K., 2008. Absorption spectral slopes and slope ratios as indicators of molecular weight, source and photobleaching of chromophoric dissolved organic matter. Limnology and Oceanography $53,955-969$.

Hu, C., Muller-Karger, F.E., Zepp, R.G., 2002. Absorbance, absorption coefficient, and apparent quantum yield: A comment on common ambiguity in the use of these optical concepts. Limnology and Oceanography 47, 1261-1267.

Jaffé, R., Ding, Y., Niggeman, J., Vähätalo, A.V., Stubbins, A., Spencer, R.M., Campbell, J., Dittmar, T., 2013. Global charcoal mobilization from soils via dissolution and riverine transport to oceans. Science 340,345-347.

Lou, T., Xie, H., 2006. Photochemical alteration of the molecular weight of dissolved organic matter. Chemosphere 65, 2333-2342.

Perminova, I.V., Grechishcheva, N.Y., Petrosyan, V.S., 1999. Relationships between structure and binding affinity of humic substances for polycyclic aromatic hydrocarbons: Relevance of molecular descriptors. Environmental Science and Technology 33, 37813787. 
Peuravuori, J., Pihlaja, K., 2004. Preliminary study of lake dissolved organic matter in light of nanoscale surpamolecular assembly. Environmental Science and Technology 38, 5958-5967.

Piccolo, A., 2001.The supramolecular structure of humic substances. Soil Science 166, 810-832.

Romera-Castillo, C., Chen, M., Yamashita, Y., Jaffe, R., 2014. Fluorescence characteristics of size-fractionated dissolved organic matter: Implications for a molecular assembly based structure? Water Research 55, 40-51.

Schneider, M.P.W., Hilf, M., Vogt, U.F., Schmidt, M.W.I., 2010. The benzene polycarboxylic acid (BPCA) pattern of wood pyrolyzed between $200^{\circ} \mathrm{C}$ and $1000^{\circ} \mathrm{C}$. Organic Geochemistry 41, 1082-1088.

Simpson, A.J., Kingery, W.L., Hayes, M.H.B, Spraul, M., Humpfer, E., Dvortsak, P., Kerssebaum, R., Godejohann, M., Hofmann, M., 2002. Molecular structures and associations of humic substances. Naturwissenschaften $89,84-88$.

Spencer, R.G.M., Butler, K.D., Aiken, G, R., 2012. Dissolved organic carbon and chromophoric dissolved organic matter properties of rivers in the USA. Journal of Geophysical Research 117, G03001.

Stubbins, A., Spencer, R.G.M., Chen, H., Hatcher, P.G., Mopper, K., Hernes, P.J., Mwamba, V.L., Mangangu, A.M., Wabakanghanzi, J.N., Six, J., 2010. Illuminated darkness: Molecular signatures of Congo River dissolved organic matter and its photochemical alteration as revealed by ultrahigh resolution mass spectrometry. Limnology and Oceanography 55, 1467-1477.

Stubbins, A., Niggemann, J., Dittmar, T., 2012. Photo-lability of deep ocean dissolved black carbon. Biogeosciences 9, 1661-1670.

Stubbins, A., Lapierre, J.F., Berggren, M., Prairie, Y.T., Dittmar, T., del Giorgio, P.A., 2014. What's in an EEM? Molecular signatures associated with dissolved organic fluorescence in boreal Canada. Environmental Science and Technology 48, 10598-10606.

Štulík, K., Pacáková, V., Tichá, M., 2003. Some potentialities and drawbacks of contemporary size-exclusion chromatography. Journal of Biochemical and Biophysical Methods 56, 1-13.

Ward, C.P., Sleighter, R.L., Hatcher, P.G., Cory, R.M., 2014. Insights into the complete and partial photooxidation of black carbon in surface waters. Environmental Science Processes and Impacts 16, 721-731. 
Woods, G.C., Simpson, M.J., Kelleher, B.P., McCaul, M., Kingery, W.L., Simpson, A.J. 2010. Online high-performance size exclusion chromatography - Nuclear magnetic resonance for the characterization of dissolved organic matter. Environmental Science and Technology 44, 624-630.

Ziolkowski, L.A., Chamberlin, A.R., Greaves, J., Druffel, E.R.M., 2011. Quantification of black carbon in marine systems using the benzene polycarboxylic acid method: A mechanistic and yield study. Limnology and Oceanography: Methods 9, 140-149. 
CHAPTER VI

CONCLUSIONS 
$\mathrm{BC}$ was initially considered to be a carbon sink, resistant to degradation and mobilization in terrestrial systems. However, under favorable environmental conditions, $\mathrm{BC}$ in the solid phase can easily undergo oxidation via biotic and/or abiotic processing. The addition of oxygen-containing functionalities, such as phenolic or carboxylic acid groups, to the polycondensed aromatic core structure of BC likely encourages the dissolution and translocation of DBC to the aqueous phase. The soluble component of $\mathrm{BC}$ is variable with regards to its molecular composition. $\mathrm{DBC}$ released from soils and char was shown to be generally highly oxidized, containing multiple oxygen-containing moieties. It was also observed that, in some cases, more than $50 \%$ of the DBC molecular formulae identified in soil and char leachates contained nitrogen. In general, it was observed that greater proportions of dissolved black nitrogen (DBN) were released from soils and grass-derived charcoals, which suggested that the proportion of DBN solubilized from charcoal and fire-impacted soils appears to be controlled by both the organic source material and extent of $\mathrm{BC}$ processing in soils after thermal alteration. The presence of DBN likely influences the reactivity and ultimate fate of the bulk DBC pool, therefore it is necessary to further understand how this pyrogenic component of DOM is released into and exported via aquatic systems. DBN was identified in global rivers and could be linked to watershed land use. The contribution of DBN to the pyrogenic DOM signature was significantly positively correlated with the proportion of agricultural area within the catchment. The burning of protein-enriched, grassy-type biomass in farmland areas could have resulted in riverine pyrogenic DOM composition with higher DBN content. Additionally, the long term application of nitrogen-based fertilizers to agricultural fields may be incorporated into the $\mathrm{BC}$ molecular structure during burn 
events and subsequently exported as DBN over time. Further research is needed to fully assess how DBN content impacts the lability of the bulk DBC pool, and if this DBN is available to heterotrophic organisms. The persistence of DBN and other anthropogenically-derived compounds in downstream areas of large rivers may have major implications for the reactivity and global cycling of both DBC and DOM.

The riverine export of DBC was not shown to be substantially influenced after a recent wildfire burned considerable portions of a Colorado mountain watershed. Instead, the removal and fluvial transport of freshly-generated BC occurred primarily in the particulate phase $(\mathrm{PBC})$, which indicates that export mechanisms for $\mathrm{PBC}$ and $\mathrm{DBC}$ are decoupled in watersheds recently affected by wildfire. The mobilization of PBC appears to be a significant, yet previously unstudied, mechanism for BC cycling in aquatic systems. These observations suggest that the gradual oxidation and aging of BC in soils may be a prerequisite to its dissolution and translocation to the dissolved phase, whereas freshly-generated charcoal can be immediately transferred to rivers as PBC. Although a significant portion of $\mathrm{BC}$ formed during a wildfire event is removed from the burned landscape as $\mathrm{PBC}$ via surface erosion, the time deferred release of aged DBC from deeper soils may ultimately become a greater, long-term contributor to in-stream BC. Future studies should focus on PBC dynamics in surface waters in order to assess how environmental processes, such as photodissolution or sedimentation, impact the mobility and fate of particulate charcoal.

It is analytically challenging to study DBC because it is a heterogeneous molecular mixture which is inherently associated with an even more complex bulk DOC pool. However, DBC-DOC relationships can be investigated using a combination of 
analytical techniques. DBC is characterized by its fused aromatic ring structure, which makes it highly photoreactive. Photodegradation preferentially removed DBC from an Everglades-area surface water sample compared to bulk DOC. DBC in higher molecular weight DOM fractions was also more photolabile than DBC in lower molecular weight fractions. This suggests that that $\mathrm{DBC}$ associated with DOM over a range of size fractions may not exhibit the same degree of photoreactivity, thereby resulting in different environmental fates for pyrogenic DOM. For instance, microbial processing of DBC in lower molecular weight DOM fractions could be enhanced by interactive priming effects of labile compounds commonly associated with smaller DOM size fractions. The mineralization of DBC may also be increased via synergistic photooxidation and biodegradation processes, thereby reducing the relatively long turnover rates of pyrogenic DOM.

Fire is a process that occurs across all landscapes and DBC will continue to be released from soils and sediments into aquatic systems for years to come. Although a global correlation between DBC and DOC exists, the composition and reactivity of DBC is not entirely consistent among all DOM pools. Research investigating the dynamics of $\mathrm{DBC}$ in aquatic systems has advanced significantly in recent years, however many questions still remain. PBC may be a significant source of pyrogenic material to inland waters, therefore mechanisms that control interactions between $\mathrm{BC}$ in both the particulate and dissolved phase must be further assessed. Photodegradation breaks down DBC structures into smaller, more aliphatic components that may be more biolabile than their pyrogenic precursors. However, such sequential degradation studies have yet to be 
carried out for DBC. The benzenepolycarboxylic acid method is only capable of detecting the most recalcitrant forms of DBC. Therefore, future research should incorporate the measurement of more labile components of the pyrogenic carbon pool in order to obtain an understanding of $\mathrm{BC}$ dynamics across a broader range of the combustion continuum. BC is a major component of the terrestrial organic matter pool which can be mobilized via inland waters. Addressing these research gaps will allow for a more accurate assessment of $\mathrm{BC}$ residence times in the environment and constrain the role $\mathrm{BC}$ plays in global carbon cycling. 
APPENDICES 


\section{Appendix 2.1}

Kendrick plots for DBN formulae detected in PNAS and PNAC. Points falling on a horizontal line separated by a nominal mass of $44 \mathrm{Da}$ indicated homologous molecular formulae differing by the gain or loss of $\mathrm{a} \mathrm{CO}_{2}$ group.

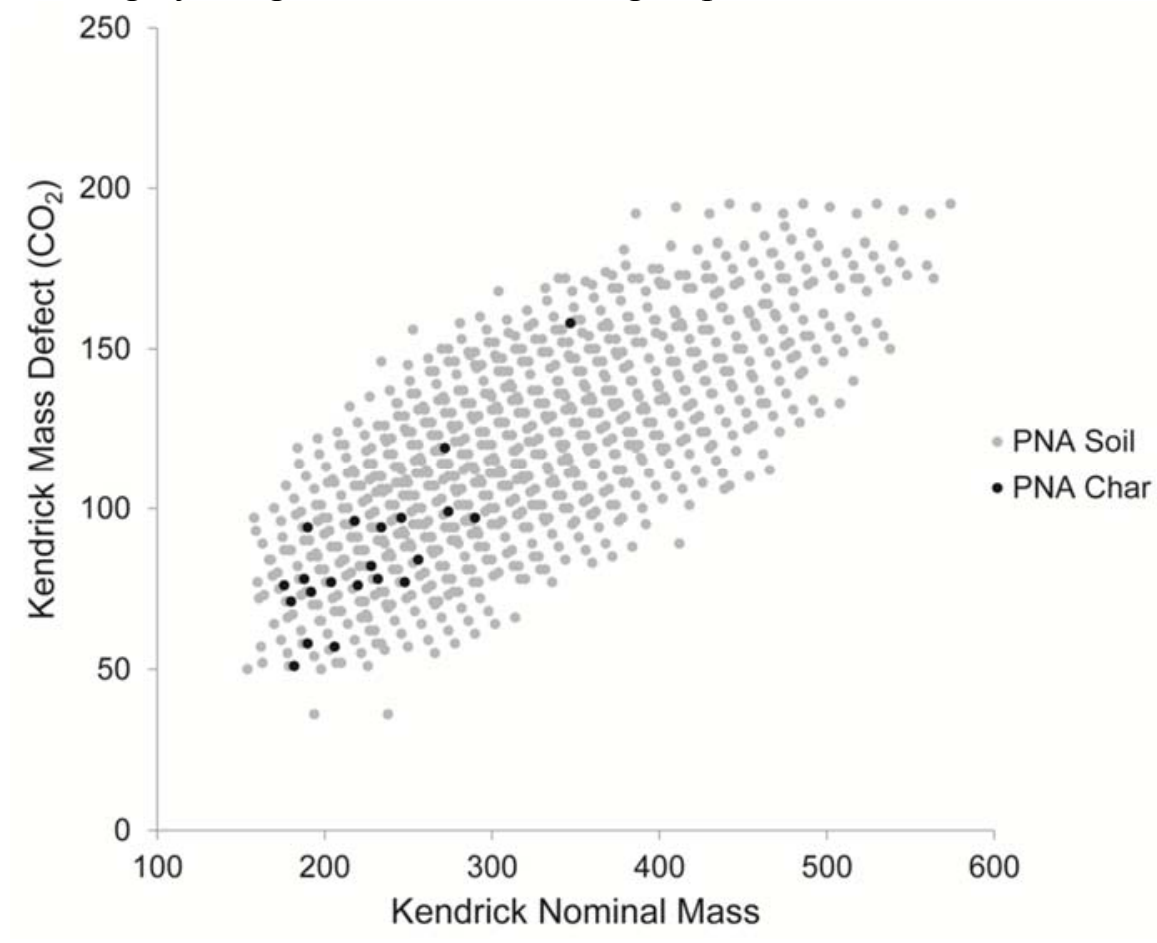




\section{Appendix 3.2}

Global river basin characteristics obtained from the Watersheds of the World database compiled by IUCN-The World Conservation Union, the International Water Management Institute, the Ramsar Convention Bureau and the World Resources Institute (http://multimedia.wri.org/watersheds_2003/).

\begin{tabular}{|c|c|c|c|c|c|c|c|}
\hline River & Forest (\%) & Grassland (\%) & Wetland (\%) & Dryland (\%) & Cropland (\%) & Urban $(\%)$ & Basin Area $\left(\mathrm{km}^{2}\right)$ \\
\hline Amazon & 73.4 & 10.2 & 8.3 & 6 & 14.1 & 0.6 & 6145186 \\
\hline Congo & 44 & 45.4 & 9 & 0.2 & 7.2 & 0.2 & 3730881 \\
\hline Danube & 18.2 & 3.2 & 1.4 & 13.7 & 66.9 & 10.7 & 795656 \\
\hline Ganges-Brahmaputra & 9.8 & 25.6 & 18.9 & 35.3 & 55.6 & 4.8 & 1667459 \\
\hline Yangtze & 6.3 & 28.2 & 3 & 2 & 47.6 & 3 & 1722193 \\
\hline Lena & 64.7 & 11.4 & 0.6 & 1.5 & 1.7 & 0.4 & 2306743 \\
\hline Mekong & 41.5 & 17.2 & 8.7 & 0.8 & 37.8 & 2.1 & 805604 \\
\hline Mississippi & 22.2 & 28.5 & 20 & 46.7 & 35.8 & 12.6 & 3202185 \\
\hline Paraná & 18.1 & 33 & 10.9 & 0.6 & 43.3 & 4.2 & 2582704 \\
\hline St. Lawrence & 43.5 & 0.1 & 47.2 & 0 & 16.4 & 14.5 & 1049636 \\
\hline
\end{tabular}




\section{Appendix 3.3}

Total number and proportion of molecular formulae assigned to each compound class for global river DOM.

\begin{tabular}{|c|c|c|c|c|c|c|c|c|}
\hline River & $\begin{array}{l}\text { No. of } \\
\text { Assigned } \\
\text { Formulae }\end{array}$ & $\begin{array}{l}\text { Condensed } \\
\text { Aromatics } \\
(\mathrm{AI}>0.66)\end{array}$ & $\begin{array}{c}\text { Polyphenols } \\
(0.5<\mathrm{AI} \leq 0.66)\end{array}$ & $\begin{array}{c}\text { Highly } \\
\text { Unsaturated } \\
\text { Aliphatics } \\
(\mathrm{AI}<0.5 ; \\
\mathrm{H} / \mathrm{C}<1.5)\end{array}$ & $\begin{array}{c}\text { Unsaturated } \\
\text { Aliphatics } \\
(1.5 \leq \mathrm{H} / \mathrm{C}<2)\end{array}$ & $\begin{array}{c}\text { Saturated } \\
\text { Fatty } \\
\text { Acids } \\
(\mathrm{H} / \mathrm{C}>2)\end{array}$ & $\begin{array}{c}\text { Sugars } \\
(\mathrm{O} / \mathrm{C} \geq 0.9)\end{array}$ & $\begin{array}{l}\text { Peptides } \\
(\mathrm{H} / \mathrm{C}>1.5)\end{array}$ \\
\hline Amazon & 4839 & $672(13.9 \%)$ & $1101(22.8 \%)$ & $2729(56.4 \%)$ & $312(6.4 \%)$ & $2(0.04 \%)$ & $9(0.19 \%)$ & $14(0.29 \%)$ \\
\hline Congo & 6 & & & 79 & 23 & $0(0 \%)$ & & \\
\hline Danube & 5 & ) & & 03 & 507 & $4(0$. & 10 & \\
\hline Gang & & & & 60 & 32 & & & \\
\hline Yar & & & & o) & & & & \\
\hline Lena & 4 & o) & 0 & \%) & 37 & ()) & o) & 24 \\
\hline Mekong & 5298 & $734(13.9 \%)$ & & $2968(56.0 \%)$ & & & $1 \%)$ & 53 \\
\hline Mississippi & 5236 & $578(11.0 \%)$ & $1007(19.2 \%)$ & $3016(57.6 \%)$ & $568(10.8 \%)$ & $3(0.06 \%)$ & $8(0.15 \%)$ & $56(1.07 \%)$ \\
\hline Paraná & 6818 & $861(12.6 \%)$ & $1360(19.9 \%)$ & $3715(54.5 \%)$ & $775(11.4 \%)$ & $7(0.10 \%)$ & $17(0.25 \%)$ & $83(1.22 \%)$ \\
\hline St. Lawrence & 5865 & $654(11.2 \%)$ & $1117(19.0 \%)$ & $3332(56.8 \%)$ & $668(11.4 \%)$ & $5(0.09 \%)$ & $15(0.26 \%)$ & $74(1.26 \%)$ \\
\hline
\end{tabular}




\section{Appendix 3.4}

Cluster analysis (squared Euclidean) of log-normalized peak intensities found to be common among all ten global river DOM.

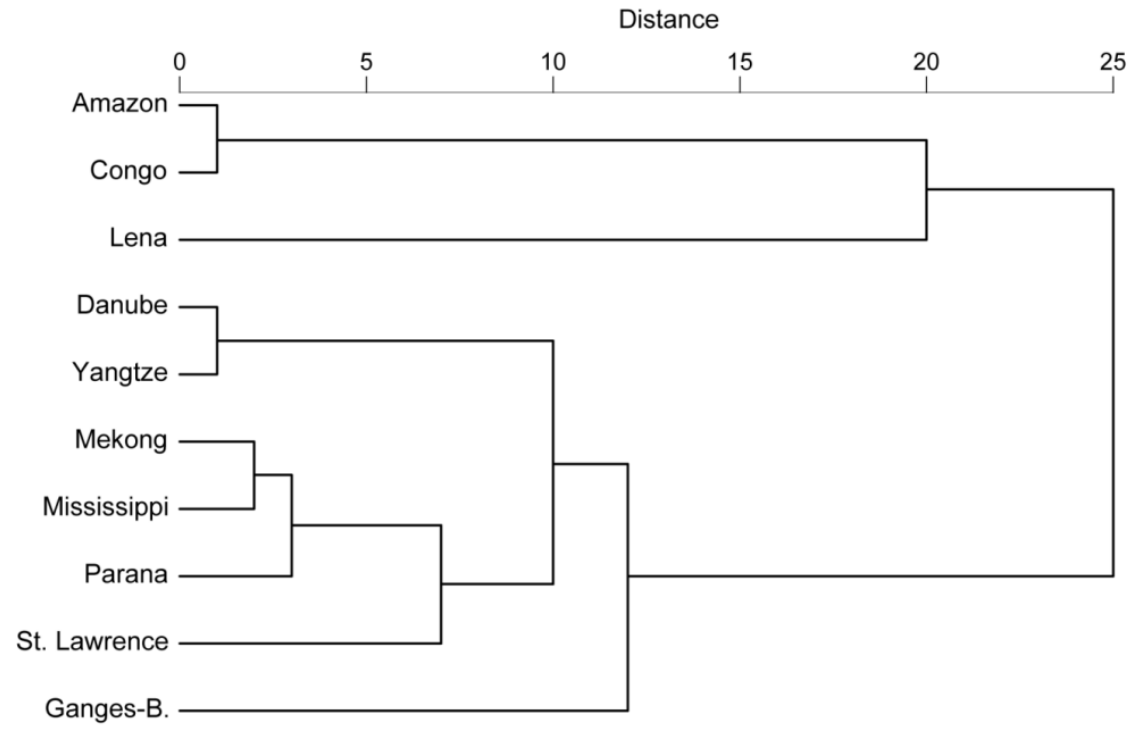




\section{Appendix 3.5}

Van Krevelen diagrams of molecular formulae identified for DOM from the (a) Amazon, (b) Congo, (c) Danube, (d) Ganges-Brahmaputra, (e) Yangtze, (f) Lena, (g) Mekong, (h) Mississippi, (i) Paraná and (j) St. Lawrence Rivers. Formula types are classified by color: $\mathrm{CHO}$ (black), CHON (blue), CHOS (red), CHOP (purple) and CHONSP (green). The CHONSP formula type represents molecular formulae that contain two different heteroatoms (e.g., $\mathrm{N}$ and $\mathrm{S}, \mathrm{S}$ and $\mathrm{P}$ or $\mathrm{N}$ and $\mathrm{P}$ ).
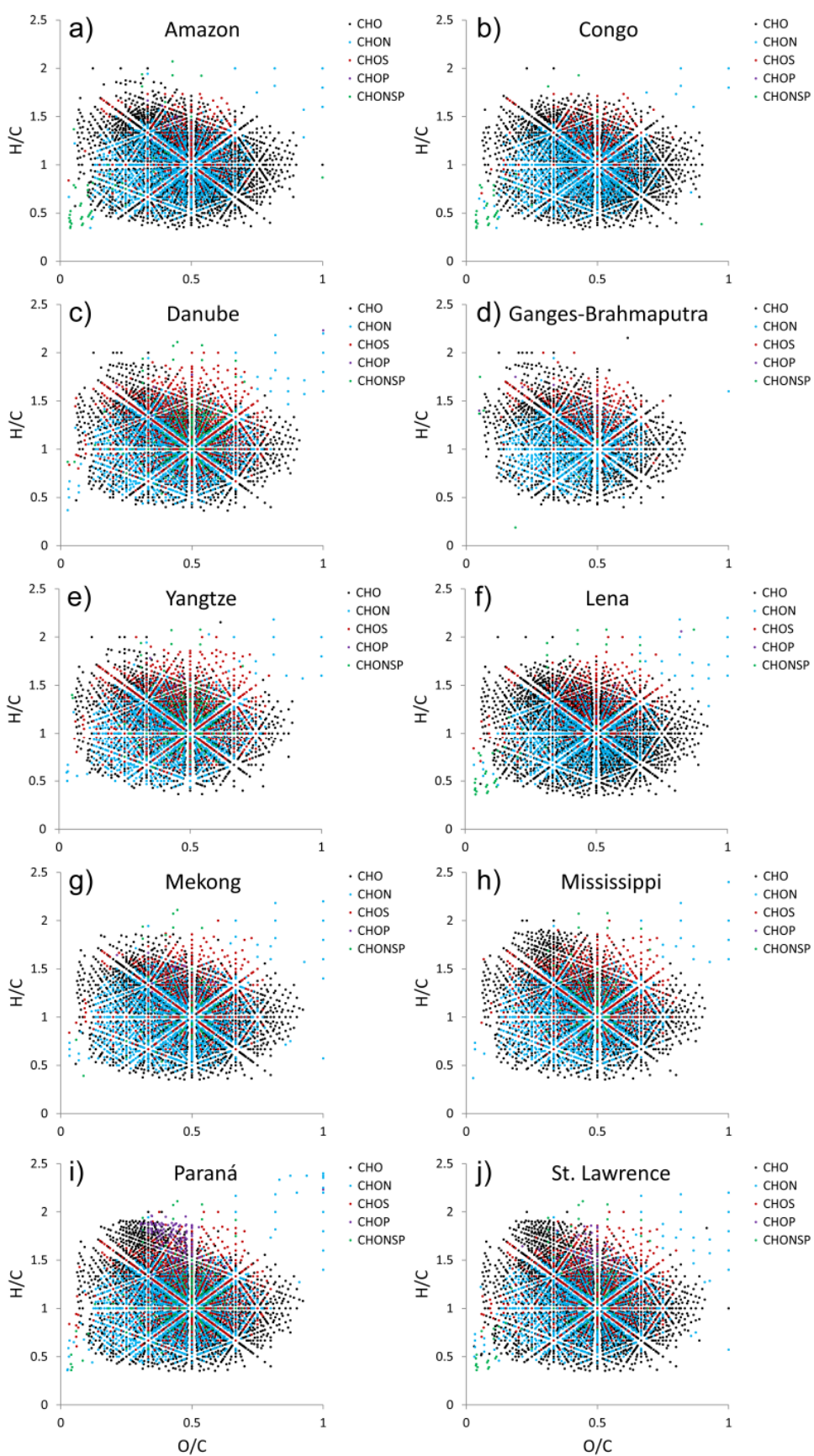
VITA

\section{SASHA WAGNER}

Born, Allentown, Pennsylvania

2009

B.S., Biochemistry

University of Delaware

Newark, Delaware

$2009-2011$

Research Assistant

Princeton University

Princeton, New Jersey

$2011-2015 \quad$ Doctoral Candidate

Florida International University

Miami, FL

Teaching Assistant

Florida International University

Miami, Florida

\section{PUBLICATIONS AND PRESENTATIONS}

Wagner, S., Riedel, T., Niggemann, J., Vähätalo, A.V., Dittmar, T., Jaffé, R. (in review) Linking the molecular signature of heteroatomic dissolved organic matter to watershed characteristics in world rivers. Environmental Science and Technology

Wagner, S., Jaffé, R. (2015) Effect of photodegradation on molecular size distribution and quality of dissolved black carbon. Organic Geochemistry 86:1-4.

Wagner, S., Cawley, K.M., Rosario-Ortiz, F.L., Jaffé, R. (2015) In-stream sources and links between particulate and dissolved black carbon following a wildfire.

Biogeochemistry 124:145-161.

Wagner, S., Dittmar, T., Jaffé, R. (2015) Molecular characterization of dissolved black nitrogen by electrospray ionization Fourier transform ion cyclotron resonance mass spectrometry. Organic Geochemistry 79:21-30.

Wagner, S. (March 2015) Presented seminar entitled "Black carbon: Sources, mobility and fate in freshwater systems" at the Skidaway Institute for Oceanography in Savannah, Georgia, USA 
Wagner, S., Riedel, T., Niggemann, J., Vähätalo, A.V., Dittmar, T., Jaffé, R. (February 2015) Presented a paper entitled "Linking the molecular signature of heteroatomic dissolved organic matter to watershed characteristics in world rivers" at the ASLO Aquatic Sciences Meeting in Granada, Spain

Wagner, S., Cawley, K.M., Rosario-Ortiz, F.L., Jaffé, R. (December 2015) Presented a paper entitled "The riverine export of particulate and dissolved black carbon following a Colorado wildfire" at the AGU Fall Meeting in San Francisco, California, USA

Wagner, S., Dittmar, T., Jaffe, R. (May 2014) Presented a paper entitled "Molecular characterization of dissolved black nitrogen" at the Joint Aquatic Sciences Meeting in Portland, Oregon, USA

Jaffe, R., Ding, Y., Wagner S. (May 2014) Presentation entitled "Assessing the mechanisms of translocation of black carbon from soils to the aqueous phase" at the Joint Aquatic Sciences Meeting in Portland, Oregon, USA

Wagner, S., Dittmar, T., Jaffe, R. (May 2014) Presented a paper entitled "Molecular characterization of dissolved black nitrogen" at the ACS Florida Annual Meeting and Exposition in Tampa, Florida, USA

Wagner, S., Dittmar, T., Jaffe, R. (March 2014) Presented a paper entitled "Molecular characterization of dissolved black nitrogen" at the Chemistry and Biochemistry Department Visitation Day Poster Session in Miami, Florida, USA 